\title{
GEOSTATISTICAL ORE RESERVE ESTIMATION FOR A ROLL-FRONT TYPE URANIUM DEPOSIT
(PRACTITIONER'S GUIDE)
}

Young C. Kim and Harvey P. Knudsen

\author{
University of Arizona \\ Department of Mining and Geological Engineering \\ Tucson, Arizona 85721
}

January 1977

MASTER

Work performed under Bendix Field

Engineering Corporation Grand Junction

Operations Subcontract No. 76-003-E, and

Bendix Contract EY-76-C-13-1664. 


\section{DISCLAIMER}

This report was prepared as an account of work sponsored by an agency of the United States Government. Neither the United States Government nor any agency Thereof, nor any of their employees, makes any warranty, express or implied, or assumes any legal liability or responsibility for the accuracy, completeness, or usefulness of any information, apparatus, product, or process disclosed, or represents that its use would not infringe privately owned rights. Reference herein to any specific commercial product, process, or service by trade name, trademark, manufacturer, or otherwise does not necessarily constitute or imply its endorsement, recommendation, or favoring by the United States Government or any agency thereof. The views and opinions of authors expressed herein do not necessarily state or reflect those of the United States Government or any agency thereof. 


\section{DISCLAIMER}

Portions of this document may be illegible in electronic image products. Images are produced from the best available original document. 
This report was prepared as an account of work sponsored by the United States Government. Neither the United States nor the United States Energy Research and Development Administration, nor any of their employees, nor any of their contractors, subcontractors, or their employees, makes any warranty, expressed or implied, or assumes any legal liability or responsibility for the accuracy, completeness, or usefulness of any information, apparatus, product or process disclosed, or represents that its use would not infringe privately owned rights. 
GEOSTATISTICAL ORE RESERVE ESTIMATION FOR

A ROLL-FRONT TYPE URANIUM DEPOSIT.

(PRACTITIONER'S GUIDE)

Young C. Kim and Harvey P. Knudsen

University of Arizona

Department of Mining and Geological Engineering

Tucson, Arizona 85721

January, 1977

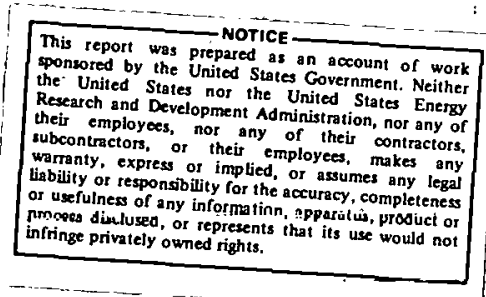

Work pcrformed under Bendix

Field Engineering Corporation

Grand Junction Operations Sub-

contract No. 76-003-E, and

Bendix Contract EY-76-C-13-1664.

PREPARED FOR THE U.S. ENERGY RESEARCH AND DEVELOPMENT ADMINISTRATION

GRAND JUNCTION, COLORADO 81501 


\section{ACKNOWLEDGMENTS}

The authors would like to acknowledge the U. S. Energy Research and Development Administration for the funding of this study; also, the management, the mine planning engineers and the geologists of the mining company for supplying the necessary data for this study.

Special thanks are due to the following individuals, all of whom contributed to the successful completion of this report: Dr. Donald Myers of the University of Arizona for his technical assistance; Mr. Taesin Chung of ERDA for being the technical coordinator of this study; Mr. Jack Griggs of Bendix Field Engineering Corporation for project coordination of this contract; and Mrs. Alice. Yelverton for typing this report. 
Acknowledgements

I. OBJECTIVE AND SCOPE OF THIS REPORT

1.1 Objective of This Report. . . . . . . . . . 1

1.2 Scope of This Report. . . . . . . . . . . . 2

II. A CAPSULE VIEW OF GEOSTATISTICAL ORE RESERVE ESTIMATION METHOD

2.1 Introduction. . . . . . . . . . . 5

2.2 Variogram . . . . . . . . . . . . . . 5

2.3 Geostatistical Ore Reserve Estimation Method. . . . 10

III. EXAMPLES OF VARIOGRAM DEVELOPMENT

3.1 Example of Computations . . . . . . . . . . . . 12

3.2 Example of Variogram Development. . . . . . . 15

IV. TECHNIQUE OF LAGRANGE MULTIPLIERS

4.1 Unconstrained vs Constrained Optimization . . . . . 27

4.2 The Classical Calculus Method for a Function of Many Variables. . . . . . . . . . . . 28

4.3 Constrained Optimization Problems and Their Solution Methods. . . . . . . . . . . 30

4.4 The Method of Lagrange Multiplier . . . . . . . . 34

V. ILLUSTRATION OF KRIGING PROCEDURE AND EXAMPLES

5.1 Variance of Point Samples Within Any Size Volume V. . 41

5.2 Block Variance in a Deposit . . . . . . . . 44

5.3 Extension (or Estimation) Variance $\left(\sigma_{E}^{2}\right) \ldots 45$

5.4 Explanation of Kriging Procedure. . . . . . . . . 47

5.5 Examples of Kriging . . . . . . . . . . 53

REFERENCES

APPENDIX A: Variogram Computation Program "UGAMM"

User's Guide. . . . . . . . . . . . . . . Al-A24

APPENDIX B: Variogram Display Program "VARPLOT"

User's Guide. . . . . . . . . . . . . . B1-B16

APPENDIX C: Kriging Program "UKRIG" User's Guide. . . . . . . . . . C1-C24

APPENDIX D: Map Creation Program 'MAP" User's Guide. . . . . . . D1-D14

APPENDIX E: Estimation Variance Program "ESTVAR" User's Guide. . . E1-E15 


\subsection{OBJECTIVE OF THIS REPORT}

This report is prepared for the U. S. Energy Research and Development Administration (ERDA) as part of contractual research entitled "A Case Study of the Geostatistical Ore Reserve Estimation for a Roll-Front Type Uranium Deposit."

The primary objective of this report is to provide a useful guide to implementing geostatistics into the ore reserve estimation procedures for a roll-front type uranium deposit.

In order to accomplish this objective, the report has been prepared in a textbook format, comprehensible to the practitioners in ore reserve estimation. As such, this report can be used as a guide not only by the ERDA personnel but also by others involved in ore reserve estimation.

In the past, the advantages of using geostatistics in ore reserve estimation have been sufficiently emphasized in the literature. However, the comparative study performed by the authors ${ }^{1,2}$ in 1975 under the sponsorship of ERDA was the first published treport of its kind. In this comparative study, the practicality' as 'well as the superiority of geostatistics were. compared over the conventional methods using real life data. Obviously, the outcome of the study was in favor of geostatistics.

The theoretical basis of geostatistics has been fairly well documented, although there is only one text by Matheron ${ }^{3}$ which contains most of the theory. Unfortunately, this text is not readily comprehensible to the average practitioners in ore reserve estimation. Consequently, this difficulty in understanding has served as one of the obstacles, in implementing 
this new methodology to ore reserve estimation.

In other words, what has been missing to date is a practical comprehensible text that gives illustrative examples of each phase of a geostatistical study and that provides comprehensive user's manuals for the computer programs necessary to make a practical geostatistical study. This report, therefore, is intended to provide the above missing link, thus paving the way to future implementation of geostatistics.

\subsection{SCOPE OF THIS REPORT}

This report essentially consists of two parts. Part I contains illustrative examples of each phase of a geostatistical study using a rollfront type uranium deposit. Part II contains five (5) computer programs and comprehensive user's manuals for these programs which are necessary to make a practical geostatistical study.

In developing these examples and computer programs, emphasis has been placed naturally on the feasibility of implementing geostatistics into ERDA reserve estimation procedures. However, the developed illustrations as well as the tools are general enough to be used by all practitioners in ore reserve estimation.

The remaining Part I portion of this report consists of Chapters 2 through Chapters 5. In Chapter 2, a capsule view of the geostatistical ore reserve estimation method is presented in which the reader is exposed to; a) the basic difference between classical statistics and Matheron's geostatistics, b) variogram, and c) the role of "kriging" in geostatistics. These topics are subsequently expanded in Chapters 3 through Chapters 5, using illustrative examples and a sufficient amount of mathematical finesse. 
Specifically, Chapter 3 discusses a formal definition, procedures and examples of variogram modeling. In Chapter 4, the Lagrange multiplier method of converting a constrained optimization problem into an equivalent form of unconstrained optimization method is discussed. Understanding of the Lagrange multiplier method is mandatory for technical comprehension of the kriging procedure. Chapter 5 provides a concise explanation and a mathematical derivation of the kriging process and presents two examples that explain in detail the calculations involved in kriging.

Part II of this report which contains five (5) computer program user's manuals complete with program listings, consists of five appendices. These five computer programs are:
a) Variogram computation program called UGAMM.
b) Calcomp plotter variogram display program called VARPLOT.
c) : Printer map creation program called MAP.
e) Estimation variance computation program called ESTVAR.

Each manual describes in detail all the program capabilities, limitations, and sample.inputs and outputs.

Program UGAMM is designed to conveniently accept data from ERDA's SCOR program output in its variogram computation. The SCOR prngram, which is not included in this report, calculates the grade, thickness and grade thickness product for the combined total of all ore zones encountered in each drill hole. Program VARPLOT provides a plot of both the variogram calculated by ULAMM and, if specified, the theoretical variogram model that best describes the calculated variogram.

The kriging program UKRIG accepts data from ERDA's SCORE program. The output from UKRIG consists of a file containing the grade, thickness 
and grade thickness product of the ore within each block of the deposit. Program MAP prints a plan map of the block values computed by program UKRIG. Program ESTVAR calculates the estimation variance due to giving the grade of a set of samples to some volume. An example of its use would be to calculate the probable error in an ore reserve estimate made by assigning the average grade of a group of samples within a deposit to the deposit. 
A CAPSULE VIEW OF GEOSTATISTICAL ORE RESERVE ESTIMATION METHOD

\subsection{INTRODUCTION}

The geostatistical ore reserve estimation method (or geostatistics in short) is a relatively new method developed by G. Matheron in France during the eariy 1960 's. The underlying mathematical basis of the method is called "The Theory of Regionalized Variables," and the method somewhat resembles the classical statistical approach.

However, there exists one fundamental difference between geostatistics and the classical statistics. In the latter, the samples taken to infer the unknown population are always assumed to be random samples. Furthermore, they are assumed to be independent of each other; i.e., obtaining one sample does not affect the outcome of the next sample.

Since the above conditions are rarely satisfied when one takes drill hole assay. samples, geostatiștics does not demand that samples be independent. On the contrary, this method assumes that adjoining samples are correlated to each other spatially (or in space). It also assumes that the particular relationship expressing the extent of the above correlation can be analytically and statistically captured in a function known as "variogram function" or. "variogram" in short.

Geostatistics, therefore, has a special appeal to a geologist or to a mining engineer, not only because of the above explicit recognition of the spatial relationship existing between adjoining samples, but also due to its ability to provide this relationship in quantitative terms.

\subsection{VARIOGRAM}

The variogram is used to describe the spatial correlation between grades (or any other characteristics such as the thickness of 
mineralization) within an ore deposit. Thus, it is the basic tool of geostatistics. To a mining engineer or geologist, the variogram is of interest since it incorporates several geological features that are important in ore deposit evaluation, such as the continuity of mineralization, zones of influence, and whether the zones of influence are different along different directions.

These interesting features are captured by analyzing the similarity or dissimilarity between grades for some distance (h) apart. Specifically, the squared difference between two grades (h) meters apart is calculated. To get a generalized relationship applicable to the area of interest, the calculation is repeated for all the samples that are (h) distance apart and the average squared difference obtained. This is the definition of the variogram.

Figure 2.1 shows an example of a variogram calculated for a roll-front type uranium deposit. On this graph, distance (h) is on the $X$ axis and the average squared difference of the grade in $\left(\frac{0}{0}\right)^{2}$, which is called $\gamma(h)$, is plotted on the $Y$ axis. As can be seen from this variogram, the values of $\gamma(h)$ increase with increasing distance until it levels off at a certain distance. This tells us what we intuitively knew; i.e., the samples nearby do have similar values and that samples farther away are likely to have quite different values. The variogram thus numerically describes the continuity of mineral-. ization. Figure 2.2 shows several examples of different degrees of continuity. The distance at which the variogram levels off is called the range and is simply the traditional geological notion of range of influence. It means that beyond the range the samples are no longer correlated; i.e., they are independent of one another.

The value of the variogram where it levels off is called the sill value. In Figure 2.1, this sill value of $0.0043(\%)^{2}$ is also the variance of all the 


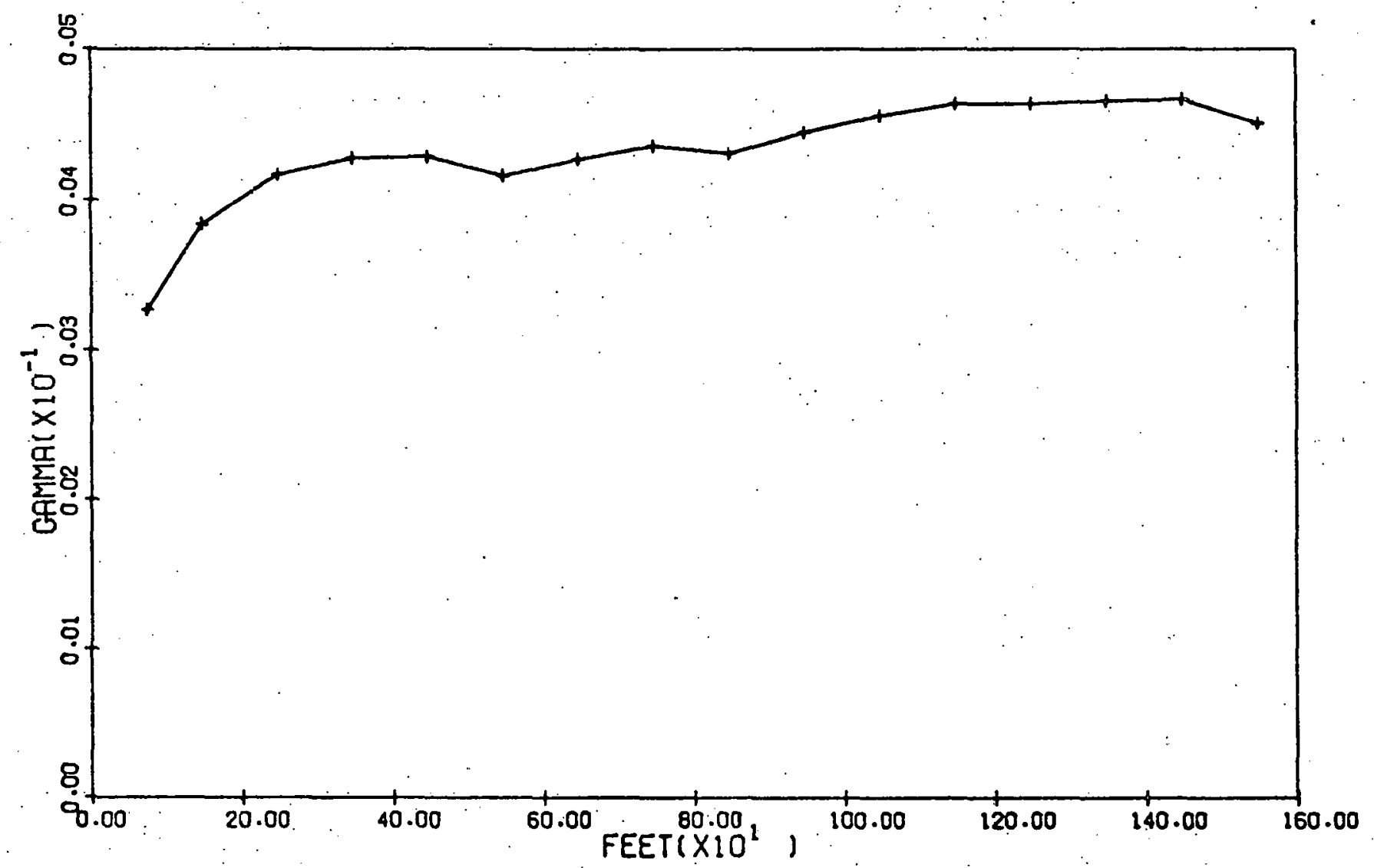

URANIUM PROJECT GRADE VARIOCRAM DIRECTION $=0 . \quad$ WLNOON $=90$. CLASS SIZE $=100.00$ WLNOON $=90^{\circ}$ MEAN :

LOCARITHMS -

VARIANCE $=0.0043$

NO. OF SAMPLES $=770$

Figure 2.1

SAMPLE VARIOGRAM FOR A ROLL-FRONT TYPE URANIUM DEPOSIT 


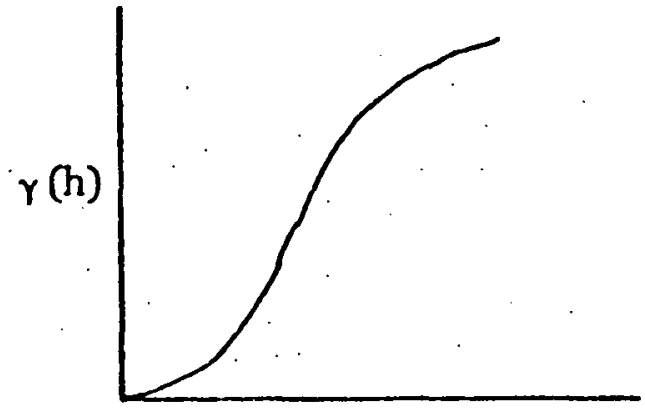

High degree of continuity. Can be approximated by parabola near the origin. Bed thickness is an example.

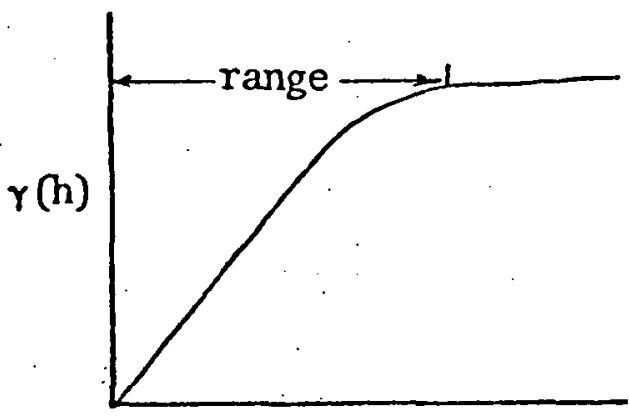

Average continuj.ty. Almost linear near origin. Typical of many metal deposits.

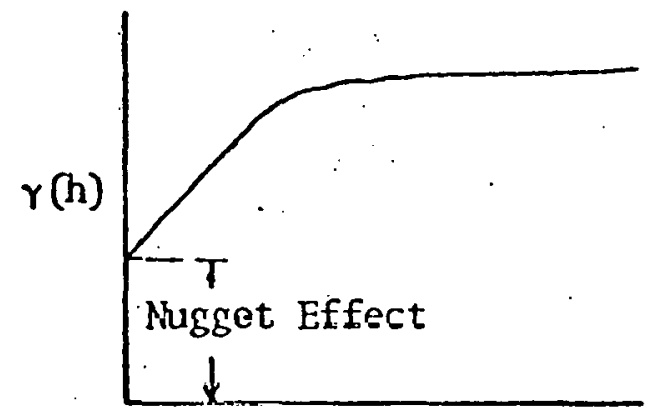

Nugget effect. Discontinuity at the origin and thereafter nuch like above variogram.

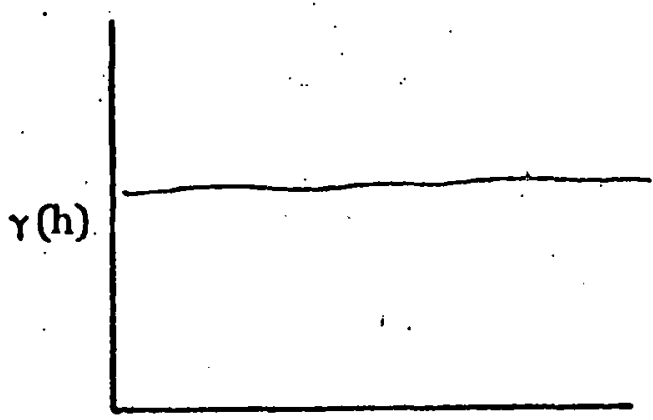

Purely randoin.

Figure 2.2

DEGREES OF CONTINUITY EXPRESSED BY VARIOGRAM 
samples used in variogram development. This is no accident because the computation of the average squared difference between samples (h) distance apart is similar to calculating a variance in classical statistics.

Just as the statistical variance of an estimate is frequently viewed as the uncertainty associated with the given estimate, the variogram can be viewed as the measurement of uncertainty that exists when a sample assay is extended some distance. This uncertainty exists mainly due to the variability bctween grades, as has been captured in the variogrann.

The value of the variogram at distance $(h)=0$ is called the nugget value. In Figure 2.1 , the estimated nugget value is approximately $0.002(\%)^{2}$ which is a relatively high value in relation to the sill value of $0.0043\left(\frac{\%}{0}\right)^{2}$. Ideally, this nugget value should be zero simply because two samples from the same point (i.e., $h=0$ ) should have the same grade. A positive nugget value, on the other hand, can have real physical meaning or be due to errors in sampling or assaying. In general the nugget should be relatively small if correct sampling and assaying procedures have been used. A relatively high nugget value is very common in the uranium deposits, thus indicating the difficulty of obtaining accurate assays from the present sampling procedures.

A third item of geological interest that can be obtained from the variogram is whether there is anisotropy in the mineralization; i.e., is the mineralization more continuous in one direction than another? Anisotropy is determined by comparing the range of influence of the variograms, computed along different directions.

It is hoped that the above brief description of the variogram gives at least some feeling of how the variogram captures and displays several of the features of the mineralization. Some examples on the process of variogram 
modeling is given in Chapter 3 of this report to further illustrate the nature of a variogram.

\subsection{GEOSTATISTICAL ORE RESERVE ESTIMATION METHIOD}

The ultimate objective of any geostatistical study is to obtain an ore reserve estimate and related confidence levels using geostatistics, thus reaping all the associated benefits of this new methodology. Two basic steps must be performed for any full-fledged geostatistical ore reserve estimation. These two basic steps are: (1) developing the representative variogram model(s) of the deposit and (2) assigning block grades using an inference (or weighting) scheme known as "kriging."

The first step is mandatory because it is a basic tool of geostatistics. Performing the first step is sufficient for obtaining a global estimate and associated confidence limits of a deposit, i.e., total tonnage and its average grades. On the other hand, the second step of kriging individual blocks within an orebody is needed if one is interested in knowing the specific ore locations in the deposit.

The attractiveness of the second step, kriging, compared to other methods of assigning block grades is that kriging provides an unbiased estimate having minimum estimation error.* It does this by utilizing the variogram to assign weights to each sample grade in such a manner that the sample information is used to best advantage.

Another tangible benefit of the geostatistical ore reserve estimation method is that it can provide statistical confidence limits around the ohtained grade estimate. For this purpose, the variations indicated by the

*Estimation error refers to the error one incurs when the sample grade from a drill hole is extended to the surrounding area for reserve estimation purposes. 
variogram are used. Consequently, the task of performing the first step, i.e., variogram development, is the most important one in any geostatistical study. "Yet, it is a step requiring a considerable amount of subjective interpretation of computation results. On the other hand, performing the second task, i.e., kriging the blocks, is quite straightforward although extremely time-consuming.

Although the task of performing kriging is straightforward, technical understanding of the kriging procedures requires a familiarity with the method of Lagrange multipliers. ${ }^{5}$ It is a method of converting a constrained optimization problem into an equivalent form of unconstrained optimization problem, so that the classical calculus method can be applied to obtain the desired solution.

Consequently, the Lagrange multiplier method is explained in Chapter 4 of this report whereas techniques and examples of kriging are provided in Chapter 5 . 


\section{EXAMPLES OF VARIOGRAM DEVELOPMENT}

Obtaining good and representative variograms involves a considerable amount of computations due to the enpirical as well as subjective nature of the work. The magnitude of the task increases as the complexity of the deposit increases. For instance, variograms may have to be calculated for 1) each variable of interest (grade, thickness, etc.), 2) various directions, 3) different geologic or mineralogic zones within the deposit and 4) different types of sampling or assaying procedures (chemical or radiometric analyses).

In this chapter procedures involved in variogram calculation will be illustrated by two examples. The first example simply illustrates the computations involved in the calculation of a variogram, whereas the second example illustrates the sequence of steps leading to the discovery of a representative variogram for a roll front uranium deposit.

\subsection{EXAMPLE OF COMPUTATIONS}

Figure 3.1 shows a small section of an uranium deposit. This section will be used to briefly illustrate the actual computations involved in calculating a variogram. The holes are on a nearly uniform grid of 100 feet, but for this illustration we will assume the grid spacing is exactly 100 feet.

The equation for the variogram is given by Equation 3.1 .

$$
\gamma(h)=\frac{1}{2 N} \sum_{i=1}^{N}\left[f\left(x_{i}\right)-f\left(x_{i}+h\right)\right]^{2}
$$

where $N=$ number of sample pairs with the samples $f\left(x_{i}\right)$ and $f\left(x_{i}+h\right)$ being h distance apart. 


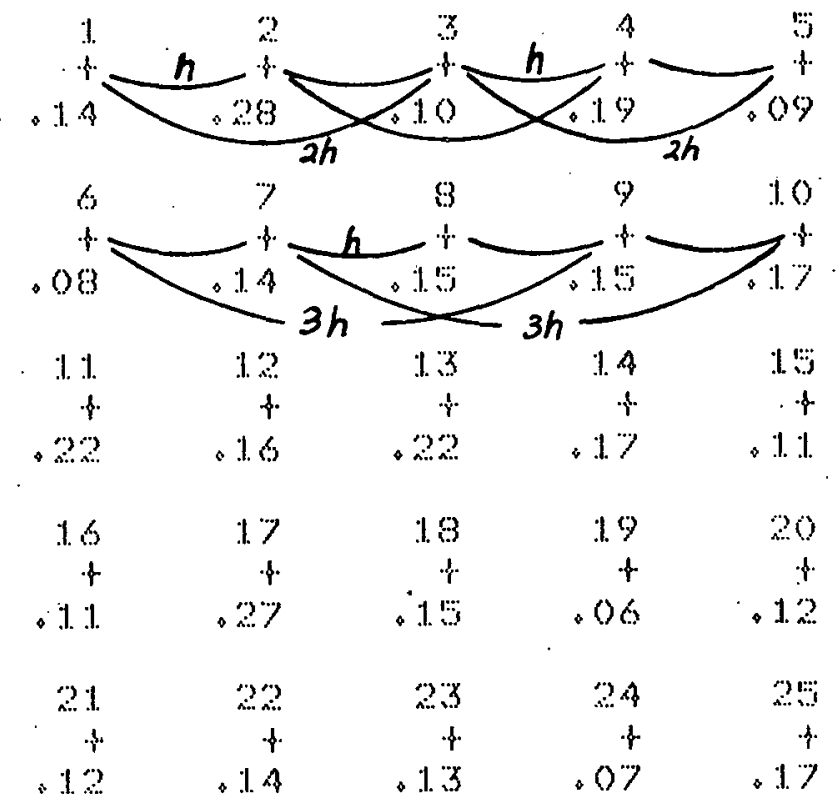

Note: $\mathrm{N}$ Hole Number

+ Hole Location

VAL Value of Intcrcst such as Grade

Figure 3.1

SMALL SECTION OF AN URANIUM DEPOSIT 
To illustrate its use a variogram will be calculated for the E-W direction. This is done by picking all the sample pairs lying E-W, squaring their difference, and grouping them by distance.

For example, for $h=100$.

$$
\begin{aligned}
& \gamma(100)=\frac{1}{2(20)}\left[\left(x_{1}-x_{2}\right)^{2}+\left(x_{2}-x_{3}\right)^{2}+\left(x_{3}-x_{4}\right)^{2}+\left(x_{4}-x_{5}\right)^{2}\right. \\
& +\left(x_{6}-x_{7}\right)^{2}+\left(x_{7}-x_{8}\right)^{2}+\left(x_{8}-x_{9}\right)^{2}+\left(x_{9} x_{10}\right)^{2} \\
& +\left(x_{11}-x_{12}\right)^{2}+\left(x_{12}-x_{13}\right)^{2}+\left(x_{13}-x_{14}\right)^{2}+\left(x_{14}-x_{15}\right)^{2} \\
& +\left(X_{16}-X_{17}\right)^{2}+\left(X_{17}-X_{18}\right)^{2}+\left(X_{18}-X_{19}\right)^{2}+\left(X_{19}-X_{20}\right)^{2} \\
& \left.+\left(x_{21}-x_{22}\right)^{2}+\left(x_{22}-x_{23}\right)^{2}+\left(x_{23}-x_{24}\right)^{2}+\left(x_{24}-x_{25}\right)^{2}\right] \\
& \gamma(100)=\frac{1}{40}\left[(.14-.28)^{2}+(.28-.10)^{2}+(.10-.19)^{2}+(.19-.09)^{2}\right. \\
& (.08-.14)^{2}+\ldots \ldots \\
& \left.(.07-.17)^{2}\right] \\
& \gamma(100)=\frac{1}{40}\left[(.14)^{2}+(.18)^{2}+(.09)^{2}+(.10)^{2} \ldots(.10)^{2}\right] \\
& \gamma(100)=\frac{1}{40}[.1533]=.0038
\end{aligned}
$$

For $h=200$ feet we take all sample pairs lying $E-W$ and separated by 200 feet.

$$
\begin{aligned}
\gamma(200)= & \frac{1}{2(12)}\left[\left(x_{1}-x_{3}\right)^{2}+\left(x_{2}-x_{4}\right)^{2}+\left(x_{3}-x_{5}\right)^{2}\right. \\
& +\left(x_{6}-x_{8}\right)^{2}+\left(x_{7}-x_{9}\right)^{2}+\left(x_{8}-x_{10}\right)^{2} \\
& +\ldots \ldots \\
& \left.\quad \ldots\left(x_{23}-x_{25}\right)^{2}\right] \\
= & \frac{1}{24}\left[(.04)^{2}+(.09)^{2}+(.01)^{2} \quad \ldots(.04)^{2}\right] \\
= & \frac{1}{24}[.0806]=.00335
\end{aligned}
$$


Similar calculations can bè made for $h=300$ feet and $h=400$ feet. Note, however, that as $\mathrm{h}$ gets larger there are fewer and fewer sample pairs that are $\mathrm{h}$ feet apart, and thus the reliability of the variogram decreases. Also note that there is no pair of samples for $h=500 \mathrm{ft}$. or larger, at least in the above example problem.

\subsection{EXAMPLE OF VARIOGRAM DEVELOPMENT}

The procedure of variogram calculation will be illustrated by the calculation of variograms for a roll front type uranium deposit located in Wyoming. Roll front uranium deposits are usually fairly complex due to their often having several mineralized zones and the mineralization being quite variable in both grade and thickness. A cross section through part of the deposit used for this example is shown in Figure 3.2. Note the variation in grade and thickness for each of the horizons and the poor horizontal continuity of the zones,

The first step in variogram modeling is to clearly define the purpose of the study in order to learn which variables are of interest in the study. For example, is it to calculate global ore reserves, or to calculate ore reserves for mine planning purposes? In this study, global ore reserves are of most interest. Thus, the interest focuses on how much uranium is present in a deposit; but not necessarily where it is located within the deposit.

The variables of interest are the grade of uranium, the thickness of uranium ore within the deposit and the grade thickness product (GT). Thus, to determine the global ore reserves it is only necessary to calculate the 


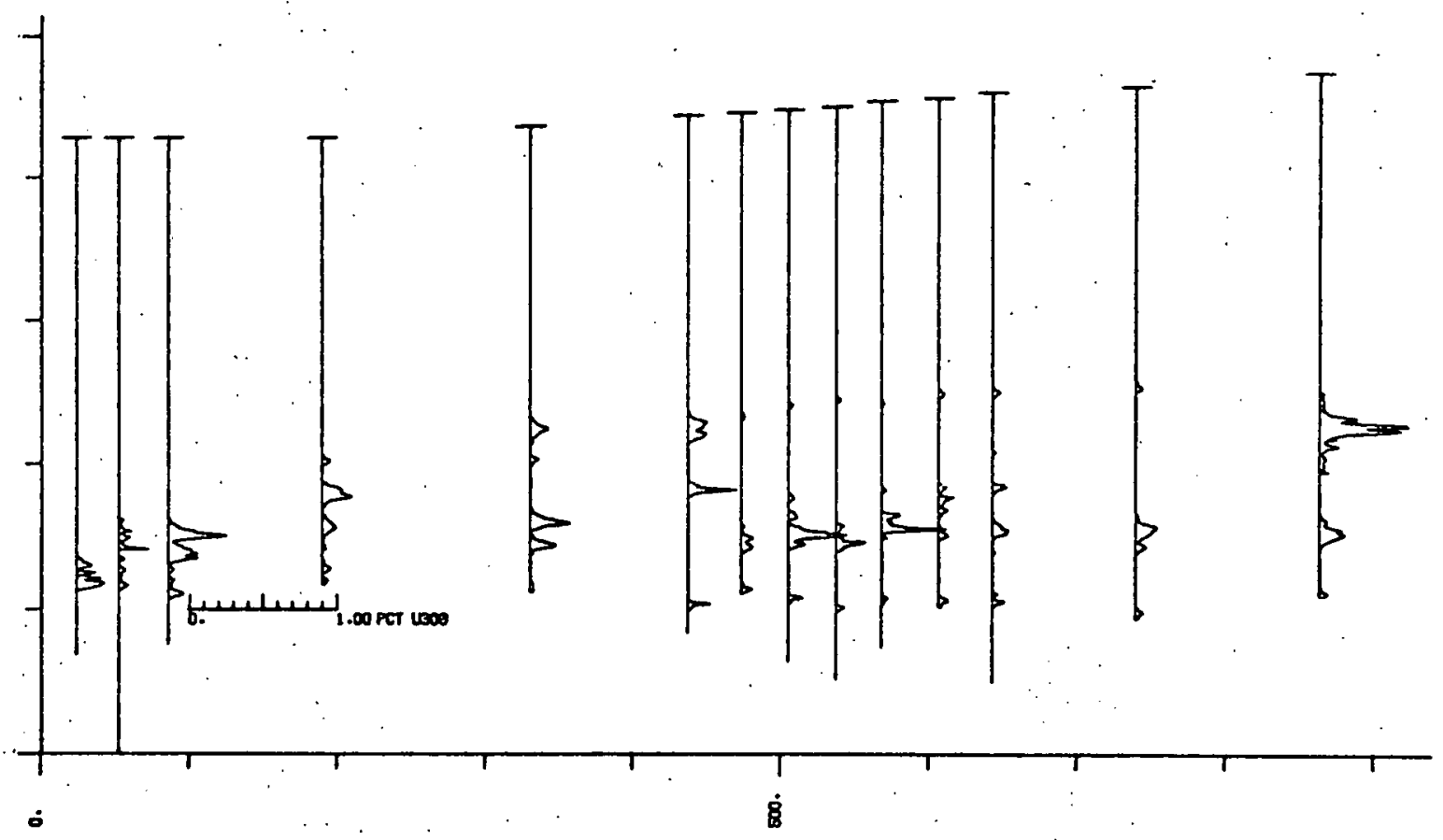

Figure 3.2

CRUSS SECTION OF URANIUM DEPOSIT 
average grade of the deposit and multiply this by the area of the deposit and the average thickness of ore. For each drill hole, the grade, thickness, and GT are calculated for each mineralized zone intersected by the drill hole. These are totaled to give the total thickness of mineralization, the average grade and the GT within each hole.

The cumulative total thickness, the average grade and the GT are chosen as the variables of interest for this study. It should be noted that the vertical distribution of ore zones is lost by this procedure, but the quantity of uranium per unit area is of course the same.

The deposit is examined to determine if there are any areas that should be analyzed separately due to mineralogical or geological differences. None are found. Since the variogram measures the degree of continuity between sample grades (or thickness, GT, etc.) within the deposit, it is necessary to delete from the variogram calculations the drill holes that are obviously not within the deposit. This is especially necessary in uranium deposits where a single project may have several. thousand drill holes of which quite a few may be outside the deposit.

Finally, actual variogram calculations begin. Variograms are calculated for the grade, the thickness and GT.

It should be mentioned here that the natural values of the variables are used in all the calculations. Optionally the variables could be transformed by taking their logarithms. Initial variograms are calculated along the E-W direction but with a window of $90^{\circ}$. This is referred to as an average variogram for all directions and mainly serves to show the general characteristics of the variogram. Figures $3.3,3.4$, and 3.5 show the average variogram for grade; thickness and G.T. 


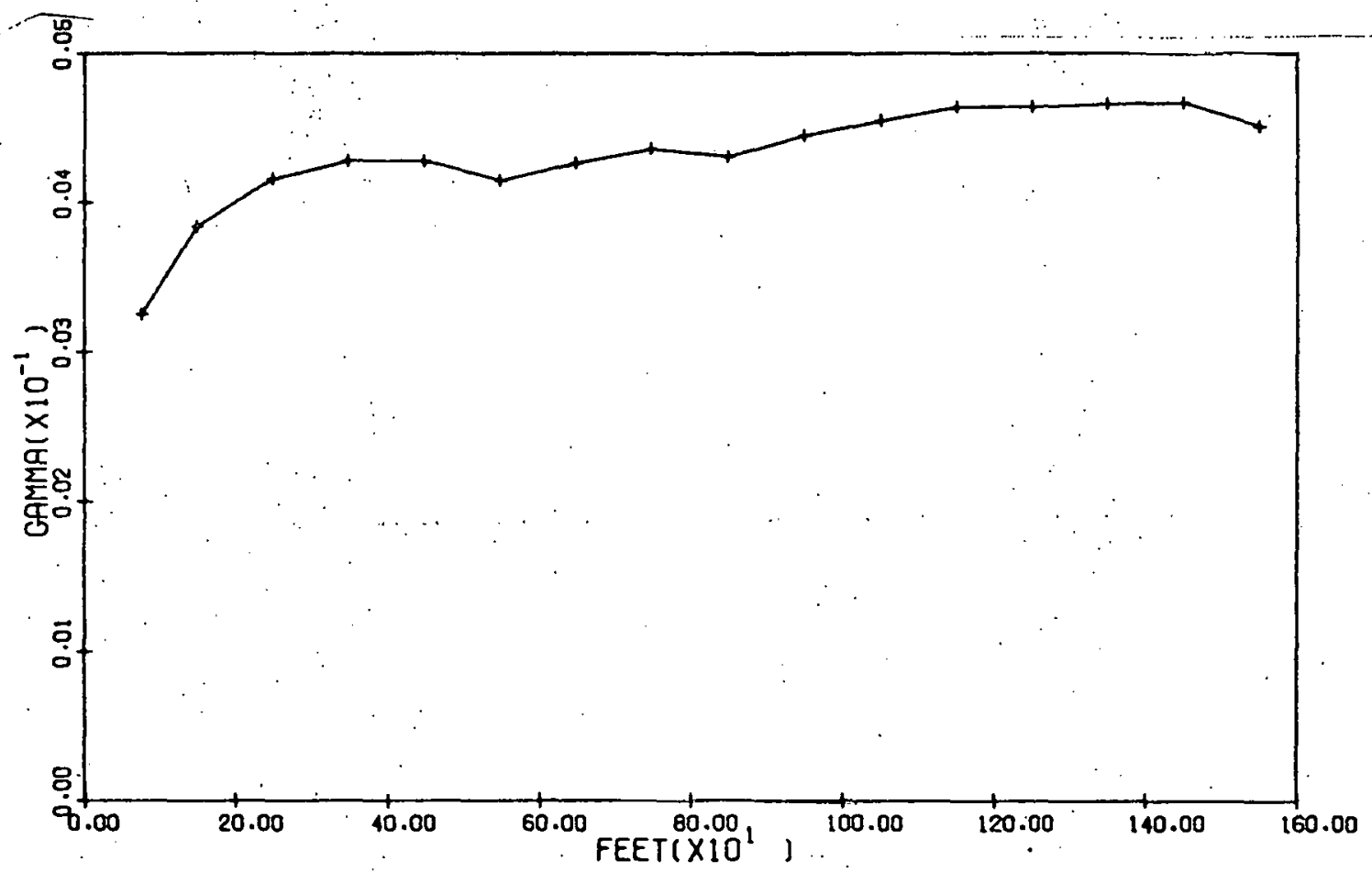

URANIUM PROJECT GRADE VARIOGRAM DIRECTION $=0 . . \quad$ WINOOW $=90$. CLASS SIZE $=100.00$

MEAN = LOCARI THMS -

VARIANCE $=0.0043$

NO. OF SAMPLES $=771$

Figure 3.3

AVERAGE VARIOGRAM FOR GRADE

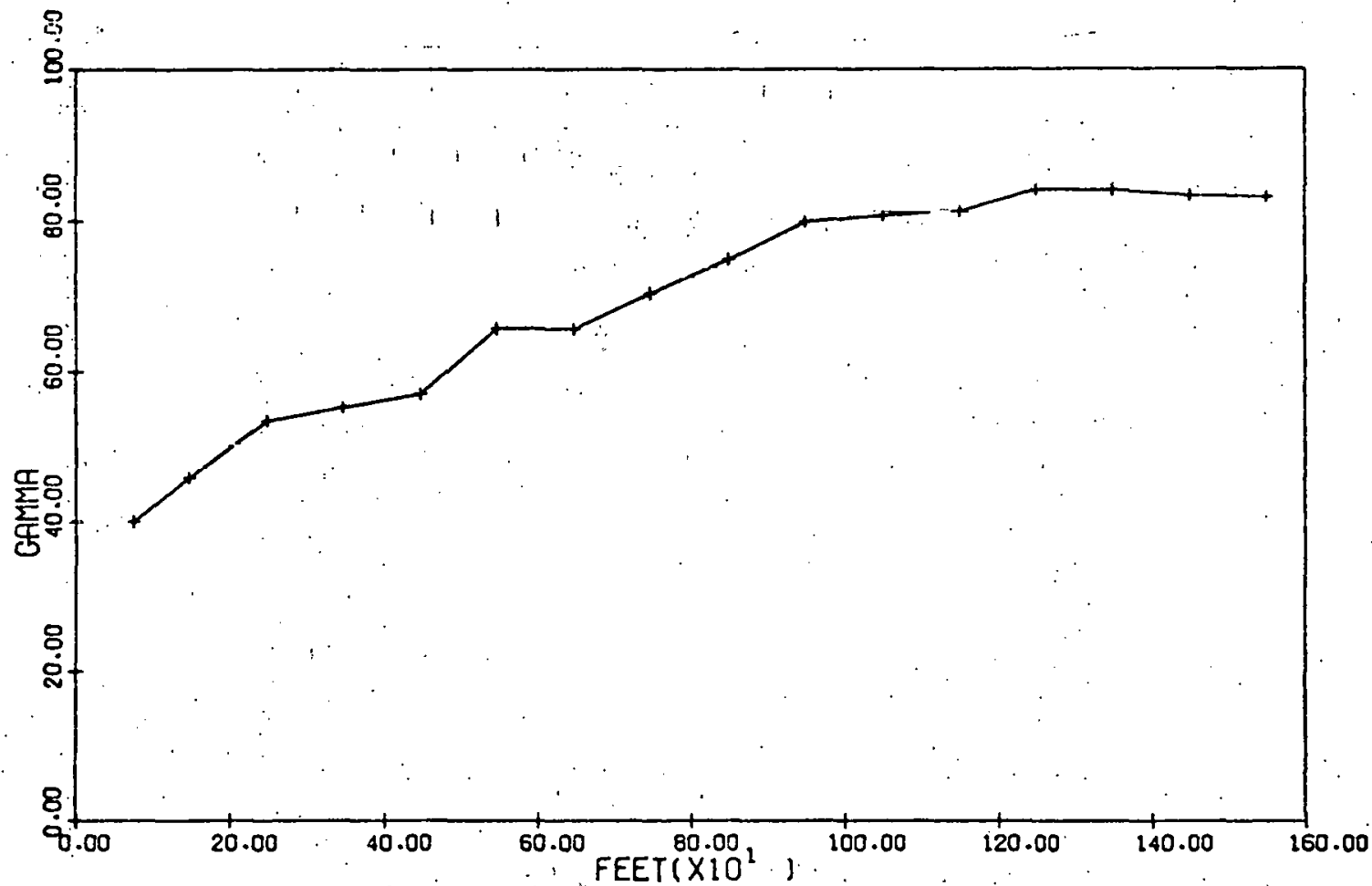

URANIUM PROJECT THICKNESS VARIOCRAM OIRECTION $=0 . \quad$ WINOOW $=90$. CLASS SIZE $=100.00$ LATARITHMS -

NO. OF SRMPLES $=771$

Figure 3.4

AVERAGE VARIOGRAM FOR THICKNESS 


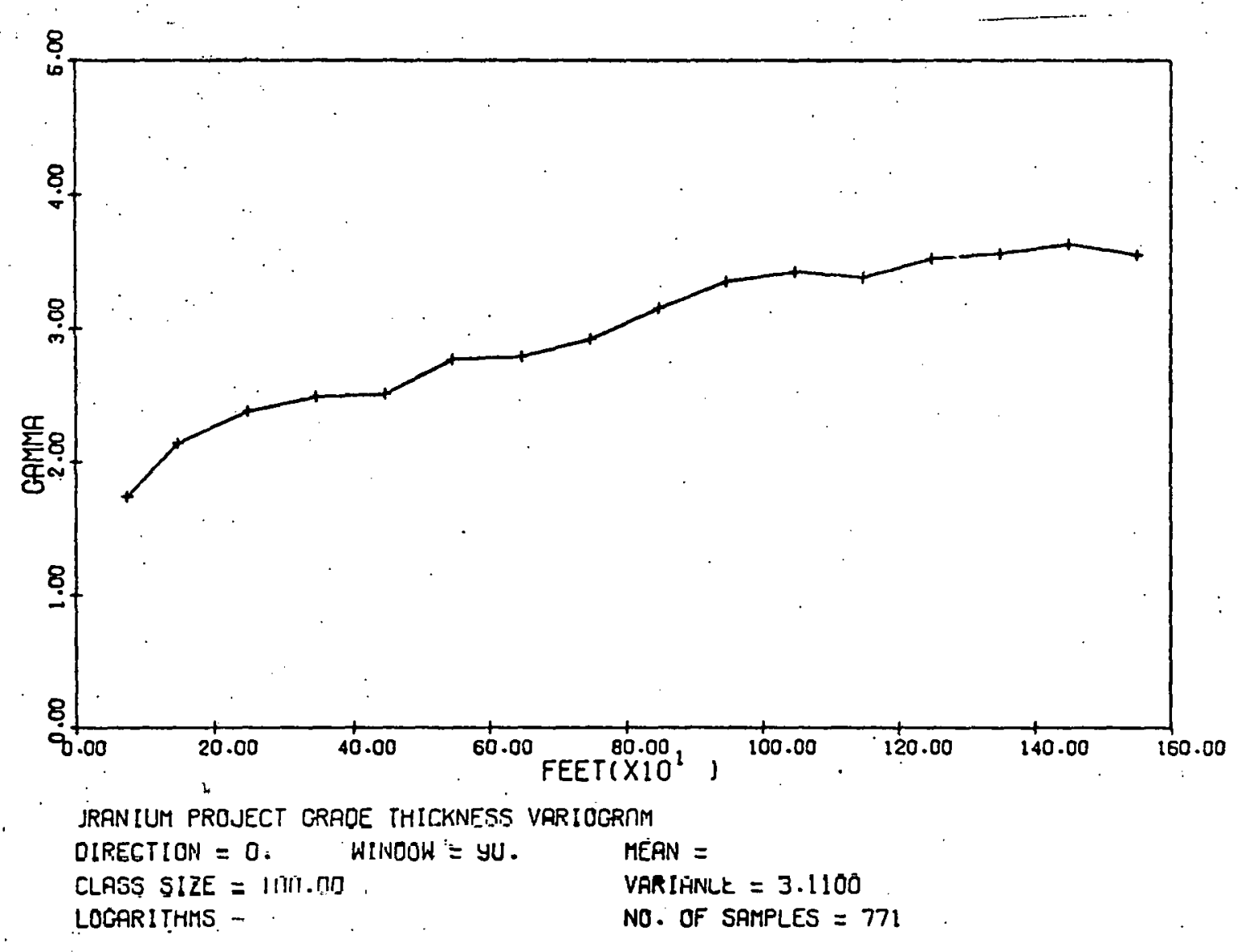

Figure 3.5

AVERAGE VARIOGRAM FOR GRADE THICKNESS 
The average variogram for grade is a good example of a spherical variogram with a range about 300 feet and a relatively high nugget value. The average variograms for thickness and GT are very similar in shape. They do not resemble the spherical variogram model as closely as the grade variogram does. Their range is about 700 feet and they also have a relatively large nugget effect.

Next, variograms are calculated along the directions of N-S, E-W, NESW and NW-SE to test for anisotropy. Sometimes the directions of anisotropy can be deduced apriori from the geology of the deposit, thus saving a lengthy search for anisotropy. For example, one might think that the continuity of grade (or thickness, or GT) is greater along the axis of the roll front than across it. The roll fronts in the deposit studied are quite variable, perhaps much like a meandering stream, but the average axis direction is probably NW-SE.

The variograms for each of the directions are shown in Figures 3.6, 3.7, and 3.8. Examination of the variograms for thickness and GT show no readily apparent geometric anisotropy.. The variograms for each direction are quite similar to each other and their differences could be due to fluctuations in the variograms. It should be remembered that as the variograms are calculated using a narrower window they become less smooth due to the decrease in the number of sample pairs used to calculate each point on the variogram.

The variograms for grade reveal a noticeable difference between the variograms of the NW-SE direction and the NE-SW direction, whereas the variograms N-S and E-W are nearly the same.

The difference between the NW-SE and NE-SW variograms is probably not 


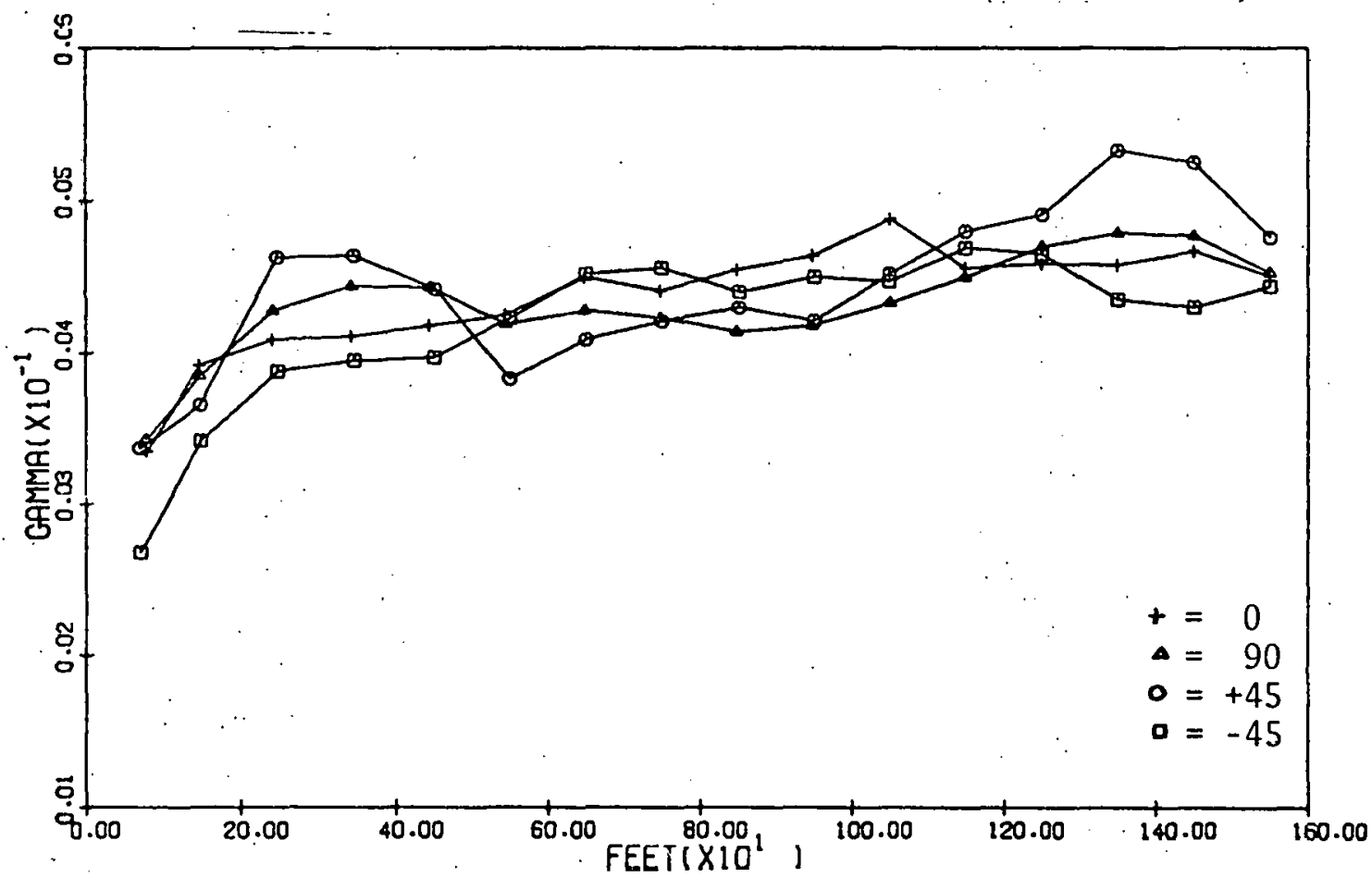

URANIUM PROJECT GRRDE VARLOCRAM OIRECTION = CLASS SIZE $=100.00$ WINOOW $=30$. LOGARI THMS -

MEAN =

VARIANCE $=0.0043$

NO. OF SAMPLES $=771$

Figure 3.6

VARIOGRAMS FOR GRADE 


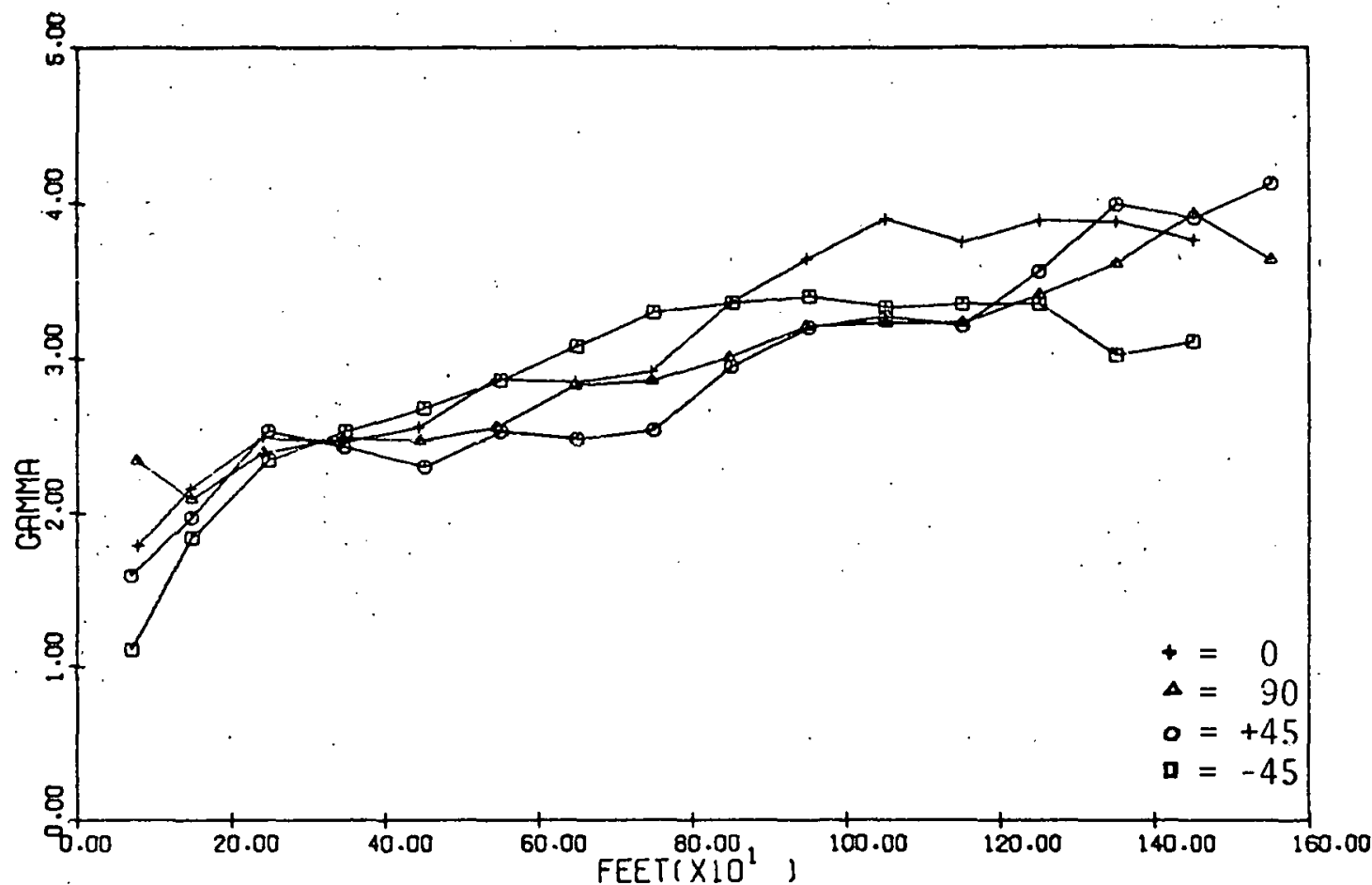

URANIUM PROJECT GRFDE THICKNESS VARIOGRAM

DIRECTION $=\because \quad$ WINDOW $=30$.

CLASS SIZE $=100.00$

MERN =

LOCHR I THMS -

VARIANCE $=3.1200$

NO. OF SAMPLES $=.771$

Figure 3.7

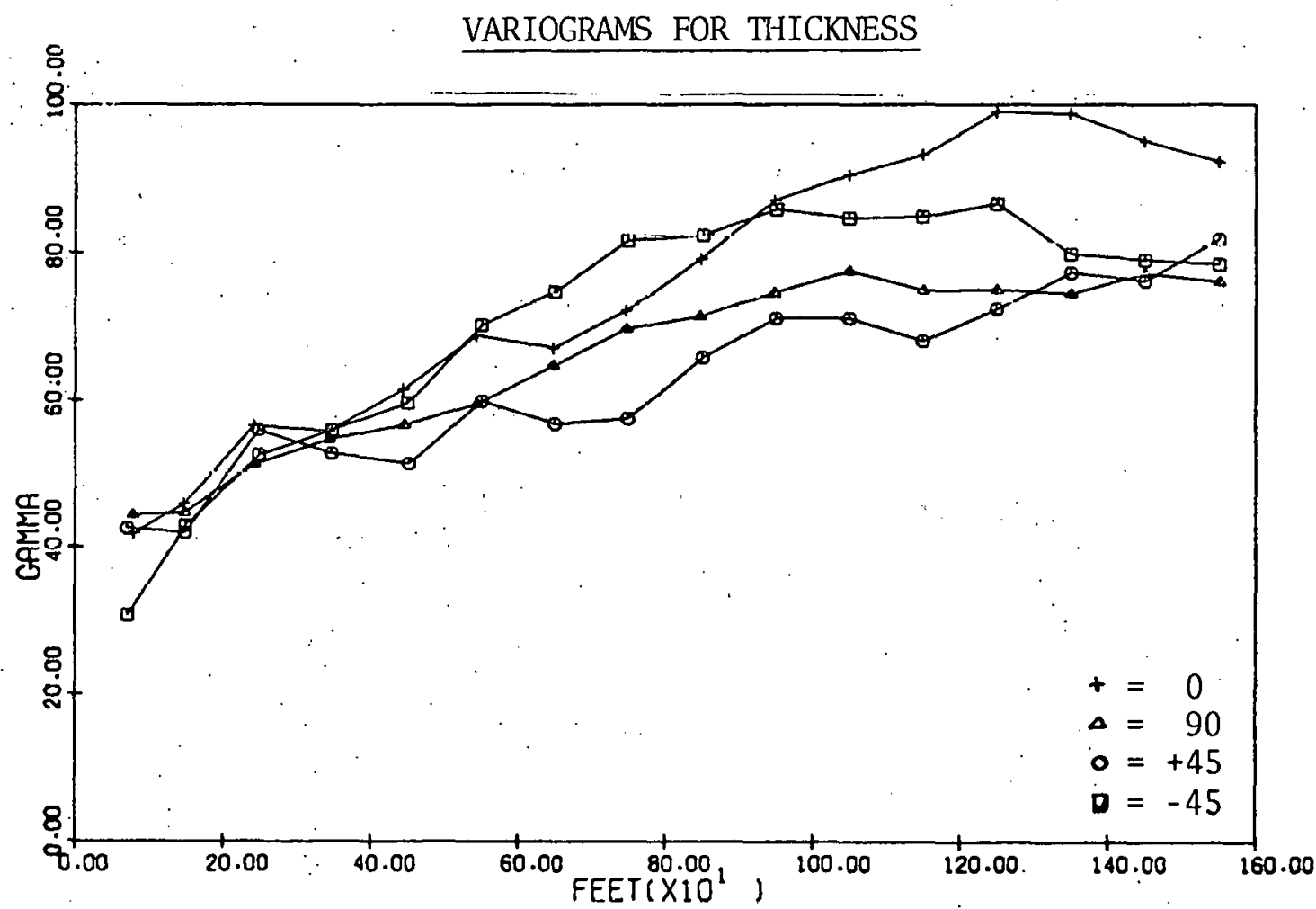

URANIUM PROJECT THICKNESS VARIOCRAM OIRECTION $=\quad$ WINOOW $=30$.

CLASS SIZE $=100: 00$

MEAN = L..GGARI THMS -

VARIANCE $=74.7000$

NO. OF SAMPLES $=771$

Figure 3.8

VARIOGRAMS FOR GRADE THICKNESS 
a simple geometric anistropy, since both variograms appear to have the same range. The difference is due to the NE-SW variogram overriding the sill value between 200 and 300 feet and then dropping down to the sill value. This effect is not uncommon, but has not been really adequately explained. One theoretical model called the hole-effect model, which is illustrated in Figure 3.9, has a similar behavior. This model has been used to describe a deposit where a series of rich and poor zones exist. While the NE-SW and NWSE have obvious differences, they both can be modeled by the same spherical variogram.

The final step in the analysis of the variograms is to find the theoretical variogram that best describes the experimental variograms. Both choosing the model and estimating its parameters is quite subjective. Fortunately, the selection of a model can often be narrowed to the choice of either a spherical model or a DeWijsian model, with the spherical model being the more common.

I'he experimental variograms calculated for this example are best described by the spherical model. The variograms for grade are especially good examples of spherical type variograms. A simple procedure is available to fit the spherical model and will be illustrated with the average variogram for grade, shown in Figure 3.3.

The spherical variogram is defined by Equation 3.2

$$
\begin{array}{rlrl}
r(h) & =C o+C\left[\left(1.5 \cdot\left(\frac{h}{a}\right)-.5\left(\frac{h}{a}\right)^{3}\right] \quad \text { for } \quad h<a\right. \\
& =C o+C & h \geq a
\end{array}
$$

The nugget effect is $C_{1}$, the range $a$, and the sill value $C+C o$. 


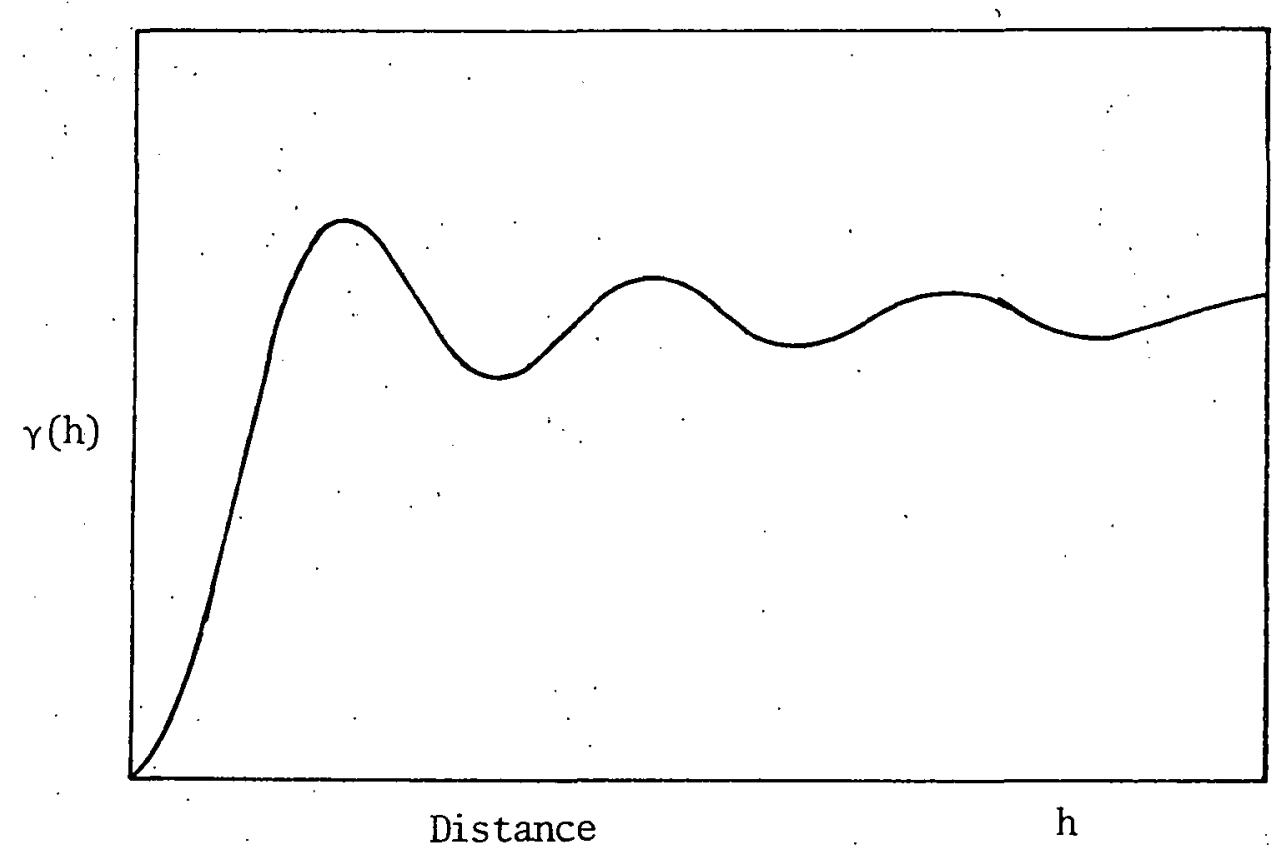

Figure 3.9

PLOT OF THEORETICAL "HOLE-EFFECT" MODEL 
The first step is to draw a tangent line through the first two or three points as shown on Figure 3.10. The $y$ intercept of this line is an estimate of the nugget effect, Co (.0027). Next, the sill is drawn. Remember the sill is equal to the variance of samples (.0043). Thus $\mathrm{C}+\mathrm{Co}=.0043$ and $\mathrm{C}=0.0016$. The intersection of the tangent and the sill is an estimate of $2 / 3 a$, or $a=210^{\prime}$. The fit can be checked by plotting the fitted curve and comparing it with the experimental variogram. As can be seen on Figure 3.11 the fit is quite good. If necessary the parameters can be modified to give a better fit.

Although this procedure is subjective; it usually leads to good fits and is very quick. It should be noted that the nugget value, Co, should be estimated most closely, while errors in $\mathrm{C}$ and a are less important. This is because the values of the variogram near the origin are of most importance in estimation problems. 


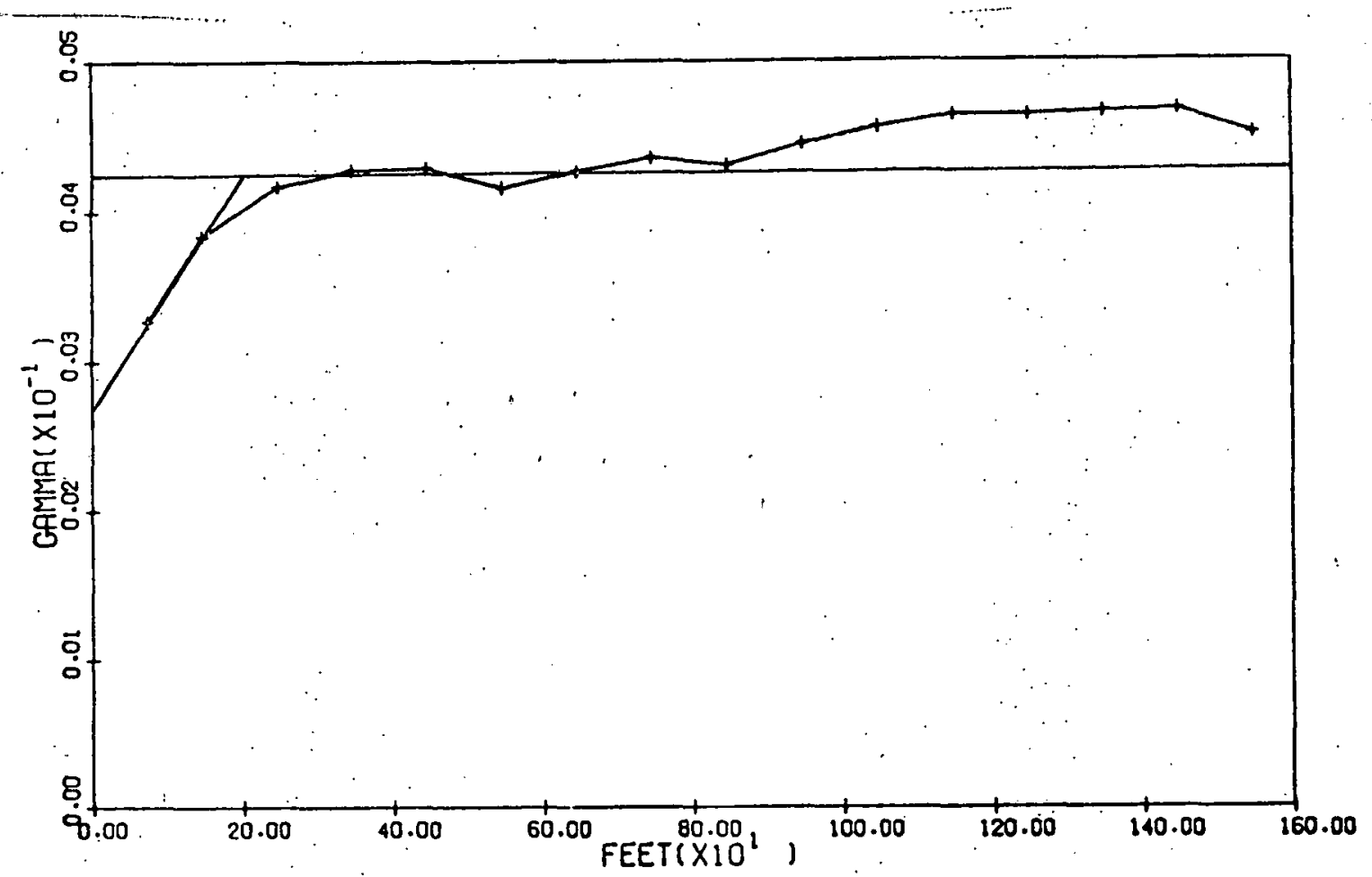

URANIUM PROJECT'. GRADE VARIOCRAM

OIRECTION $=0 . \quad$ WLNOOW $=90$.

CLASS SIZE $=100.00$

LOGARITHMS -

MEAN =

VARIANCE $=0.0043$

NO. OF SAMPLES $=770$

Figure 3.10

FITTING A SPHERICAL MODEL

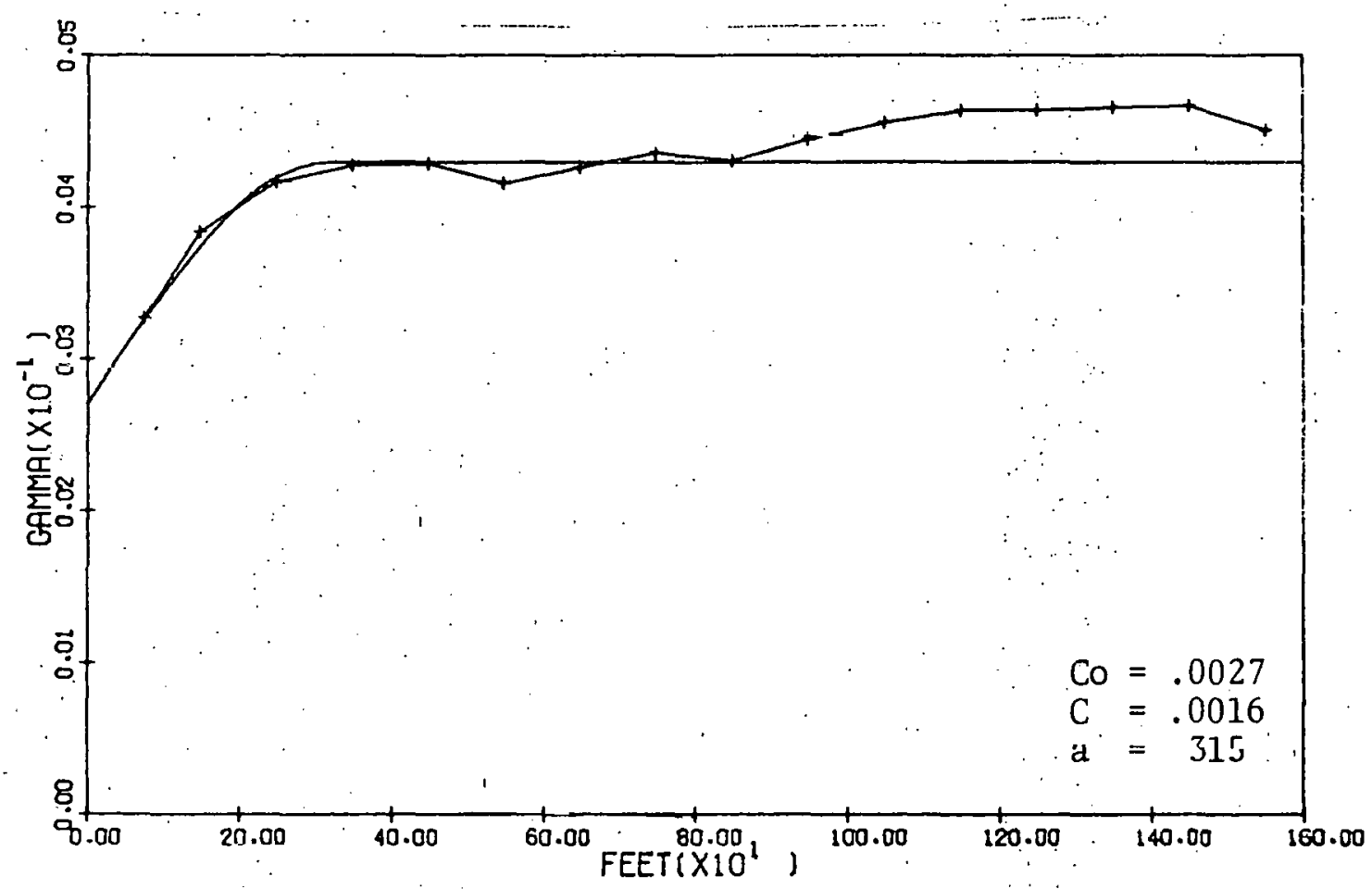

URANIUM PROJECT GRRDE VARIOCRAM OLRECTION $=0 . \quad$ WINDOW $=90$. CLASS SIZE $=100: 00$ LOGARITHAS -

MEAN =

VARIANCE $=0.0043$

NO. OF SAMPLES $=770$

Figure 3.11

FITTED SPHERICAL MODEL 
TECHNIQUE OF LAGRANGE MULTIPLIERS

The method of Lagrange multipliers is a technique for converting a constrained optimization problem into an unconstrained problem so that the classical calculus method can be applied to obtain the desired answer. Although this method has been known to mathematicians for quite some time, the practical significance of the Lagrange multiplier has not been appreciated until very recently by engineers, scientists, and economists.

\subsection{UNCONSTRAINED VS CONSTRAINED OPTIMIZATION}

From calculus, one is familiar with an unconstrained optimization problem. The simplest form of such a problem is to find either the maximum or the minimum point of some function such as $f(x)=x^{2}-2 x+4$. Mathematically, this problem can be stated as follows:

$$
\begin{array}{ll}
\text { Minimize } & f(x)=x^{2}-2 x+4 \\
\text { subject to } & -\infty \leq x \leq \infty
\end{array}
$$

The above problem is an unconstrained optimization problem because the variable $\mathrm{x}$ is not confined to within some specified range. In other words, the desired point can be sought within all possible ranges of $x$. In an unconstrained optimization problem, the solution can be always found at one of the stationary points, i.e., where the slope (or the derivative) is zero. Conscquently, one attempts to obtain the solution to the above problem by first locating one or more stationary points through differentiating the function with respect to the variable $x$ and then equating to zero. 
Unfortunately, however, the approach may not always work for a constrained optimization problem, i.e., the range of variable is restricted. In the above problem, suppose one restricts the value of $\mathrm{x}$ to within the range of 5 to 10 instead of $-\infty$ to $+\infty$. Then, the problem becomes:

$$
\begin{array}{lr}
\text { Minimize } & f(x)=x^{2}-2 x+4 \\
\text { subject to } & 5 \leq x \leq 10
\end{array}
$$

The resulting solution to the above constrained problem is $x=5$ which is not the stationary point of the given function. (Note that $x=1$ is the stationary point.) As can be seen from this example, solving the constrained optimization problems by the classical calculus approach is in most instances quite difficult and sometimes impossible. To overcome this difficulty, Lagrange devised an ingenious technique about 1797 which, since then, became known as the method of Lagrange multipliers. However, he gave no explanation beyond the statement that the rules he gave worked.

\section{. 4.2 THE CLASSICAL CALCULUS METHOD FOR A FUNCTION OF MANY VARIABLES}

Most real life problems including kriging problems possess many variables. Furthermore, most of us are less familiar with the technique of 10cating the stationary points when the function contains many variables. Hence, this method is reviewed here prior to the discussion of the Lagrange multiplier method.

Suppose a function 'F with 'many variables can he expressed as in Equation 4.3:

$$
F=f\left(x_{1}, x_{2}, x_{3}, \ldots, x_{n}\right)
$$


Theorem 1: The necessary condition that this function has a stationary point at the point $x^{0}=\left(x_{1}^{0}, x_{2}^{0}, x_{3}^{0}, \ldots, x_{n}^{0}\right)$ is as follows:

$$
f_{i}\left(x_{1}^{0}, x_{2}^{0}, x_{3}^{0}, \ldots, x_{n}^{0}\right)=0 \text { for } i=1,2, \ldots, n
$$

where $f_{i}\left(x_{1}^{0}, x_{2}^{0}, x_{3}^{0}, \ldots, x_{n}^{0}\right)$ is the partial derivative function of $F$ with respect $x_{i}$ evaluated at the point $x^{0}$.

It should be noted that Equation 4.4 above consists of a set of $n$ simultaneous equations having $n$-variables. Therefore, this set of simultaneous equations must be solved in order to locate the point $x^{0}=\left(x_{1}^{0}, x_{2}^{0}\right.$, $\ldots, x_{n}^{0}$, where the solution to this set of simultaneous equations provides values for $x_{1}^{0}, x_{2}^{0}, \ldots, x_{n}^{0}$.

Locating the stationary point $\mathrm{X}^{0}$, however, is not sufficient to know whether that point is the maximum (or the minimum) of the function $F$ in Equation 4..3. For this purpose, the sufficient condition as given in Theorem 2 below must be satisfied by that point $x^{0}$.

Theorem 2: The sufficient condition that a function $\mathrm{F}$ is strictly maximum at the point $X^{0}=\left(x_{1}^{0}, x_{2}^{0}, x_{3}^{0}, \ldots, x_{n}^{0}\right)$ is to satisfy the following conditions: 6

$$
\begin{aligned}
& f_{11}\left(X^{0}\right)<0 \\
& \left|\begin{array}{lll}
f_{11}\left(X^{0}\right) & f_{12}\left(X^{0}\right) \\
f_{21}\left(X^{0}\right) & f_{22}\left(X^{0}\right)
\end{array}\right|>0 \\
& \left|\begin{array}{lll}
f_{11}\left(X^{0}\right) & f_{12}\left(X^{0}\right) & f_{13}\left(X^{0}\right) \\
f_{21}\left(X^{0}\right) & f_{22}\left(X^{0}\right) & f_{23}\left(X^{0}\right) \\
f_{31}\left(X^{0}\right) & f_{32}\left(X^{0}\right) & f_{3.3}\left(X^{0}\right)
\end{array}\right|<0 \\
& \text { etc. } \\
& -29-
\end{aligned}
$$


In Equation 4.5 above, $f_{i j}\left(x^{0}\right)$ is second-order partial derivative evaluated at that point.

If the indicated determinants in Equation 4.5 alternate in sign as shown, then the function $F$ is strictly maximum at that point. If the indicated determinants are all positive, it is strictly minimum. The word "strict" implies that there exists no doubt regarding the point $\mathrm{X}^{0}$. However, if the indicated determinants are all zeros or if they fail to satisfy the condition strictly, then there exists doubt, i.e., the sufficiency test is inconclusive.

Because of the rather involved nature, the testing of sufficient condition is frequently by-passed in favor of some empirical procedure such as viewing the nature of this function $F$. Such is the case with kriging.

\subsection{CONSTRAINED OPTIMIZATION PROBLEMS AND THEIR SOLUTION METHODS}

Most real life problems fall under the category of r.nnctrained optimi zation problems because a problem without any constraint is really not a problem. There are several solution methods for the constrained optimization prublem. Some of these are:
1) The substitution method.
2) The method of Lagrange multiplier.
3) Mathematical programming.

The subject matter of mathematical programuing is too,broad to be discussed in this report. Therefore, the substitution method is first illustrated here using an example problem, followed by the Lagrange multiplier mothod. 
Illustrative Example Problem:

A lot has the form of a right triangle with the two legs equal to $60 \mathrm{ft}$. and $100 \mathrm{ft}$., respectively. A rectangular building is to be erected on the lot. Determine its dimensions for maximum floor area.

Solution:

This problem is obviously a constrained optimization problem in which we want to maximize the floor space of the building subject to the geometry constraints of the lot as well as the building. 'Ihe size of lot and the proposed rectangular building are shown in Figure 4.1 below.

If one defines the dimensions of this building along $x$ direction to be $x_{1}$ and along $y$ direction to be $x_{2}$, the geometry constraint of the problem can be specified using the relationship of two similar triangles $\triangle A B C$ and $\triangle D E C$ in Figure 4.1. That is:

$$
\begin{gathered}
\frac{100}{60}=\frac{x_{2}}{60-x_{1}} \\
\left(60-x_{1}\right) 100=60 x_{2} \\
5 x_{1}+3 x_{2}-300=0
\end{gathered}
$$

Consequently, the constrained optimization problem can now be stated formally as follows:

$$
\begin{array}{ll}
\text { Maximize } \quad & F=x_{1} x_{2} \\
\text { subject to } & 5 x_{1}+3 x_{2}-300=0
\end{array}
$$




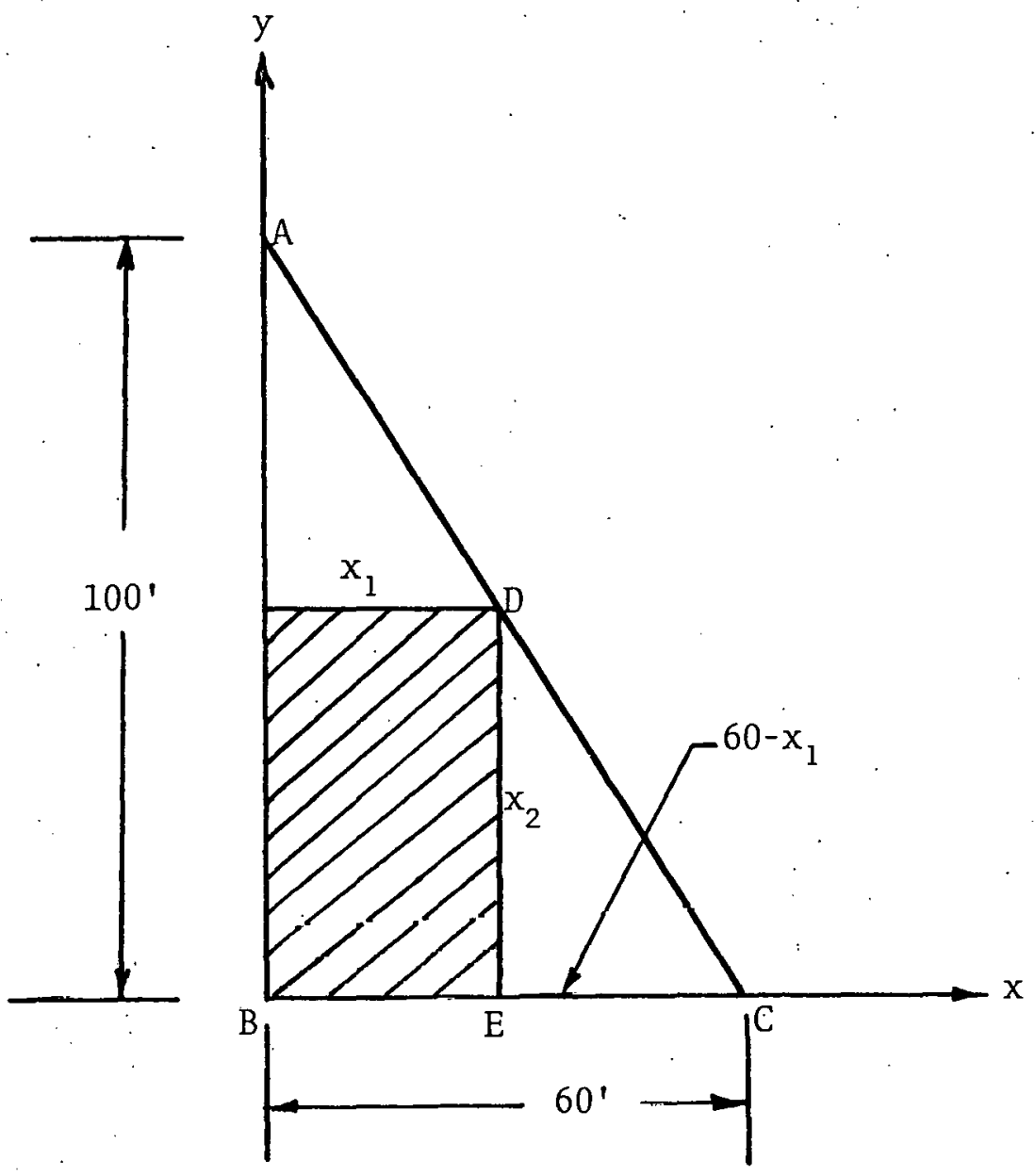

Figure 4:1 
Initial Attempt: (Classical Calculus Method of Section 4.2 Ignoring Constraint)

This problem contains two variables, $x_{1}$ and $x_{2}$, and one equality constraint. Attempting to locate the stationary point of the objective function, i.e., $F=x_{1} x_{2}$, by performing the partial differentiation of the function $F$ with respect to each variable while ignoring the constraint equation provides the following answer:

$$
\begin{aligned}
x_{1} & =0 \\
\dot{x}_{2} & =0 \\
\text { Area } & =0
\end{aligned}
$$

Although the stationary point of the above function $F$ is readily found, it is not the answer to the problem. The sufficiency condition testing using Equation 4.5 also provides an inconclusive answer because the secondorder partial derivatives are both zero which results in the determinant being zero. Thus, this is, a good example in which the direct application of the classical calculus method fails to provide the answer.

\section{The Substitution Method}

In this method, the constraint equation of Equation 4.7 is incorporated into the objective function through direct substitution of one variable in terms of the other variable, using the constraint equation. Afterwards, the previous attempt is repeated to locate the stationary point of the revised objective function, and subsequently the optimum solution to the problem.

$$
\begin{aligned}
& \text { From Equation 4.7, one has } 5 x_{1}+3 x_{2}-300=0 \\
& \text { or } x_{2}=\frac{5}{3}\left(60-x_{1}\right)
\end{aligned}
$$


The revised objective function is:

$$
\begin{gathered}
F=\frac{5}{3}\left(60-x_{1}\right) x_{1}=100 x_{1}-\frac{5}{3} x_{1}^{2} \\
f_{1}=\frac{d F}{d x_{1}}=100-\frac{10}{3} x_{1} \\
f_{11}=\frac{d^{2} F}{d x_{1}^{2}}=-\frac{10}{3}
\end{gathered}
$$

By setting $f_{1}=0$, we obtain the desired stationary point $x^{0}=(30,50)$, i.e., $x_{1} \doteq 30 \mathrm{ft}$. and $x_{2}=50 \mathrm{ft}$. The floor area is consequently $1500 \mathrm{sq}$. ft. which is the maximum attainable. The fact that the answer $\mathrm{X}^{0}$ is the maximum point of the revised objective function can be easily demonstrated through the sufficiency condition given earlier, i.e., $f_{11}$ is negative.

\subsection{THE METHOD OF LAGRANGE MULTIPLIER}

This procedure will now be explained using the above example problem. Although the substitution method can be used for a simple constrained optimization problem such as the example problem, it is not always possible to make the required substitution particularly when the constraint equations have product terms, i.e., the variables are not separable. Fortunately, the method of Lagrange multiplier does not possess this drawback. Even when the substitution is passible, the Lagrange multiplier method is frequently chosen for the additional information that is obtained. 


\section{Procedure:}

First, the optimization problem of Equation 4.7 is repeated below:

$$
\begin{array}{ll}
\text { Maximize } & F=x_{1} x_{2} \\
\text { subject to } & 5 x_{1}+3 x_{2}=300
\end{array}
$$

or

$$
\begin{array}{ll}
\text { Maximize } & f\left(x_{1}, x_{2}\right) \\
\text { subject to } & g\left(x_{1}, x_{2}\right)=b
\end{array}
$$

The procedure begins by converting the above constrained optimization problem into an unconstrained optimization of a new function called Lagrangean function. To do this, the following steps must be performed.

i) Convert ail constraint equations into equality constraints of the form given above.

ii) Multiply each equality constraint by a new variable $\lambda_{i}$, where $\lambda_{j}$ is the Lagrange's undetermined multiplier for the $i_{i-t h}$ cơnstraint.

iii) Simply add (or subtract) the resulting constraint equations to the original objective function $f$ to obtain the Lagrangean function.

In the example problem, we can start from step ii). Since there is only one constraint equation; we need only one $\lambda$. Consequently, the obtained Lagrangean function has three variables, $x_{1}, x_{2}$, and $\lambda$.

$$
\begin{aligned}
L\left(x_{1}, x_{2}, \lambda\right) & =f\left(x_{1}, x_{2}\right)-\lambda\left[g\left(x_{1}, x_{2}\right)-b\right] \\
\therefore & =x_{1} x_{2}-\lambda\left(5 x_{1}+3 x_{2}-300\right)
\end{aligned}
$$

Equation 4.11 can now be treated as an unconstrained optimization problem. Thus, the method of Section 4.2 can be applied directly to obtain 
the solution. Differentiating the Lagrangean function with respect to each variable and setting the resulting equations to zero, the stationary point is obtained after solving Equation 4.12.

$$
\begin{aligned}
& \frac{\partial L}{\partial x_{1}}=x_{2}-5 \lambda=0 \\
& \frac{\partial L}{\partial x_{2}}=x_{1}-3 \lambda=0 \\
& \frac{\partial L}{\partial \lambda}=-\left(5 x_{1}+3 x_{2}-300\right)=0
\end{aligned}
$$

Equation 4.12 is a set of simultaneous equations having three variables and three equations. Also, note that the original constraint reappears and becomes part of the set of equations. Solving Equation 4.12, one obtains the following answer.

$$
\begin{aligned}
x_{1} & =30 \mathrm{ft} . \\
x_{2} & =50 \mathrm{ft} . \\
\lambda & =10 \\
\text { Area } & =1500 \mathrm{sq} . \mathrm{ft} .
\end{aligned}
$$

Testing the sufficiency condition for this situation gives an inconclusive answer due to the vanishing of all second-order partial derivatives. However, one can conclude that the obtained solution is the maximum point of the function $f$, simply from the nature of the function which can only increase in value (See Figure 4.2) 


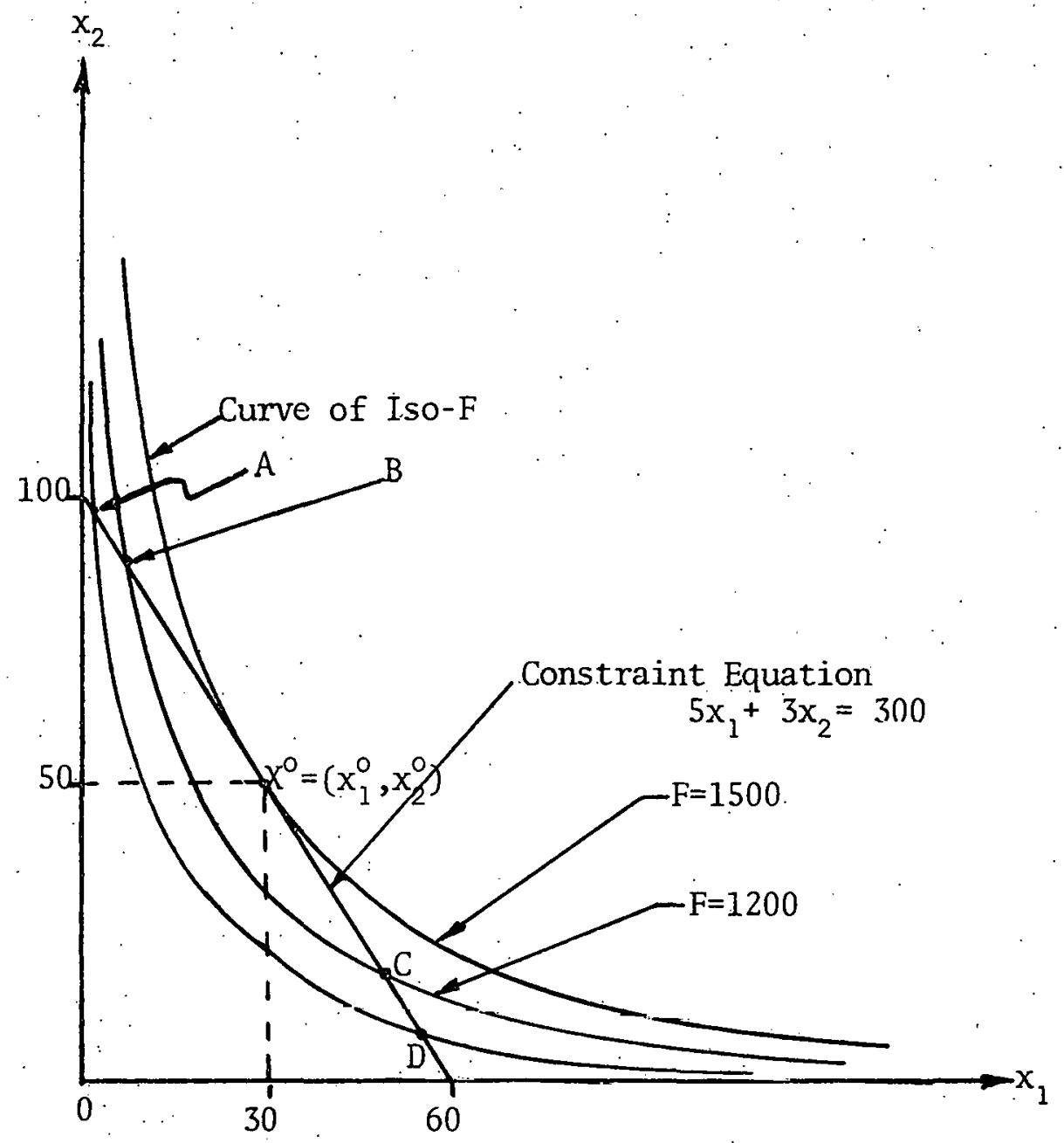

Figure 4.2

LOMATTON OF THE OPTIMAL SOLUTION

$$
-37-
$$


Justification and Significance of the Lagrange Multiplier:

The development and an interpretation of the Lagrange multiplier method can be made by utilizing Iiigure 4.2. It shows the ranges of $x_{1}$ and $x_{2}$, the constraint equation of $5 x_{1}+3 x_{2}=300$, and some iso- $F$ curves. An iso-F curve is equivalent to a contour line having the same objective function value.

As one searches for the $x_{1}$ and $x_{2}$ values that maximize $F=f\left(x_{1}, x_{2}\right)$, the constraint equation restricts us to the set of points defined by $g\left(x_{1}, x_{2}\right)=b$. In other words, as we move from one point of this set to another point, the value of $\mathrm{g}$ is not permitted to change. Or, one must search the maximizing point only along the constraint equation.

From Figure 4.2, one notes that the desired solution is at point $X^{0}$ which lies along the constraint equation $\left(5 x_{1}+3 x_{2}=500\right)$ and which touches one of the iso-F curves. Other points such as A, B, C, D, all of which also lie on the constraint equation, can not be the maximum point because these puints intersect inferior iso-F curves. Thus, the Lagrange multiplier methud expresses the condition that the best iso-F curve attainable is the one which is just tangent to the constraint curve.

In a more general situation in which the constraint equation is not linear, the condition for the maximizing point is that the tangent gradient of the constraint equation $g$ must be equal to that of the objective function F. In other words, we need only to look at those points where two tangent gradients are equal. This fact naturally eliminates much of needless searching along the points of $g\left(x_{1}, x_{2}\right)=b$, such as points $A, B, C$, and $\mathrm{D}$ in Figure 4.2 . 
The above requirement can be expressed mathematically as

$$
\frac{\partial F / \partial x_{1}}{\partial F / \partial x_{2}}=\frac{\partial g / \partial x_{1}}{\partial g / \partial x_{2}}
$$

or

$$
\frac{\partial F / \partial x_{1}}{\partial g / \partial x_{1}}=\frac{\partial F / \partial x_{2}}{\partial g / \partial x_{2}}=-\lambda
$$

The proportionality factor expressed as $-\lambda$ in Equation 4.13 is the Lagrange multiplier. It can also be shown that $-\lambda$ has a special significance in economics. That is, it gives the "shadow price" of the constraint, i.e., $\partial \mathrm{F} / \partial \mathrm{b}$. For example, $\lambda=10$ in the above example problem indicates that one can increase the floor space by $10 \mathrm{sq.} \mathrm{ft.,} \mathrm{if} \mathrm{the} \mathrm{constraint} \mathrm{value} \mathrm{of}$ $b=300$ is relaxed by one unit, i.e., $b=301$.

In case of a function of more than two variables and (for simplicity) one conslraint equation, the partial derivatives of $f$ and $g$ with respect to each variable must be proportional at the maximizing point $\left(x_{1}^{0}, x_{2}^{0}, x_{3}^{0}\right.$, $\left.\cdots, x_{n}^{0}\right)$.

$$
\frac{\partial F / \partial x_{1}}{\partial g / \partial x_{1}}=\frac{\partial F / \partial x_{2}}{\partial g / \partial x_{2}}=\ldots=\frac{\partial F / \partial x_{n}}{\partial g / \partial x_{n}}=-\lambda
$$

Finally, the generalized Lagrangean function involving $\mathrm{n}$ variables and $m$ constraints are:

$$
\begin{gathered}
L\left(x_{1}, x_{2}, \ldots, x_{n} ; \lambda_{1}, \lambda_{2}, \ldots, \lambda_{m}\right)=f\left(x_{1}, x_{2}, \ldots, x_{n}\right) \\
+\sum_{i=1}^{m} \lambda_{i} g_{i}\left(x_{1}, x_{2}, \ldots, x_{11}\right)
\end{gathered}
$$


Then the necessary condition is comprised of a system of $(n+m)$ equations that can (at least in principle) be solved for the $(n+m)$ unknowns. The practical aspects of solving such a system of simultaneous equations is discussed in the following chapter on kriging. 
In order to comprehend the theoretical basis of the kriging procedure, one must be familiar with the following concepts from Matheron's geostatistics (or geostatistics in short).

1. The variogram function (or variogram).

2. Variance of point samples o within any size volume $v$, given as $\sigma^{2}(\mathrm{o} / \mathrm{v})$

3. Block variance in a deposit, given as $\sigma_{(\mathrm{v} / \mathrm{D})}^{2}$.

4. Krige's Relationship.

5. Extension (or Estimation) variance, given as $\sigma_{E}^{2}$.

In addition, one must be familiar with the method of Lagrange multiplier. Since a detailed exposition on all of the above concepts is clearly beyond the scope of this report, only a brief review will be given here. The reader is referred to other sourses of references. ${ }^{1}, 2,3,4$

\subsection{VARIANCE OF POINT SAMPLES WITHIN ANY SIZE VOLUME V.}

Bypassing a review on the variogram function, the variance of point samples o within any size volume can be defined as:

$$
\sigma_{(n / v)}^{2}=\frac{1}{v^{2}} \cdot \int_{v} d x \int_{v} \gamma(x-y) \cdot d y
$$

In Equation 5.1 above, the variables $x$ and $y$ are two dummy variables used for integration of the variogram function values over the volume of interest. Strictly speaking, the equation corresponds to sextuple integrals, 
if $v$ is a volume in a 3 -dimensional space. On the other hand, it reduces to quadruple integrals when $v$ is reduced to an area.

As an illustration, suppose $v$ i.s a square area of $10^{\prime}$ by $10^{\prime}$. liurther, suppose the point $(0,0)$ is the south-west corner of the area as shown in Figure 5.1a. Then, for a given variogram function, the variance of point samples (such as DDH assays) within this $10^{\prime} \times 10^{\prime}$ area can be obtained by performing the following integration.

$$
\sigma_{(0 / v)}^{2}=\frac{1}{(10 \times 10)^{2}} \int_{0}^{10} \int_{0}^{10} d x d y \int_{0}^{10} \int_{0}^{10} \gamma\left(\sqrt{x^{2}+y^{2}}\right) d x \cdot d y
$$

Evaluation of the above integral is both time consuming as well as difficult. Therefore, a numerical approximation is used to obtain the answer. Specifically, some discrete number of points are located in the area $\mathrm{v}$ as shown in Figure 5.1b.

Next, the distances between the first point and the remaining points are computed, thus obtaining eight distinct distances in Figure 5.1b. Afterwards, variogram values corresponding to these distances are obtained from the given variogram function and these values are summed up.

The above steps are repeated for each and every point in the block, i.e., 9 holes in Figure 5.1b. Finally, the cumulated variogram value is divided by the total number of points in the block. The resulting value, therefore, represents the average value of the variogram in the block. In other words, Equation 5.1 can be viewed as the average value of the variogram within a given size volume $v$. 


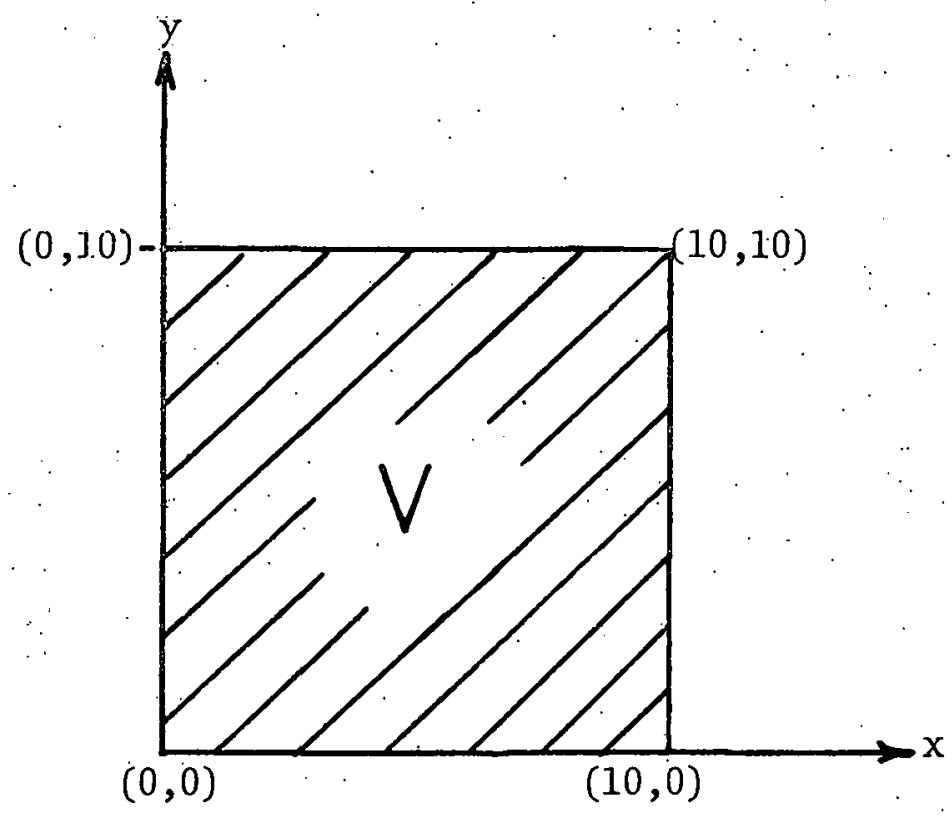

Figure $5.1 \mathrm{a}$

SAMPLE AREA OF INTEGRATION

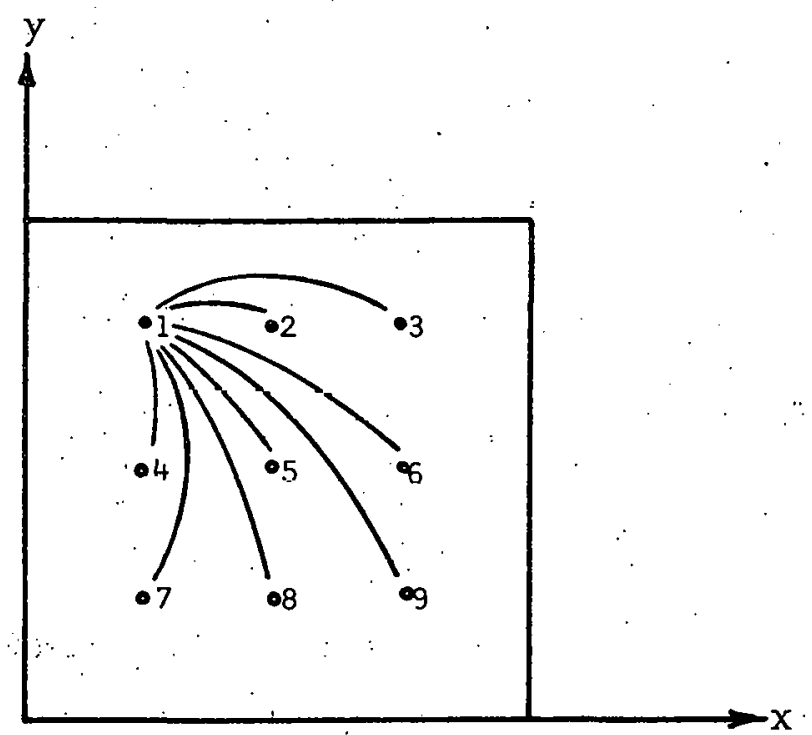

Figure 5.1b

NINE (9) POINT NUMERICAL APPROXIMATION FOR INTEGRATION 
If this volume $\mathrm{v}$ is enlarged to coincide with the deposit under consideration, the variance of point samples in a deposit can be given as Equation 5.3 below and simply represents the sample variance.

$$
\begin{aligned}
\sigma_{(O / D)}^{2} & =\frac{1}{D^{2}} \int_{D} d x \int_{D} \gamma(x-y) d y \\
& =\text { Sample variance in the deposit } \\
& =\text { Sill value (in a spherical variogram model) }
\end{aligned}
$$

Consequently, one can also view the sample variance in the deposit as being equivalent to the average value of the variogram function in the deposit (D) .

\subsection{BLOCK VARIANCE IN A DEPOSIT}

Using a similar notation given in the previous section, the block variance in a deposit can be written as $\sigma_{(v / D)}^{2}$, . If nne divides the entire deposit into blocks of a given size $v$, then the block variance is the variance of these block grades. For computational purposes, it can be computed using Krige's relationship as follows:

$$
\sigma_{(\mathrm{V} / \mathrm{D})}^{2}=\sigma_{(\mathrm{O} / \mathrm{D})}^{2}-\sigma_{(\mathrm{O} / \mathrm{V})}^{2}
$$

Equation 5.4 states that the block variance is simply the difference between the "average value" of the variogram in the deposit minus the "average value" of the variogram in a given size block. Since the first term on the right hand side of Equation 5.4 is also the sample variance in the deposit 
(or the sill value) and since the second term can be easily computed for a given variogram function, the desired block variance can also be computed readily.

\subsection{EXTENSION (OR ESTIMATION) VARIANCE $\left({ }^{\sigma}{ }^{2}\right)$.}

Extension variance refers to the variance (or error) one incurs when the grade of a known volume $v$ is extended to infer the grade of another volume $V$. If a small known volume $v$ is a DDH sample and a larger volume $V$ is a block in a mine, then the extension variance $\sigma_{\mathrm{E}}^{2}$ can be defined as:

$$
\begin{aligned}
\sigma_{E}^{2} & =\sigma_{(\mathrm{V} / \mathrm{D})}^{2}-2{ }^{2}(\mathrm{~V}, \mathrm{~V} / \mathrm{D})+\sigma^{2}(\mathrm{~V} / \mathrm{D}) \\
& =\sigma_{(\mathrm{O} / \mathrm{D})}^{2}-2{ }_{(\mathrm{o}, \mathrm{V} / \mathrm{D})}+\sigma^{2}(\mathrm{~V} / \mathrm{D})
\end{aligned}
$$

Equation 5,5 says that the extension variance is equal to the variance of the sariple minus twice the covariance between the sample and the block plus the variance of the block. It was shown in the preceding section that the sample variance and the block variance can be readily computed. Similarly, the covariance between the sample and the block can be computed using the numerical approximation technique shown in Figure 5.1b. Consequently, the desired extension error can be computed for a given size block and a given variogram function.

In estimating the block grade, it is conceivable that more than one DDH samples are used to improve estimation. If a number of sample grades are extended to a block, the error one incurs is called "Estimation Variance" instead of "Extension Variance." When a number of sample grades are used 
to estimate the block grade, one obvious way for estimation is to use the average grade of all $\mathrm{N}$ samples. If such mode of estimation is used, the estimation variance $\left(\sigma_{\mathrm{E}}^{2}\right)$ can be given by the following equation:

$\sigma_{E}^{2}=\frac{2}{N v} \sum_{i=1}^{N} \int_{v} \gamma\left(x-x_{i}\right) d x-\frac{1}{v^{2}} \int_{v} d x \int_{v} \gamma(x-y) d y-\frac{1}{N^{2}} \sum_{i=1}^{N} \sum_{j=1}^{N} \gamma\left(x_{i}-x_{j}\right)$

Equation 5.6 is similar to Equation 5.5 with one exception. That is, a sample grade is replaced by the average grade of $\mathrm{N}$ samples. Consequently, the estimation variance is now equal to twice the "average value" of the variogram between samples and the block minus the variance of a point within the block minus the "average value" of the variogram between the samples. Using the average value of $\mathrm{N}$ samples is equivalent to assigning an equal weight to each sample grade, where this equal weight is given as $1 / \mathrm{N}$. However, one can conceivably assign different weights to different holes for obvious reasons. For instance, holes closer to the block can be given greater weights (or influence) than those that are farther away. Kriging is the procedure which attempts to do just this.

If different weights $\lambda_{i}$ 's (where $\lambda_{i}$ is the weight to be assigned to the $i$-th hole) are to be used instead of the equal weight of $1 / N$, then Equation 5.6 can be rewritten as follows to obtain the desired "Estimation Variance," or more appropriately the "Kriging Variance."

$$
\sigma_{K}^{2}=\sigma_{E}^{2}=\sigma_{v}^{2}-2 \sum_{i=1}^{N} \lambda_{i} \sigma_{v x_{i}}+\sum_{i=1}^{N} \sum_{j=1}^{N} \lambda_{i} \lambda_{j} \sigma_{x_{i}} x_{j}
$$


Equation 5.7 can be obtained directly from Equation 5.6 by substituting $\lambda_{i}$ for $1 / \mathrm{N}$ and then by expressing the resulting equation in terms of the covariogram instead of the variogram function. The above equation says that the "Kriging variance" is equal to the block variance minus twice the weighted covariance function values between the samples and the block plus the weighted covariance function values between samples.

Since there exists a direct relationship between the variogram and the covariogram functions, the kriging variance as given by Equation 5.7 can be readily computed for a given variogram function and for a given set of weights, i.e., $\lambda_{1}, \lambda_{2}, \ldots, \dot{\lambda}_{n} \cdot *$

\subsection{EXPLANATION OF KRIGING PROCEDURE}

In estimating block grades by kriging, one is interested in minimizing the estimation variance $\sigma_{\mathrm{E}}^{2}$ which is synonymous with the kriging variance $\sigma_{\mathrm{K}}^{2}$. This task of minimization is accunplished through a proper choice of the weights, i.e., $\lambda_{i}$ 's in Equation 5.7, with one constraint. The constraint is that the sum of the weights must be equal to 1 , as any weighting scheme should be. In other words, the weighting process of kriging is equivalent to solving a constrained optimization problem, where the objective function is given by Equation 5.7 and the one constraint as given below:

$$
\begin{array}{ll}
\text { Minimize } & \sigma_{K}^{2}=F\left(\lambda_{1}, \lambda_{2}, \lambda_{3}, \ldots, \lambda_{n}\right) \\
\text { subject to } & \sum_{i=1}^{N} \lambda_{i}=1
\end{array}
$$

\footnotetext{
* Note that the character $\lambda$ is used for the weights in this section, even though the same character is used to represent the Lagrange multipliers in Chapter 4.
} 
This constrained optimization problem can be readily solved by the method of Lagrange multiplier.

Forming the Lagrangean function $L\left(\lambda_{i}{ }^{\prime} s, u\right)$, one obtains Equation 5.9 below:

$\dot{L}\left(\lambda_{1}, \lambda_{2}, \ldots, \lambda_{n}, u\right)=\sigma_{v}^{2}-2 \sum_{i=1}^{N} \lambda_{i} \sigma_{v x_{i}}+\sum_{i=1}^{N} \sum_{j=1}^{N} \lambda_{i} \lambda_{j} \sigma_{i} x_{i} x_{j}-2 u\left(\sum_{i=1}^{N} \lambda_{i}-1\right)$

In the above equation, it should be noted that " $2 \mathrm{u}$ " instead of " $\mathrm{u}$ " was used for the Lagrange multiplier, and that Equation 5.9 is a quadratic equation having $N+1$ variables, i.e., $\lambda_{1}, \ldots, \dot{\lambda}_{N}$, plus one additional variable " $u$ ", i.e., the Lagrange multiplier. Using the classical calculus approach to determine the stationary point of Equation 5.9, we differentiate with respect to $\lambda_{i}{ }^{\prime} s$ and $u$ and obtain a set of simultaneous equations having $N+1$ equations.

For the convenience of notation and understanding, $v$ is replaced by 0 and $X$ 's are dropped keeping only the subscripts in Equation 5.9. The resulting equation is given by Equation 5.10 below:

$$
\begin{aligned}
L\left(\lambda^{\prime} s, u\right) & =\sigma_{v}^{2}-2 \sum_{i=1}^{N} \lambda_{i} \sigma_{v x}+\sum_{i=1}^{N} \sum_{j=1}^{N} \lambda_{i} \lambda_{j}{ }^{\sigma} x_{i} x_{j}-2 u\left(\sum_{i=1}^{N} \lambda_{i}-1\right)=0 \\
& =\sigma_{0}^{2}-2 \sum_{i=1}^{N} \lambda_{i} \sigma_{o i}+\sum_{i=1}^{N} \sum_{j=1}^{N} \lambda_{i} \lambda_{j} \sigma_{i j}-2 u\left(\sum_{i=1}^{N} \lambda_{i}-1\right)=0
\end{aligned}
$$


Expanding Equation 5.10 gives the following:

$$
\begin{aligned}
& L\left(\lambda^{\prime} s, u\right)=\sigma_{0}^{2}-2 \lambda_{1} \sigma_{01}-2 \lambda_{2} \sigma_{02}-2 \lambda_{3} \sigma_{03}-\ldots-2 \lambda_{N} \sigma_{0 N} \\
& +\lambda_{1}^{2} \sigma_{11}+\lambda_{2}^{2} \sigma_{22}+\lambda_{3}^{2} \sigma_{33}+\cdots+\lambda_{\mathrm{N}}^{2} \sigma_{\mathrm{NN}} \\
& +2 \lambda_{1} \lambda_{2} \sigma_{12}+2 \lambda_{1} \lambda_{3} \sigma_{13}+2 \lambda_{1} \lambda_{4} \sigma_{14}+\cdots+2 \lambda_{1} \lambda_{N} \sigma_{1 N} \\
& +2 \lambda_{2} \lambda_{3} \sigma_{23}+2 \lambda_{2} \lambda_{4} \sigma_{24}+\cdots+2 \lambda_{2} \lambda_{N}{ }^{\sigma}{ }_{2 N} \\
& +2 \lambda_{3} \lambda_{4} \sigma_{34}+\therefore+2 \lambda_{3} \lambda_{N} \sigma_{3 N} \\
& +2 \lambda_{4} \lambda_{N}{ }^{\sigma} 4 \mathrm{~N} \\
& +2 \lambda_{\mathrm{N}-1} \lambda_{\mathrm{N}} \mathrm{N}_{\mathrm{N}-1, \mathrm{~N}} \\
& -2 \mathrm{u}\left(\lambda_{1}+\lambda_{2}+\lambda_{3}-\ldots+\lambda_{N}-1\right)
\end{aligned}
$$

Next, partial differentiation of Equation 5.11 is performed for each variable and the resulting quantity is set equal to zero to obtain the stationary point. For example:

$$
\frac{\partial L}{\partial \lambda_{1}}=-2 \sigma_{01}+2 \lambda_{1} \sigma_{11}+2 \lambda_{2} \sigma_{12}+2 \lambda_{3} \sigma_{13}+\ldots+2 \lambda_{N} \sigma_{1 N}-2 u=0
$$

or

$$
=-\sigma_{01}+\lambda_{1} \sigma_{11} \quad+\sum_{j=2}^{N} \lambda_{j} \sigma_{1 j}-u=0
$$

or

$$
\sum_{j=1}^{N} \lambda_{j} \sigma_{1 j}-u=\sigma_{01}
$$


Similarly,

$\frac{\partial L}{\partial \lambda_{2}}=-2 \sigma_{02}+2 \lambda_{2} \sigma_{22}+2 \lambda_{1} \sigma_{12}+2 \lambda_{3} \sigma_{23}+2 \lambda_{4} \sigma_{24}+\ldots+2 \lambda_{N} \sigma_{2 N}-2 u=0$

or

$$
\sum_{j=1}^{N} \lambda_{j} \sigma_{2 j}-u=\sigma_{02}
$$

$\frac{\partial L}{\partial \lambda_{3}}=-2 \sigma_{03}+2 \lambda_{3} \sigma_{33}+2 \lambda_{3} \sigma_{13}+2 \lambda_{2} \sigma_{23}+2 \lambda_{4} \sigma_{34}+2 \lambda_{N} \sigma_{3 N}-2 u=0$

or

$$
\sum_{j=1}^{N} \lambda_{j} \sigma_{3 j}-u=\sigma_{03}
$$

The general form of Equations 5.12, 5.13, and 5.14 can be given in Equation 5.15

$$
\frac{\partial L}{\partial X_{i}}=0 \Longrightarrow \sum_{j=1}^{N} \lambda_{j} \sigma_{i j}-u=\sigma_{o i}
$$

Finally, differentiating Equation 5.11 with respect to $u$, we obtain the original constraint equation.

$$
\sum_{j=1}^{N} \lambda_{j}=1
$$


The resulting set of $\mathrm{N}+1$ simultaneous equations are:

$$
\begin{aligned}
\sum_{j=1}^{N} \lambda_{j} \sigma_{i j}-u & =\sigma_{0 i} \quad \text { For } i=1, \ldots, N . \\
& \sum_{i=1}^{N} \lambda_{i}=1
\end{aligned}
$$

In matrix notation, Equation 5.17 can be expressed as $\mathrm{AX}=\mathrm{B}$ where $\mathrm{A}, \mathrm{X}$, and $B$ are as given below:

$$
A=\left[\begin{array}{ccccc}
\sigma_{11} & \sigma_{12} & \cdots & \sigma_{1 n}-1 \\
\sigma_{21} & \sigma_{22} & \cdots & \sigma_{2 n}-1 \\
\vdots & & & \vdots \\
\vdots & & & \vdots \\
\sigma_{n 1} & \sigma_{n 2} & \cdots & \sigma_{n n}-1 \\
1 & 1 & \cdots & 1 & 0
\end{array}\right] \quad x=\left[\begin{array}{c}
\lambda_{1} \\
\vdots \\
\lambda_{2} \\
\vdots \\
\lambda_{n} \\
u
\end{array}\right] \quad B=\left[\begin{array}{c}
\sigma_{01} \\
\sigma_{02} \\
\vdots \\
\vdots \\
\sigma_{0 n} \\
1
\end{array}\right]
$$

The desired solution is obtained by pre-multiplying the Equation 5.18 by $A^{-1}$, or $X:=A^{-1} B$. Having obtained the solution which provides the optimal weights $\lambda_{i}$ 's and the Lagrange multiplier $u$, the kriging variance $\sigma_{K}^{2}$ for the block can be computed from Equation 5.7 which was given earlier and is also repeated below.

$$
\begin{aligned}
\sigma_{\mathrm{K}}^{2} & =\sigma_{\mathrm{V}}^{2}-2 \sum_{i=1}^{N} \lambda_{i} \sigma_{V x_{i}}+\sum_{i=1}^{N} \sum_{j=1}^{N} \lambda_{i} \lambda_{j} \sigma x_{i} x_{j} \\
& =\sigma_{0}^{2}-2 \sum_{i=1}^{N} \lambda_{i} \sigma_{o i}+\sum_{i=1}^{N} \sum_{j=1}^{N} \lambda_{i} \lambda_{j} \sigma_{i j}
\end{aligned}
$$

( $\Lambda$ fter replacing $v$ by 0 and dropping $X ' s$ from Equation 5.7 ) 
In practice, however, the above equation is somewhat modified in order to utilize the already computed value, i.e., u. The desired modification is accomplished as follows:

Consider Equation 5.17 which resulted when the Lagrangean function was differentiated with respect to each variảble.

$$
\sum_{j=1}^{N} \lambda_{j} \sigma_{i j}-u=\sigma_{o i} \quad \text { For } i=1,2, \ldots, N
$$

If we multiply $\lambda_{i}$ to both sides of the $i$-th equation and sum up the resulting quantities, we obtain Equation 5.19 below:

$$
\sum_{j=1}^{N} \sum_{i=1}^{N} \lambda_{j} \lambda_{i} \sigma_{i j}-u \cdot \sum_{i=1}^{N} \lambda_{i}=\sum_{i=1}^{N} \sigma_{o i} \lambda_{i}
$$

However, the original constraint requires that $\sum_{i=1}^{N} \lambda_{i}=1$. Therefore, one obtains the following from Equation 5.19:

$$
\sum_{j=1}^{N} \sum_{i=1}^{N} \lambda_{j} \lambda_{i} \sigma_{i j}=\sum_{i=1}^{N} \sigma_{o i} \lambda_{i}+u
$$

Substituting Equation 5.20 into Equation 5.7, one obtains Equation 5.21 which is the one actually utilized in kriging variance determination.

$$
\begin{aligned}
\sigma_{K}^{2} & =\sigma_{0}^{2}-2 \sum_{i=1}^{N} \lambda_{i} \sigma_{o i}+\sum_{i=1}^{N} \lambda_{i} \sigma_{o i}+u \\
& =\sigma_{0}^{2}-\sum_{i=1}^{N} \lambda_{i} \sigma_{o i}+u
\end{aligned}
$$




\subsection{EXAMPLES OF KRIGING}

Two illustrative example problems, one for point kriging and the other for block kriging, are provided here. The point kriging example demonstrates the fact that kriging in fact minimizes the estimation variance.

\section{Point Kriging Example}

This is an identical example problem given in Reference 1 (Kim and Knudsen) .

Figure 5.2 shows two different sampling grids each with 3 holes. The problem will be to estimate the grade at point $\mathrm{X}_{\mathrm{o}}$ for each grid. Assume that the theoretical variogram model is a transitive variogram described by Equation 5.22.

$$
\begin{array}{ll}
\gamma(h)=0.01 \mathrm{~h} & \text { for } h \leq 400 \mathrm{ft} . \\
\gamma(h)=4.0 & \text { for } h>400 \mathrm{ft} .
\end{array}
$$

The following steps show the calculations for the first grid.

Step 1. Calculate the covariance between each of the sample points. Remember that $K(h):=K(0)-\gamma(h)$.

$$
\begin{aligned}
\sigma_{(1,1)} & =\sigma_{(2,2)}=\sigma_{(3,3)}=K(0)=4.0 \\
\sigma_{(1,2)} & =\sigma_{(2,1)}=\sigma_{(1,3)}=\sigma_{(3,1)}=\mathrm{K}(200)=4.0-.01(200)=2.0 \\
\sigma_{(2,3)} & =\sigma_{(3,2)}=\mathrm{K}(20)=4.0-.01(20)=3.8
\end{aligned}
$$




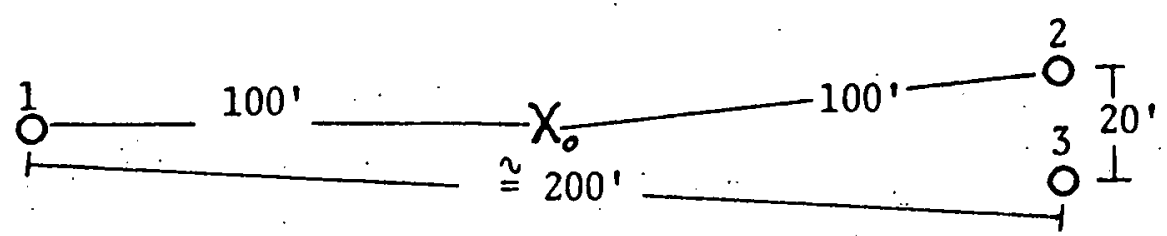

Grid 1

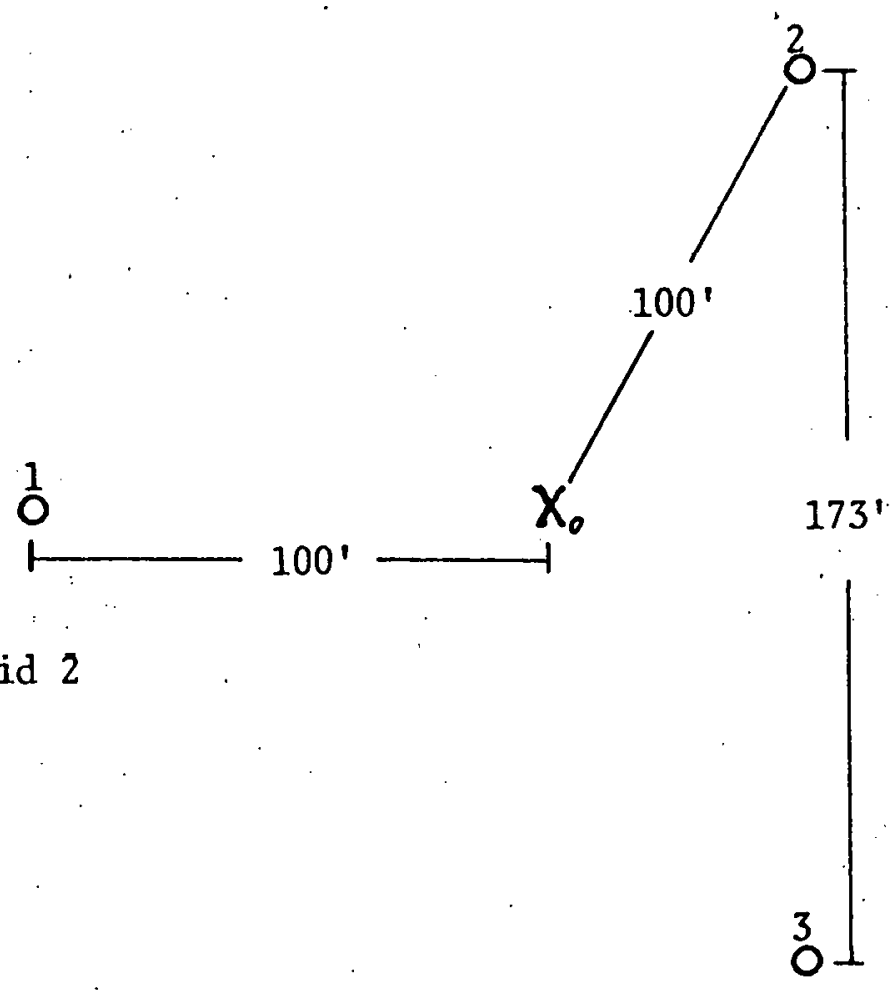

Figure 5.2

HYPOTHETICAL SAMPLING GRIDS TO ILLUSTRATE KRIGING 
Step 2. The covariance between each sample point and the point $X_{0}$ is computed.

$$
\sigma_{\left(1, x_{0}\right)}=\sigma_{\left(2, x_{0}\right)}=\sigma_{\left(3, x_{0}\right)}=K(100)=4.0-01(100)=3
$$

Step 3. The matrices of Equation 5.18 can now be filled in.

$$
\left[\begin{array}{cccc}
4.0 & 2.0 & 2.0 & -1 \\
2.0 & 4.0 & 3.8 & -1 \\
2.0 & 3.8 & 4.0 & -1 \\
1 . & 1 & 1 & 0
\end{array}\right] \cdot\left[\begin{array}{l}
\lambda_{1} \\
\lambda_{2} \\
\lambda_{3} \\
u
\end{array}\right]=\left[\begin{array}{l}
3 \\
3 \\
3 \\
1
\end{array}\right]
$$

Step 4. Solving this system of equations gives the following weights and Lagrange multiplier.

$$
\begin{aligned}
& \lambda_{1}=0.487 \\
& \lambda_{2}=0.256 \\
& \lambda_{3}=0.256 \\
& u=-0.026
\end{aligned}
$$

Step 5. The kriging variance calculated from Equation 5.21 is 0.974 .

$$
\begin{aligned}
\sigma_{\mathrm{K}}^{2} & =\sigma_{\mathrm{o}}^{2}+\mathrm{u}-\sum_{i=1}^{3} \lambda_{i} \sigma_{\mathrm{oi}} \\
& =4.0-.026-0.487(3)+0.256(3)+0.256(3) \\
& =0.974
\end{aligned}
$$


For the second grid Steps 3 through 5 are shown below.

Step 3. The matrices for the second grid are:

$$
\left[\begin{array}{cccc}
4.0 & 2.27 & 2.27 & -1 \\
2.27 & 4.0 & 2.27 & -1 \\
2.27 & 2.27 & 4.0 & -1 \\
1 & 1 & 1 & 0
\end{array}\right] \cdot\left[\begin{array}{l}
\lambda_{1} \\
\lambda_{2} \\
\lambda_{3} \\
u
\end{array}\right]=\left[\begin{array}{l}
3 \\
3 \\
3 \\
1
\end{array}\right]
$$

Step 4. Solving the set of equations gives the following results:

$$
\lambda_{1}=\lambda_{2}=\lambda_{3}=0.333
$$

and

$$
\mathrm{u}=-0.847
$$

Step 5. The kriging variance is 0.13

$$
\sigma_{\mathrm{K}}^{2}=4.0-0.847-3.0=0.13
$$

As can be seen in Step 4 above, each sample has the same weight for the second grid. This solution is obvious in retrospect by just looking at the grid. It also seems reasonable to assume that the kriging variance for the second grid should be less than for the first grid. This fact is borne out in Step 5 .

The above example clearly shows that kriging was able to distinguish between the two sampling grids and to adjust the weights to give minimum kriging variance. The sample points 2 and 3 in the first grid were given the same weight but the weight was less than the weight given to sample 1 . This is the "transfer of influence" phenomena and is due to the points being close together in relation to the other sampling point. 


\section{Block Kriging Example}

A more common estimation problem is to estimate the grade of a block by the nearby drill holes. Figure 5.3 shows a block with 10 surrounding drill holes. For this example, the problem is to estimate the thickness of ore in the block from the 10 surrounding drill holes. The theoretical variogram used for this example is described by Equation 5.23.

$$
\begin{array}{ll}
\gamma(h)=30.0+44\left[1.5\left(\frac{h}{a}\right)-.5\left(\frac{h}{a}\right)^{3}\right] & \text { for } h \leq a \\
\gamma(h)=74.0 & \text { for } h>a
\end{array}
$$

The same sequence of steps is followed as in the previous example.

Step 1. Calculate the covariance between each of the sample points.

$$
\begin{array}{ll}
\sigma(i, i)=K(0)=74 & \text { for } i=1,10 \\
u(1,2)=\sigma(2,1)=K(0)-\gamma\left(61^{\prime}\right)=32.78 \\
\sigma(1,3)=\sigma(3,1)=K(0)-\gamma\left(75^{\prime}\right)=29.93 \\
\text { etc. }
\end{array}
$$

Step 2. The covariance between the sample point and the block is computed. The block is represented by 16 points spread over the block. Figure 5.4 shows sample point 5 and the 16 grid points within the block.

$$
\begin{aligned}
\sigma_{(5 v)} & =K(0)-\frac{1}{16}\left[\gamma\left(p t 5-Y_{i}\right) \quad i=1,16\right. \\
\sigma_{(5 v)} & =K(0)-\frac{1}{16}\left[\gamma\left(p t 5-Y_{1}\right)-\gamma\left(p t-Y_{2}\right)-\ldots\right] \\
& =K(0)-\frac{1}{16}\left[\gamma\left(60^{\prime}\right)-\gamma\left(80^{\prime}\right) \ldots\right] \\
& =74 .-46.31=27.69
\end{aligned}
$$




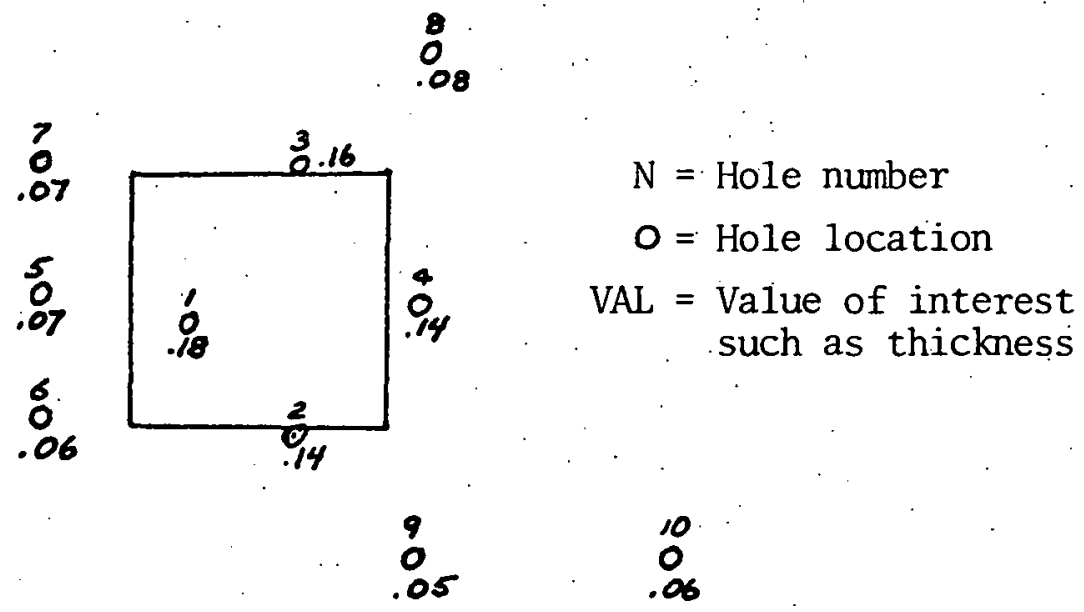

Scale 1 inch to $100 \mathrm{ft}$.

Figure 5.3

BLOCK KRIGING EXAMPLE

$5 \quad\left[\begin{array}{cccc|}1 & ! & 9 & 4 \\ 5 & 6 & 7 & 9 \\ ! & 10 & 11 & 12 \\ 13 & 14 & 15 & 16 \\ \hline\end{array}\right.$

Figure 5.4

SAMPLE POINT 5 AND BLOCK(v)

$-58-$ 
Step 3. The matrices of Equation 5.18 can be filled in as shown in Figure 5.5 .

Step 4. The solution to the system gives the following weights:

$$
\begin{array}{ll}
\lambda_{1}=.18 & \lambda_{6}=.06 \\
\lambda_{2}=.14 & \lambda_{7}=.07 \\
\lambda_{3}=.16 & \lambda_{8}=.08 \\
\lambda_{4}=.14 & \lambda_{9}=.05 \\
\lambda_{5}=.07 & \lambda_{10}=.06 \\
& u=-.779
\end{array}
$$

Step 5. The Kriging variance is 7.20

$$
\begin{aligned}
\sigma_{\mathrm{K}}^{2}= & 36.51+(-.779) \\
- & {[.18(35.77)+.14(32.46)+.16(32.33)+.14(30.45)+.07(27.69)} \\
& +.06(2.5 .41)+.07(25.36)+.08(24.63)+.05(23.76)+.06(21.23)] \\
= & 36.51-.779-30.08=7.20
\end{aligned}
$$

This example illustrates the numerous calculations necessary for kriging. The number of computations for each block is related to the number of drill holes included and the number of grid points used in approximating the block. In the example above only 10 holes were used in the kriging, but of those the nearest. 4 accounted for $63 \%$ of the weight. 


$\dot{.} \quad\left[\begin{array}{rrrrrrrrrrr}74.0 & 32.7 & 29.9 & 26.8 & -33.0 & 30.7 & 28.4 & 24.4 & 26.7 & 20.1 & -1.00 \\ 32.7 & 74.0 & 24.9 & 30.7 & -23.4 & 25.4 & 18.3 & 16.3 & 30.5 & 30.4 & -1.00 \\ 29.9 & 24.9 & 74.0 & 30.5 & -23.1 & 18.2 & 25.3 & 31.3 & 15.4 & 15.3 & -1.00 \\ 26.8 & 30.7 & 30.5 & 74.0 & 17.2 & 16.0 & 15.9 & 19.0 & 18.4 & 25.1 & -1.00 \\ 33.0 & 23.4 & 23.1 & 17.2 & 74.0 & 34.6 & 34.2 & 23.8 & 23.3 & 12.5 & -1.00 \\ 30.7 & 25.4 & 18.2 & 16.0 & 34.6 & 74.0 & 25.3 & 16.4 & 30.5 & 15.7 & -1.00 \\ 28.4 & 18.3 & 25.3 & 15.9 & 34.2 & 25.3 & 74.0 & 31.2 & 15.6 & 8.3 & -1.00 \\ 24.4 & 16.3 & 31.3 & 19.0 & 23.8 & 16.4 & 31.2 & 74.0 & 10.3 & 7.4 & -1.00 \\ 26.7 & 30.5 & 15.4 & 18.4 & 23.3 & 30.5 & 15.6 & 10.3 & 74.0 & 25.3 & -1.00 \\ 20.1 & 30.4 & 15.3 & 25.1 & 12.5 & 15.7 & 8.3 & 7.4 & 25.3 & 74.0 & -1.00 \\ 1.0 & 1.0 & 1.0 & 1.0 & 1.0 & 1.0 & 1.0 & 1.0 & 1.0 & 1.0 & 0.00\end{array}\right] \cdot\left[\begin{array}{l}\lambda_{1} \\ \lambda_{2} \\ \lambda_{3} \\ \lambda_{4} \\ \lambda_{5} \\ \lambda_{6} \\ \lambda_{7} \\ \lambda_{8} \\ \lambda_{9} \\ \lambda_{10} \\ u\end{array}\right]=\left[\begin{array}{l}35.77 \\ 32.46 \\ 32.33 \\ 30.45 \\ 27.69 \\ 25.41 \\ 25.36 \\ 24.63 \\ 23.76 \\ 21.23 \\ 1.00\end{array}\right]$

Figure 5.5

MATRICES OF EQUATION 5.18 FOR KRIGING 


\section{REFERENCES}

1. Kim, Y. C. and Knudsen, H. P., A Comparative Study of the Geostatistical Ore Reserve Estimation Method over the Conventional Method, Report to the U. S. Energy Research and Development Administration, Grand Junction Office, Contract No. AT(05-1)-1649, Open File No. GJO-1649, August 31, 1975.

2. Knudsen, H. P., Kim, Y. C. and Mueller, E., "A Comparative Study of the Geostatistical Ore Reserve Estimation Method Over the Conventional Mcthod,". Paper Presented at the Annual AIME Meeting, Las Vegas, Nev., February, 1976.

3. Matheron, G., The Theory of Regionalized Variables' and Its Applications, Les Cahiers du Centre de Morphologie Mathematique, Fontainebleau, No. 5., 1971.

4. David, M., Geostatistical Ore Reserve Estimation $\div$ Review Copy, Ecole Polytechnique de Montrea1, Canada, March, 1975.

5. Gupta, S. K. and Cozzolino, J. M., Fundamentals of Operations Research for Management, Holden-Day, Inc., San Francisco, 1974.

6. Carr, C. R. and Howe, C. W., Quantitative Decision Procedures in Economics, McGraw Hil1, New Ynrk, 1964. 
APPENDIX A

VARIOGRAM COMPUTATION PROGRAM "UGAMM"

USER'S GUIDE 


\section{SECTION I: PROGRAM IDENTIFICATION}

\subsection{PROGRAM TITLE: Variogram Calculation}

1.2 PROGRAM CODE NAME: . UGAMM

1.3 PROGRAM WRITER:: H. Peter Knudsen

PROGRAM DOCUMENTATION: Young C. Kim

1.4 ORGANIZATION:

1.5 DATE:

1.6 UPDATES:

1.7 SOURCE LANGUAGE:

1.8 ABSTRACT:

This program is specifically tailored for use by the U. S. ERDA personnel to compute variograms directly from 'SCOR' tapes. However, it is a general purpose variogram computation program having fllaly user options. Some such options are: 1) choice of input data device, 2) automatic scaling of the variogram plot on the line printer, 3) punch out option for the variogram display program 'VARPLOT', and 4) drill hole data selection option which allows inclusion of only those data points within the specified boundary, during the variogram computation.

Program UGAMM is capable of processing a single data group or multiple groups of data, all during the same rum. It is currently dimensioned to handle up to 1000 total data points within a single data group. 


\section{SECTION II: ENGINEERING DOCUMENTATION}

\subsection{NARRATIVE DESCRIPTION:}

Program UGAMM has been specifically tailored for use by the U. S. ERDA personnel to compute variograms directly from 'SCOR' tapes. However, it is a general purpose variogram calculation program written to accept a variety of data taken either on a regular or an irregular grid.

Variograms are calculated in any specified direction within a plane, using the data that have coordinates and assay values. The plane need not be a horizontal plane, although the horizontal variograms are the rule rather than an exception for most tabular deposits such as roll-front type uranium deposit. If a vertical variogram is desired from a set of drill hole assays, it can be obtained by treating depth as the east coordinate and by letting the north coordinate as zero (i.e., the same direction)

Program UGAMM is capable of processing a single data group or multiple groups of data, all during the same run. The program can handle up to 1000 data points within a single data group. Also, the data need not be ordered within each group.

Being a general purpose program, the program possesses many user options. These options are:

1. Choicc of input data device, i.e., 'the 'SCOR' tape or the card input through the system card reader.

2. Logarithmic transformation of data.

3. Computation of the average variogranl from all the data groups, if more than one set of data are processed during the run.

4. Option to punch out the variogram results on cards in a format that is directly compatible to the input data format of the Calcomp plot display program of a variogram. "VARPLOT" (See Appendix $B$ of this report.) 
5. Automatic scaling of the variogram plot on the line printer, for each variogram that is generated.

6. Drill hole data selection option which allows inclusion of only those data points that lie within a specified boundary, during a variogram computation.

For each variogram that is computed, the program produces two types of output as shown in Figures 1 and 2. Figure 1 is a display of the results in numeric form whereas Figure 2 is a display in graphic form. For the latter type of display, the user must prespecify as to whether or not one desires a plot of a) GAMMA(H) or b) MOMENT CENTER. In general, GAMMA(H) should be specified if the data lie on a regular grid and if the class interval specified is equal to the grid interval. However, MOMENT CENTER is more frequently specified in practice due to the fact that most drill hole data are on an irregular grid.

Up to 20 class intervals along a given direction are allowed in variogram computation. In addition, the specified class interval is also utilized to limit the distance between data points within which the variogram is to be computed. For example, if the distance between two assay data exceed 20 times the class interval distance, variogram computation for these points is by-passed.

Since a variogram is a vector function, i.e., it has a direction as well as the value, the direction along which the computation is to be performed must be specified by the user. In specifying the desired direction, one must also specify the allowable spread in degrees from the direction within which to accept the assay data. This allowable spread, i.e., a tolerance is required simply because most dri.11 holes seldom lie on a straight line. If the spread is 90 degrees, then each and every hole is 


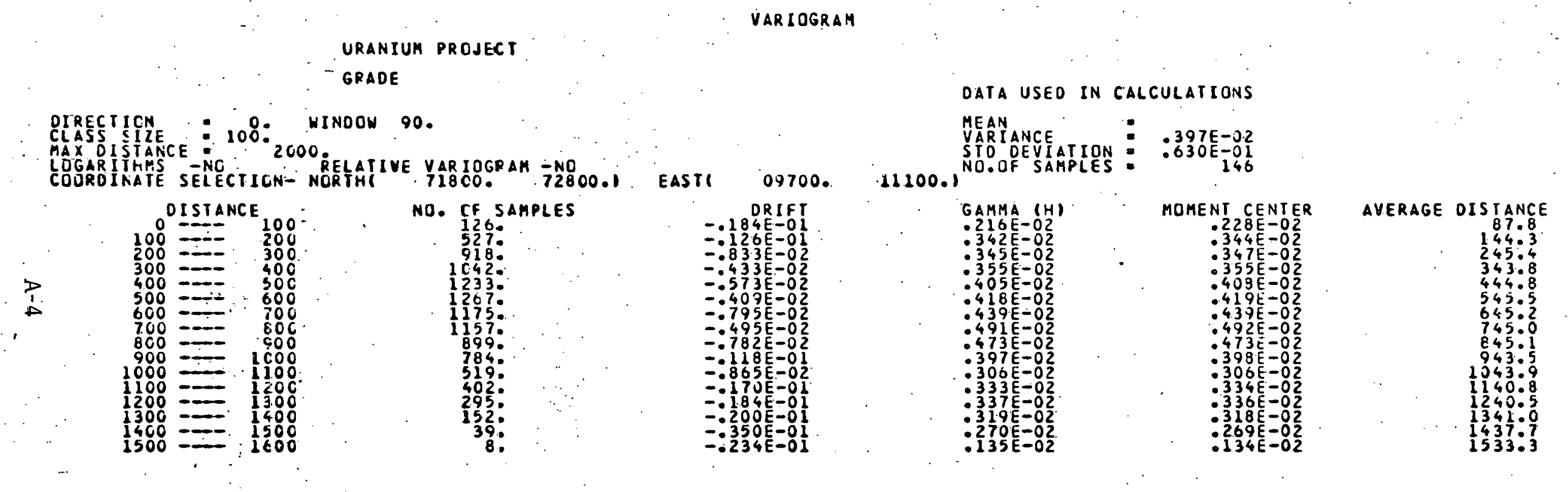

Figure 1 


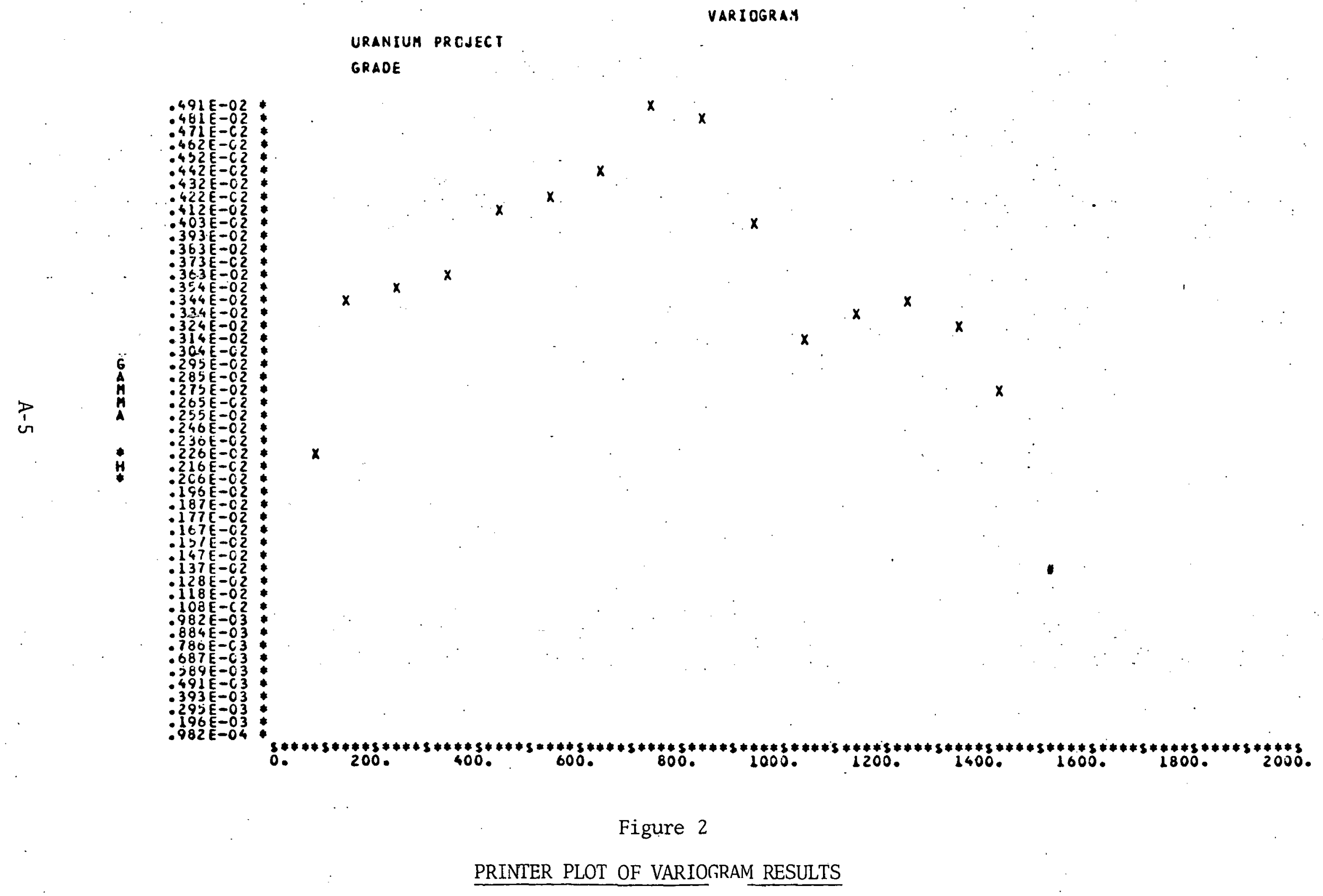


included thus resulting in an average variogram in all directions. Program UGAMM is capable of producing the average variogram from several variograms that are being computed using several different data sets. An example of such situation is to compute a variogram from each bench of an open pit mine, and then obtain the average variogram from all benches.

If desired, a relative variogram can also be obtained using program UGAMM. In a relative variogram, the obtained value for a given distance $h$ is divided by the square of the mean of samples that were used for computation.

\subsection{METHOD OF SOLUTION:}

The theoretical basis of the variogram definition as well as the physical meaning of a variogram are not discussed here. Instead the reader is referred to the main text of this report (See Chapters 2 and 3). The subject matter being discussed in this section deals mainly with the practical aspects of computing variograms from a variety of data taken either on a regular or an irregular grid.

Theoretically, a variogram is defined as Equation 1 below:

$$
\gamma(h)=\frac{1}{2 \dot{v}} \int_{v}[f(x)-f(x+h)]^{2} d x
$$

A variogram, $\gamma(\mathrm{h})$, is a vector function in three-dimensional space and it is a function of the distance $h$ between a point $x$ and another point $x+h$. The function, $f(x)$, simply defines the value of interest such as the grade at a point $x$. 
When a variogram is to be computed using a discrete number of points such as drill hole assays, the integral sign in Equation 1 must be replaced by a sumnation sign as shown in Equation 2 .

$$
\gamma(h)=\frac{1}{2 N} \sum_{j=1}^{N}\left[f\left(x_{j}\right)-f\left(x_{j}+h\right)\right]^{2}
$$

In Equation 2, it is assumed that there are $N$ pairs of samples, each pair being separated by distance $h$. In addition, all these samples are assumed to lie on a straight line, along which the variogram computation is being performed.

In practice, however, most drill holes neither lie on a straight line nor are spaced at a uniform grid. Consequently, one must not only specify the direction for the variogram computation, but also the allowable spread in degrees from the direction within which to accept the assay data. Simi1arly, the distance $h$ in Equation 2 which corresponds to a uniform grid spacing must be modified to allow an interval instead of a point. The modified version of Equation 2 which computes the variogram using a distance that falls within some interval is given by Equation 3 :

$$
r(h)=\frac{\sum_{j=1}^{N}\left(h_{j}\right) x\left[f(x)-f\left(x+h_{j}\right)\right]^{2}}{2 \sum_{j=1}^{N}\left(h_{j}\right) .}
$$

The basic unit used for the interval $(h)$ in Equation 3 is the class size 
which is also specified by the user. For example, if the class size is $100 \mathrm{ft}$. , any pair of data points whose distance is between 0 to $100 \mathrm{ft}$. are included in the computation. In using Equation 3, the actual distance $h_{j}$ for the $j$-th pair of data points is used instead of the midpoint of the class interval such as $50 \mathrm{ft}$. in the above example. Hence, the obtained $\gamma(h)$ value is the weighted average value rather than the arithmetic average of Equation 2.

After computing $\gamma(\mathrm{h})$ value for the first class size, i.e., $100 \mathrm{ft}$., the next class size of $200 \mathrm{ft} .(2 \times 100)$ is used to obtain pairs of data points whose distances fall between $100 \mathrm{ft}$. to $200 \mathrm{ft}$. The $\gamma(\mathrm{h})$ value is then computed using those pairs that have been obtained earlier. The whole process is repeated for a total of twenty (20) class intervals, i.e., $2000 \mathrm{ft}$. in the above example. Hence, the specified class interval distance effectively limits the maximum distance for which the variogram is ton he computed by program UGAMM.

Program UCAMM calculates $\gamma(h)$ values using both Equations (2) and (3) above. Values of $\gamma(h)$ calculated by Equation 2 are listed under the heading of GAMMA(H) in Figure 1, whereas those obtained by Equation 3 are listed under MOMENT CENTER. As mentioned earlier, GAMMA(H) contains the arithmetic average whereas MOMENT CENTER contains the weighted average.

The values of $\gamma(h)$. calculated by Equation 3 can be compared with those calculated by Equation 2 to determine if the class size chosen was good. Generally the class size is chosen to be the average grid size. If the differences between the GAMMA $(\mathrm{H})$ and MOMENT CENTER values are large, the class size should be adjusted slightly. In cases where the data is 
from a truly regular grid, the values will be the same.

Program UGAMM also calculates the average difference between samples separated by distance $h$. Listed under the heading DRIFT, this value is useful in determining if drift, i.e., a general increase or decrease in grade with distance for the direction specified, is present.

The last colum in Figure 1 gives the average distance of all the pairs of data points whose distances fell within the given class interval. If desired, the values of $\gamma(h)$ calculated by Equations 2 or 3 can be divided by the mean squared to get the values in relative terms.

For each variogram being computed, program UGAMM produces a two page output as shown in Figures 1 and 2. Figure 2 is simply a graphic display of a part of the results given in Figure 1. For example, the program user must specify in advance as to which column (i.e., GAMMA(H) or MOMENT CENTER) is to be plotted on the graph, since both graphs can not be printed simultaneously. In Figure 2, the distance $h$ for each $\gamma(h)$ value is the average distance and not the midpoint of each class interval.

The following four (4) formulas, in essence, summarizes the method of solution.

$$
\begin{array}{lll}
\text { Gamma }(\mathrm{h}) & \gamma(\mathrm{h}) & =\frac{\text { Cum. Difference Squared }}{2 \times \text { (No. of Samples) }} \\
\text { Moment Center } & \gamma(\mathrm{h}) & =\frac{\text { Cum. (Distance } \times \text { Diff. Squared) }}{2 \times \text { (Cum. Distance) }} \\
\text { Average Distance } & =\frac{\text { Cum. Distance }}{\text { No. of Samples }} \\
\text { Drift } & =\frac{\text { Cum. Difference }}{\text { No. of Samples }}
\end{array}
$$




\subsection{PROGRAM CAPABILITIES:}

A maximum of 1000 data cards may be included in each data set and any number of data sets included per job. If desired, the data set may be selected from a larger data set by limiting the data to points that fall. within a user specified rectangular block. A variogram is calculated for each data set, and if desired, an average variogram for all the data sets may be calculated. The variogram values may be divided by the mean squared to transform their magnitude to percents of the mean squared. The sample values may be transformed to logarithms.

2.4 DATA INPUTS:

Figure 3 below describes the data inputs whereas Figure 4 shows a 80-80 listing of sample input data.

\subsection{PRINTED OUTPUT:}

Two pages of printed output are produced for each variogram. Page one is a listing of the sample mean, sample variance, variogram direction, and a tabulation of the variogram results (see Figure 1). Page two is a plot of either GAMMA(H) or the MOMENT CENTER versus distance.

\subsection{PUNCHED CARD OUTPUT:}

For each variogram calculated, if desired, the following cards are punched out. These cards 'can be used as input for the variogram display program "VARPLOT"' (See Appendix B of this report.) 


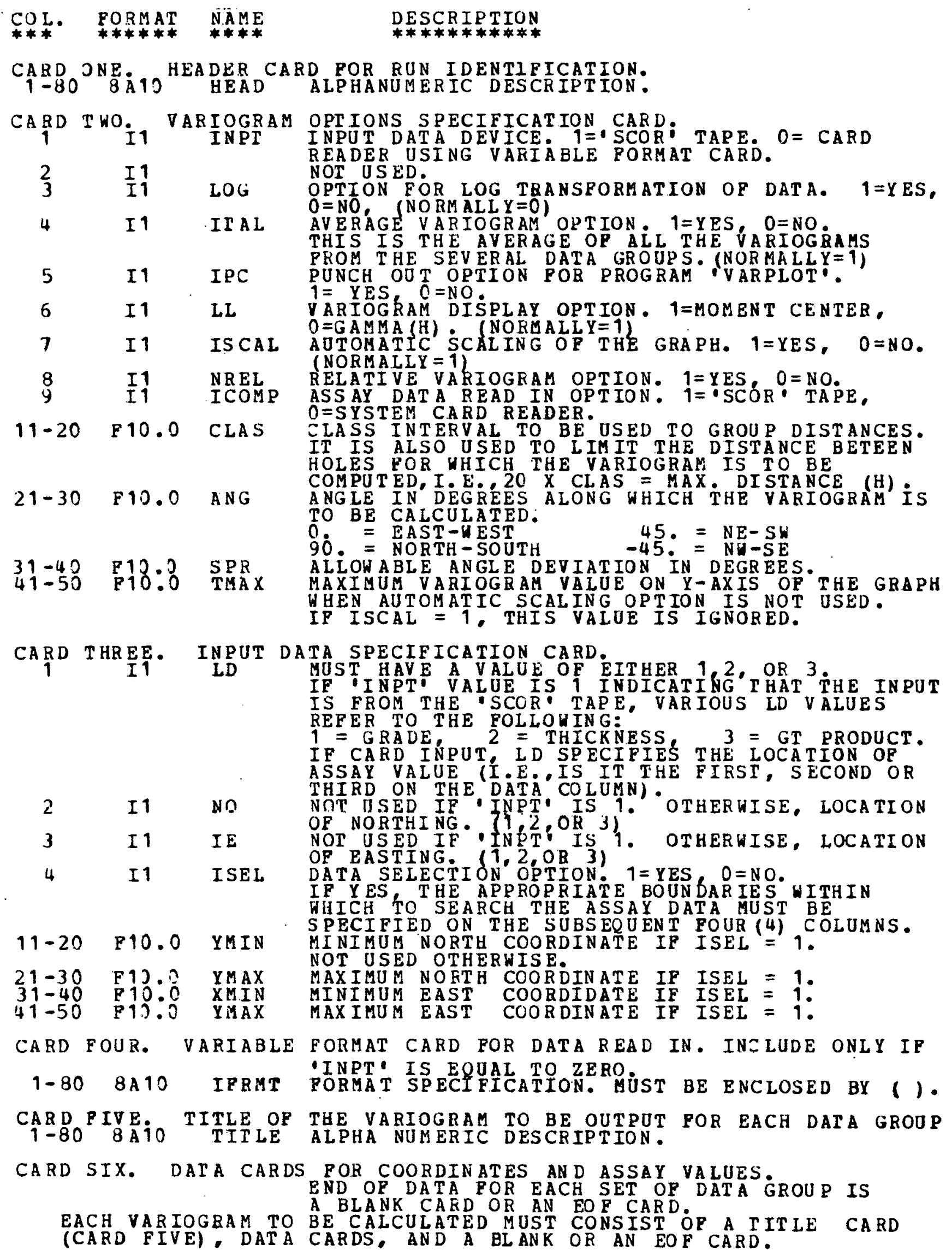

Figure 3

DESCRIPTION OF INPUT DATA 


\begin{tabular}{|c|c|c|}
\hline 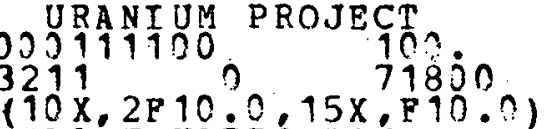 & $72800 \dot{0}$ & 097000 \\
\hline
\end{tabular}

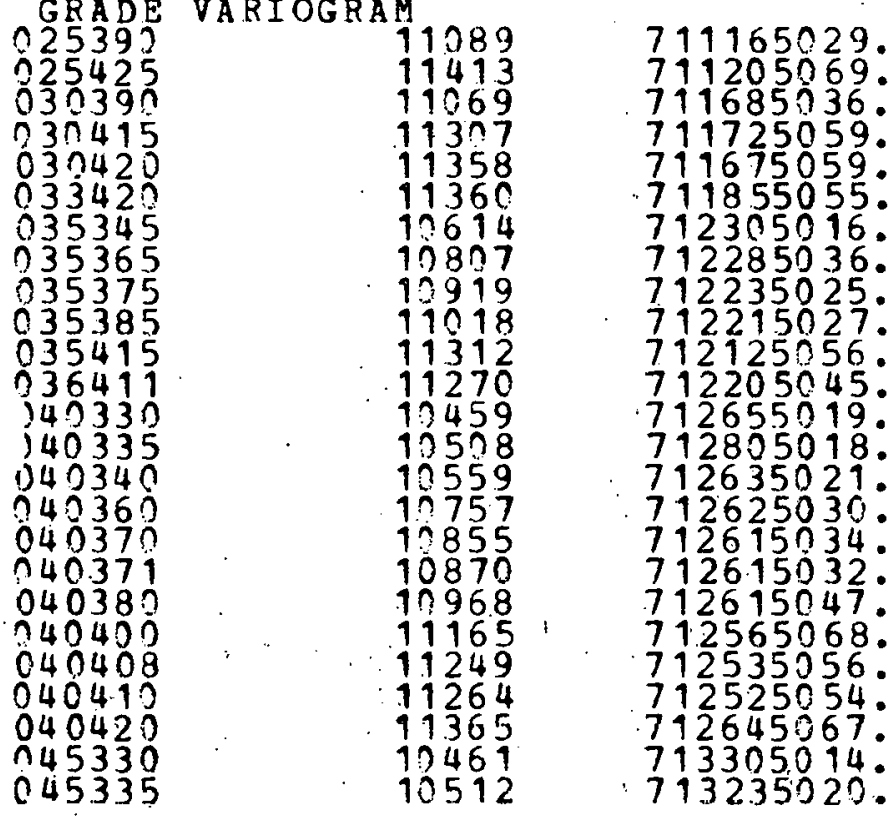

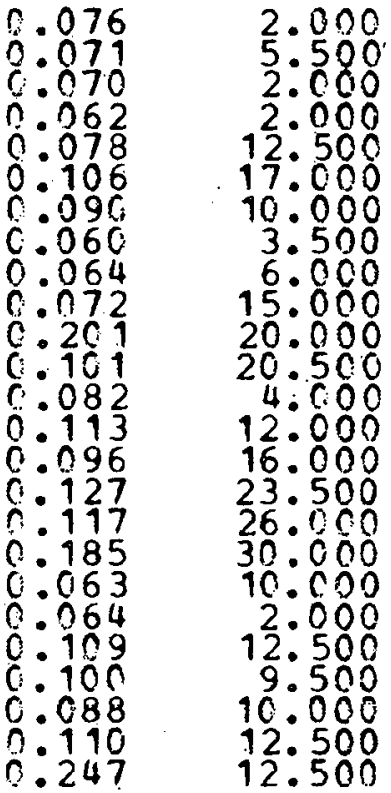

0.151

0.391

0.125
0.973
0.973

801

0.904

.

0.382

1.081

4.013

328

1.36

1.59

(034

5.549

0.127

1.366

0.954

1.380
3.088

Figure 4

SAMPLE LISTING OF INPUT DATA 
A. Lible lairl.

\begin{tabular}{|c|c|c|}
\hline COIIIMN & FOKMAI & RL :MNRKS \\
\hline $2-80$ & $7 \mathrm{~A} 10, \mathrm{~A} 9$ & Title of Variogram \\
\hline
\end{tabular}

\begin{tabular}{lcl} 
COLUMN & FORMAT.. & \multicolumn{1}{c}{ REMARKS } \\
\cline { 2 - 3 } $1-10$ & E10.3 & Direction of variogram. \\
$11-20$ & E10.3 & Allowable angle deviation. \\
$21-30$ & E10.3 & Sample mean. \\
$31-40$ & E10.3 & Sample variance. \\
$41-50$ & E10.3 & Distance interval. \\
$51-60$ & A3 & Log transform of data (yes or no) \\
$61-70$ & I10 & Number of samples.
\end{tabular}

C. Variogram Cards.

\begin{tabular}{lll} 
COLUMN & FORMAT & \multicolumn{1}{c}{ REMARKS } \\
\cline { 3 - 3 } $1-10$ & E10.3 & Number of samples. \\
$11-20$ & E10.3 & DRIFT \\
$21-30$ & E10.3 & GAMMA(H) \\
$31-40$ & E10.3 & MOMENT CENTER. \\
$41-50$ & E10.3 & Average distance.
\end{tabular}




\section{SECTION III: SYSTEM DOCUMENTATION}

\subsection{COMPUTER EQUIPMENT:}

Program UGAMM was written for a CDC-6400 computer.. A card reader, a card punch, and a line printer are necessary to run the program.

\subsection{SOURCE PROGRAM:}

The source listing of Program UGAMM is given at the end of the Appendix.

\subsection{VARIABLES AND SUBROUTINES:}

The major variables are defined in the program listing at the end of this Appendix. The program consists of the following subroutines:

1. UGAMM: Main program for input and variogram calculations.

2. VAROUT: Output subroutine.

3. RDN: Data input for variable format option.

4. RSCOR: Data input for SCOR tapcs.

5. System subroutines - Subroutines for logarithm, sine, cosine, and square root are required by the program and are provided by the system.

\subsection{STORAGE REQUIREMENTS:}

As presently stfuctured program UGAMM requires $50 \mathrm{~K}$ storage on the $\operatorname{CDC} 6400$.

3.5 MAINTENANCE AND UPDATES:

None to date. 


\title{
SECTION IV: OPERATING DOCUMENTATION
}

\subsection{OPERATING INSTRUCTIONS:}

The program is operated under the SCOPE operating system.

\subsection{OPERATING MESSAGES:}

No special operating messages are produced.

\subsection{CONTROL CARDS:}

The program may be executed with standard SCOPE 3.4 control cards. As run on the University of Arizona $\operatorname{CDC} 6400$, the makeup of the input deck is as follows:

\author{
Job Card \\ FTN. \\ LGO. \\ $7 / 8 / 9$ \\ $<$ SOURCE PROGRAM> \\ $7 / 8 / 9$ \\ $<$ INPUT DATA $>$ \\ $6 / 7 / 8 / 9$
}

4.4 FRROR RF.COVERY:

The program will terminate if errors are found in the control card parameters. The program must be restarted on error.

4.5 RUN TIME:

Run time depends on the number of variograms plotted and on the number of sample points in the data. A typical run for 1 variogram with about 200 data points is 5 seconds. 
UGAMM PROGRAM LISTING

$A=16$ 
PROGRAM UGAMM (INPUT, OUTPUT, PUNCH, TAPE1=INPUT,TAPE5=00TPOT,TAPE6= 1 P UNCH,TAPE4

DIAENSION TOT $(20,5)$, TOTVAR $(20,5)$

COMMON VAR $\left(22^{\circ}, 5\right)$. HEAD (8),LOG, CLAS, DLIM, ANG, SMEAN, VARI, STD, N

COMMON IPC,L,SPR. ISCAL, TMAX, NREL

CJMMJN /TO\%IJUT,IPT, IPCH, ICOMP, ITAPE.TITLE (8),MAXN

こOMMON /DAT/DATA $(1050,4)$, IFRGT (8), LD,NO,IE, IA

CJMMJN /DAT2\%ISEI, YMIN, YMAX,XMIN XMAX

DATA MAXN,IPI. IOUT, ITAPE IPCH/1000,.1,5,4,6/

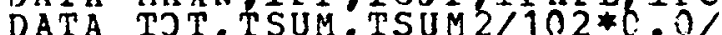

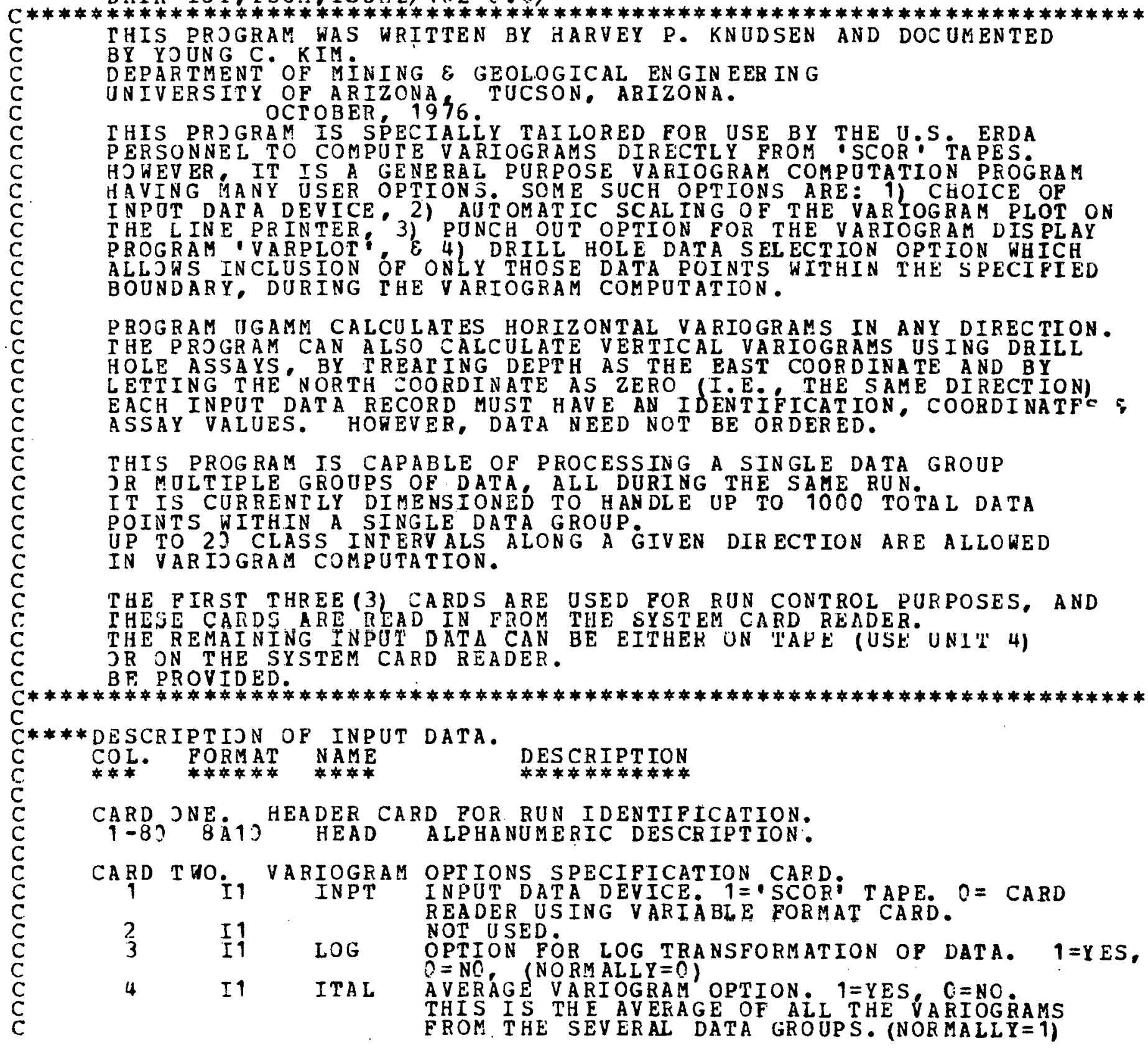

THIS PROGRAM WAS

DEPARTMENT OF MINING $\&$ GEOLOGICAL ENGINEERING OCTOBER. 1976.

IHIS PRJGRAM IS SPECIALLY TAILORED FOR USE BY THE U.S ERDA HOWEVER. IT IS A GENERAL PURPOSE VARIOGRAM COMPOTATION PROGRAM HAVING MANY USER OPTIONS. SOME SUCH OPTIONS ARE: 1) CHOICE OF I NPOT DAIA DEVICE , 2) AITOMATIC SCAL ING OE THE VARIOGRAM PLOT ON

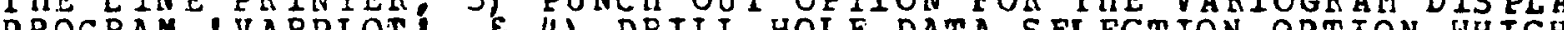
ALLJWS INCLUSION OF ONLY THOSE DATA POINTS WITHIN THE SPECIFIED BOUNDARY, DURING THE VARIOGRAM COMPUTATION.

PBOGRAM IIGAMM CALCULATES HORIZONTAL VARIOGRAMS IN ANY DIRECTION THE PRJGRAM CAN ALSO CALCULATE VERTICAL VARIOGRAMS USING DRILL HOLE ASSAYS, BY TREAIING DEPTH AS THE EAST COORDINATE AND BY EACH INPUT DATA RECORD MUST HAVE AN IDENTIÉTCATION COORDINATFC BE ORDERED

R M CAPABIE OF PROCESSING A SINGIE DATA GROUP I T IS CURRENTLY DIMENSIONED TO HANDLE UP TO 1000 TOTAL DATA POINTS WITHIN A SINGLE DATA GROUP.

UP TO 25 CLASS INTERY ALS ALONG A GIVEN DIRECTION ARE ALLOWED

THE FIRST THREE (3) CARDS ARE

วR ON THE SYSTEM CARD READER.

BP PROVTDED

DESCRIPTIJN OP INPUT DATA.

AAR JNE HEADER CARD FOR RUN IDENTIEICATION. 


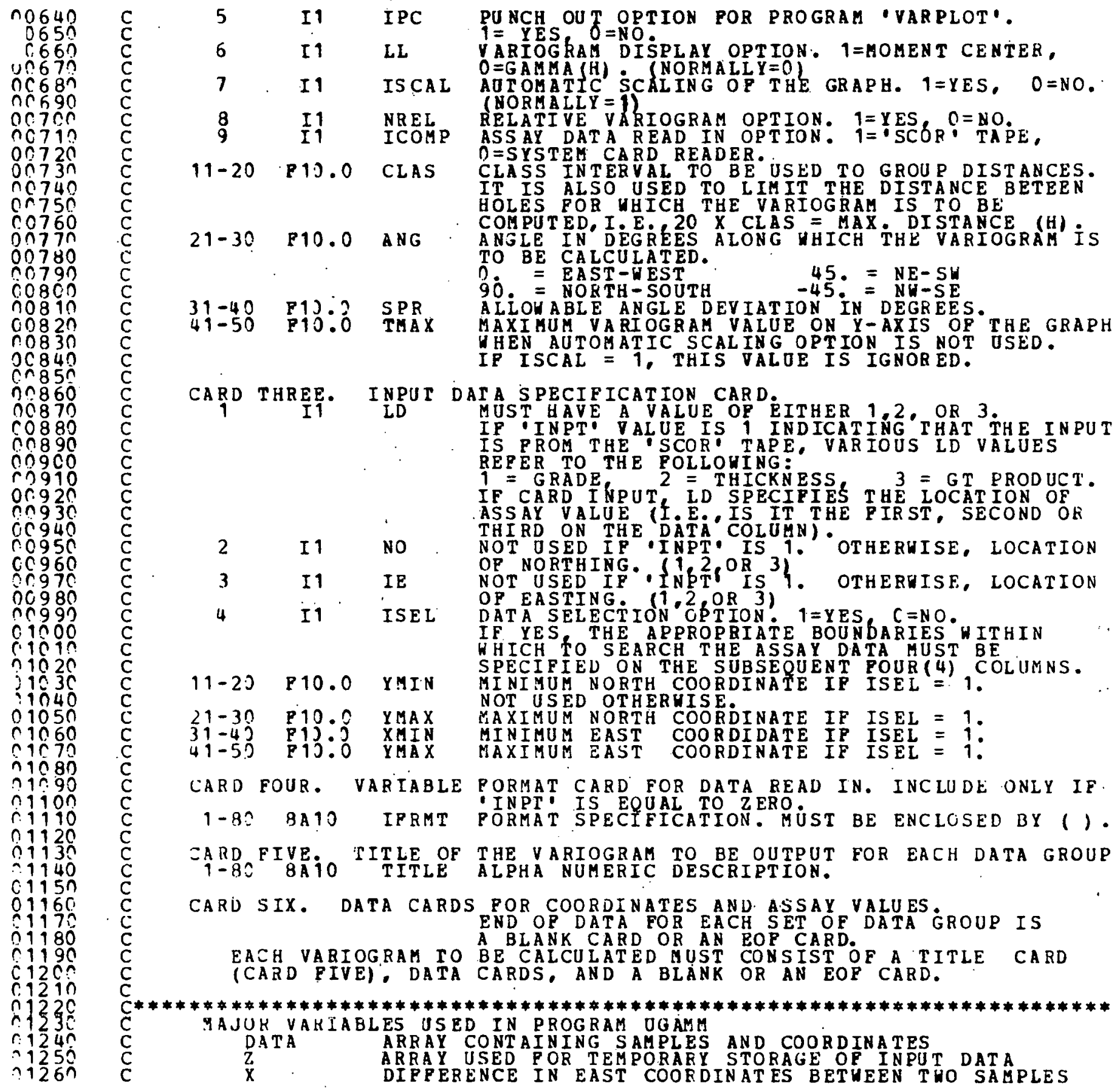


01380

01390

01410

C. 1420

01433

01440

01450

01460

C1470

ก 1480

C 1490

01500

01510

01520

01530

C 1540

C 1550

c 1560

r.1570

c 1580

01590

0160 .

त1610

ก 1620

ก1630

$\cap 1640$

c 1650

01660

$\therefore 167$ ก

01680

c 1690

$r 1700$

01710

ก1720

01730

0.1740

11750

c1760

rif7

C 1790

c1 1 \%

C 1810

ก.1820

r183

$r 1840$

$r 1850$

$-186^{\circ}$

: 1870

? 1480

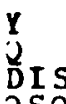

DI S

T⿱乛龰T

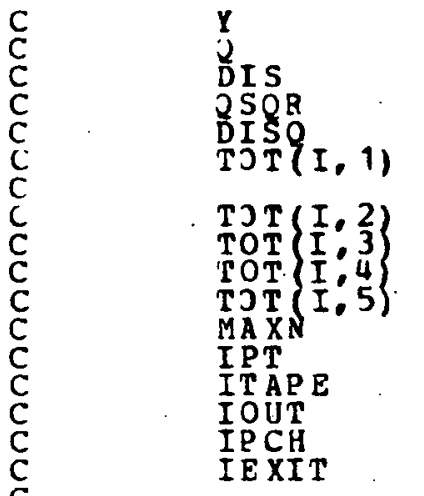

DIPEERENCE IN WEST COORDINATES

BETUEB

DIPFERENCE IN SAMPLE VALUES

DISTANCE BETUEEN THO SAHPLES

Q SQUARED

DIS IIMES Q SQUARED

TOTVAR $(I, 2)$ CUMULATIVE DIFFERENCE

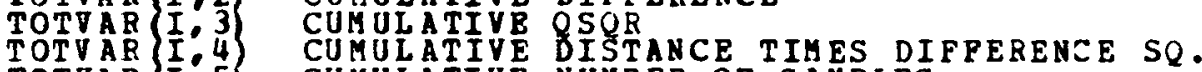
TOTVAB I 5) CUMULATIVE NUMBER OF SAMPLES

MAXIMUA NO. OF DATA POINTS CURRENTLY ALLONED.

UNIT DEVICE ON WHICH THE RUN CONTROL DATA ARE STORED

ONIT DEVICE ON UHICH ASSAY DATA IS STORED.

UNIT DEVICE FOR PRINTED OUTPUT.

UNIT DEVICE POR PUNCHED OUTPUT OP THE VARIOGRAM

CODE OSED TO TERMINATE THE RON .

$1=$ MEANS DATA YAS POUND. HENCE PROCESS IT.

$2=$ MEANS NORMAL END OF THE RUN. NO MORE DATA GROOP

3 = MEARS ABRUPT END OP THE RUN DUE TO INPUT DATA

$3=$ MEAKS

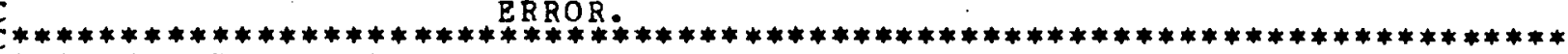

****READ IN CONTROL CARD ONE

$1 \uparrow \quad$ FORMATISATS

IF (EJP (IP T) NE.C) GO TO 200

C*** READ IN CONTROL CARD TUO

READ IPT, 2 C) INPT LOG ITAL, I PC, LL, ISCAL, NREL,

1 I COMP CLAS ANG S PR T TAX

20 FTRMAT (IT, \{X TIT, TX. 4P10.0)

C*****SIMPL LOGIC CHECKS

$\mathrm{L}=\mathrm{L} L+3$

I $P(L L \cdot G \Gamma \cdot J) \quad L=4$

I P ICOMP:E . ก) ITAPE=IPT

DLIM $=2 j$ * CIAS

DANG = ANG* 17453292519943

$\because S T=\operatorname{COS}(D A N G)$

DSPR $=$ SPR*.017453292519943

$=S P R=\operatorname{COS}(D S P R$ )

C***READ IN CARD THREE FOR INPUT OPTION (INPT) ZERO

22 FORMAT $4+1,6 \times 4$ PIJ O

FORMAT $(4$ IT TEX 4 E 19.0 )

I F IN PN.ES: i) GO FO 23

71 PORMAT 3 A 13)

IF (ESP IPT) NE.O) GO TO 200

23 IP INPT.EQ. T.AND. LD. LE. 3) GO TO 75

TF (I.D.LE.3) AND. (NO.LE.3) .AND.(IE.LE.3)) GO TO 75

C*****STOP THIS RUN 30 To 251

C****READ IN ASSAY DATA FROM APPROPRIATE SUBROUTINES BASED ON INPT VALUE

75 IF (IN PT. EQ. T) CALL RDN (N, IEXIT)

I $P$ IN PT. EQ. 1 CALL RSCOR (N, IEXIT)

85

GO TO $(35,185,261)$ I EXIT

$\div 189{ }^{\circ}$

DJ 90 I I I . N

$\operatorname{DATA}(I, 1)=\operatorname{ALOG}(\operatorname{DATA}(I, 1))$ 


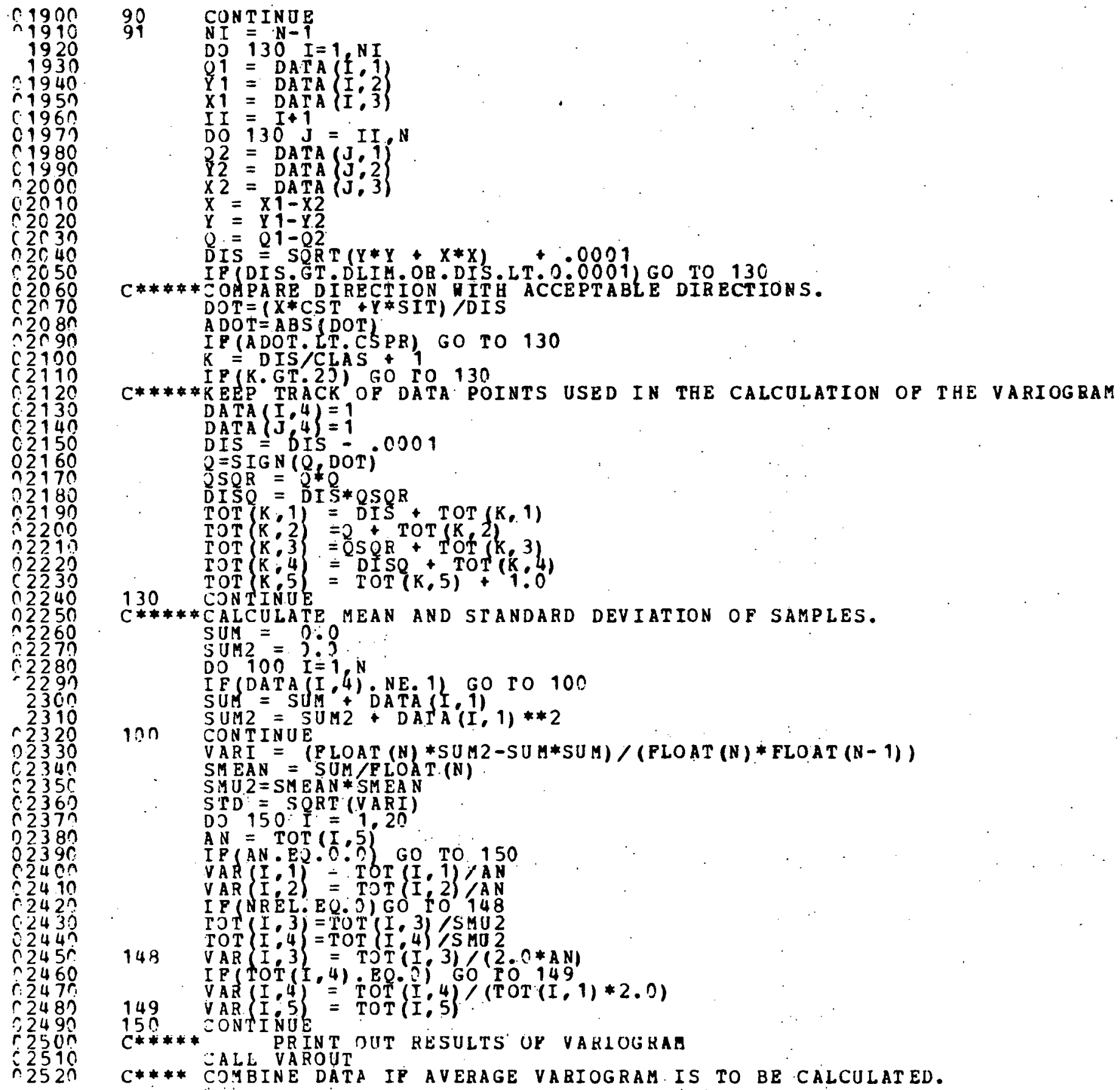


IP(ITAL.EQ.0) GO TO 170

160 CONTIR $(I, J)=\operatorname{TOTVAR}(I, J)+\operatorname{TOT}(I, J)$

C 2570

02580

O 2590

ก 2600

ก2610

C 2620

ก. 2630

C2650

C2650

02670

C 2680

02690

C 2700

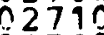

02720

ก 2730

C: 2740

C 2750

02770

ค278

(2) 270

0280

C. 2820

त2830

02849

$2285 \hat{0}$

02870

.28 8 ก

ก́28 90

C.29C

ก 2910

त. 2920

ก 2930

C. 2940

ก 2950

$0296 n$

C2977

C 2980

C 2992

C 3010

- 302 n

ก 350

- 3040

ก 3550

c $3 n 6$

r 3970

r. 3 ถูก

C. 3090

C 310

Q3115

C? 122

r $313 n$

, 3140

i) 3150

TSUH = SUH $\bullet$ TSUM

ISUM $2=\operatorname{SUM} 2+$ TSUM2

$N N=N N+N$

C*****ZERJ TOT AND VAR ARRAYS

170 DO $130 \cdot I=1,2$.

TOT $(I, J)=1,5, J$

180

VAR $\left(I_{0}, J\right)=\dot{0} .0$

GOTTJ.75

185 IF (ITAL. EQ. J) GO IO 194

C*****CAL CUIATE AVERAGE VARIOGRAM

VARI $=$ (PLOAT (NN) *TSUM2-TSUM*TSUM) / (PLOAT (NN)*PLOAT (NN-1))

$S M E A N=$ TSUM/FLOAT (NN)

STD $=$ S2RT (VARI)

$\mathrm{N}=\mathrm{N} N$

D) $190 \cdot I=1,20$

AN $=$ TOTVAR $(\dot{I}, 5)$

IP (AN.EQ.O. O) GO TO 190

VAR $(I ; 1)=$ TOTVAR $(I, 1) / A N$

VAR $\{$ I: 2$\}=$ TOTVAR $\{$ I $: 2\} / A N$

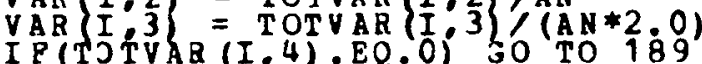

189 VAR 1 I. 4 5$\}=$ TOTVAR $(I, 4) /(\operatorname{TOTVAR}(I, 1) * 2.0)$

C*****PRINT OUI RESULTS OF AV ERAGE VARIOGRAM

TITLE $\left\{\begin{array}{l}1 \\ 2\end{array}\right)=$ "NAVERAGE

CALL VARJUT

194 WRITE(IOUT:175) " NORMAL END OP JOB")

30 TO 211

299 WRITE(IJUT, 1911 FILE ENCOUNTERED. ERROR IN JOB SETUP.")

201 STOP

END

SOBRJUTINE VAROUT

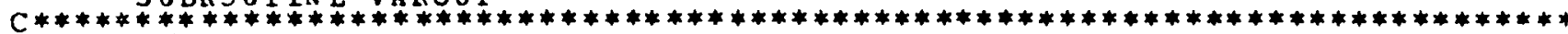

STBRJUTINE VAROUT PRINTS OUT THE RESULTS OF THE VARIOGRAM CALCULATION

DIMENSION A (10) $), C(11), D(50), \mathrm{E}(13)$

CJMMON VAR $(20,5)$, HEAD (8), LOG, CLAS, DLIM,ANG, SMEAN, VAHI,STD, NN

COMHON IPC, L S PR.ISCAL THAX NREL

CDMMON /OOFUUT IPT I PCH ICOMP ITAPE,TITLE (8), MAXN

CJMMON /DAT2/ISEL, Y HIN, YMAX, XMIN, XMAX DIMENSION I LOG 2

DATA ILSE/2HNO 3 HYES/

DATA D/2广*1H $1 \mathrm{HG} 1 \mathrm{HA}, 1 \mathrm{HM}, 1 \mathrm{HM}, 1 \mathrm{HA}, 1 \mathrm{H}, 1 \mathrm{H}, 1 \mathrm{H} * 1 \mathrm{HH}, 1 \mathrm{H}, 2 \mathrm{C} * 1 \mathrm{H} /$

DATA E/1 HM, 1HÓ $1 \mathrm{HM}, 1 \mathrm{HE}, 1 \mathrm{H}, 1 \mathrm{H}, 1 \mathrm{H}, 1 \mathrm{HC}, 1 \mathrm{HE}, 1 \mathrm{HN}, 1 \mathrm{H}, 1 \mathrm{HE}, 1 \mathrm{HR}$

I $P(L \cdot E Q=3)$ Gj to 8

$D(I+18)=E(I)$

$7 \quad$ CONTINGE

C $\int^{1} b_{5}=2=2$

35

$C$ C $=I=2 A 11=2.0+C(I-1)$ 
$C * * * *$ * PINT OUT PAGE ONE OUTPUT

10 PORMATITT 102

MITE ( OUT TO

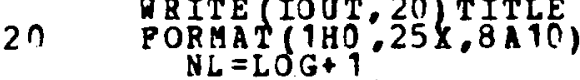

$N R=N R E L+1$

WRITESIOUT 20 HEA D

25 PJRMAT78X DATA OSED IN CALCULATIONS")

1. ILJG SN

$30 \quad$ PORHAT" $110 X$ X

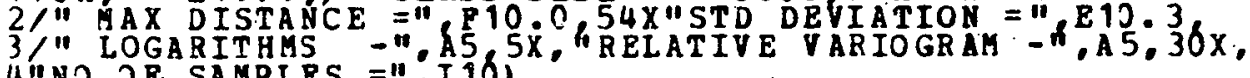
$4 " N O O P$ SAMPLES $="$ "I IOL

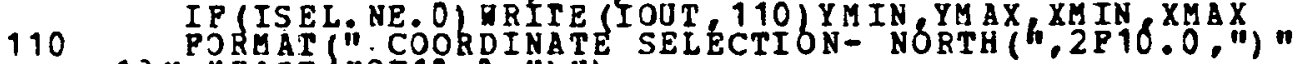
$13 \times$, "EAST "2 210.5 , "I) C*****PUNCH OUI PUT CARDS OR STORE ON DEVICE ONIT NO. 6 .

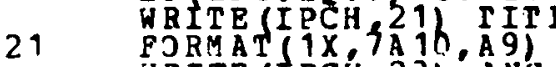

WRITE IPCY, 23 ) ANG SPR SMEAN, VARI, CLAS, ILOG (NL) , NN

23 FORMAT 5 E $35.3, A 4.6$ \&. I 16$)$

22 PORMAT 39 ETIO: 3$\}$

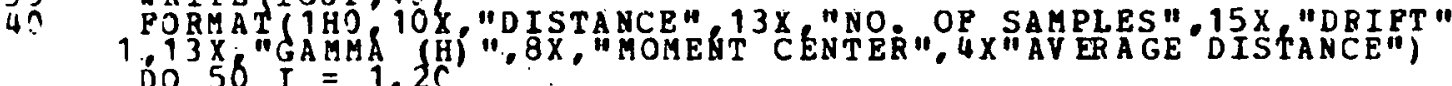

Do $56 \mathrm{I}=1,2 \mathrm{C}$

LOW $=(I-1) *$ CLAS

LUP $=I * C L A S$

IF (VAR (I, 5).GT. 2.) WRITE (IOUT, 45) LON, LUP, VAR (I,5), VAR (I, 2),

1 VAR $(I, 3)$; VAR ( $I, 4 ;$ VAR I I 1) IP (IPC EQ. 1.AND. VAR I , 5) .GT.0) URITE (IPCH,22) VAR(I,5),VAR $(I, 2), V$

$1 A R(I, 3), \nabla A R(I, 4), \nabla A R(I, 1)$

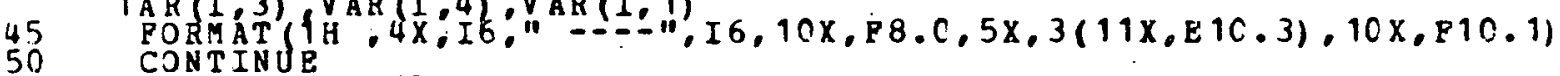

WRITE (IOOT, 1?)

C*****PRINT OUT'PAGE TVO OUTPUT

WITE (IOUT, 2C) TITLE

HRITE IOUT:25 HEAD

1.00 FORMATITOS

C IP AUTJMATIC SOALING IS NOT DESIRED SKIP TO 56

$C * * * * * P I N D$ MAX VALOE

TMA $55=\mathrm{VAR}(1, \mathrm{~L})$

55
56

I $P$ (VAR $T=2$ í

CONT IN UE

UNIT $=$ CLAS/5.

DI $=$ TMAX $/ 50$.

DO $75 \mathrm{~K}=1,5 \mathrm{C}$

TOP $=$ TEMP

$B O T=T E M P-D I V$

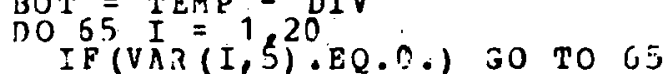

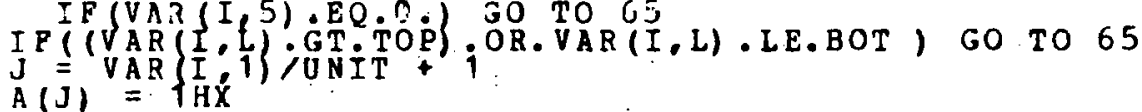


65 CONTANAR $(I, 5) \cdot \operatorname{LT} \cdot 30) \mathrm{A}(\mathrm{J})=$ "

0.3820

03380

C ARRAY "A" CONTAINS BLANKS AS VELL AS DATA POINT MARKERS.

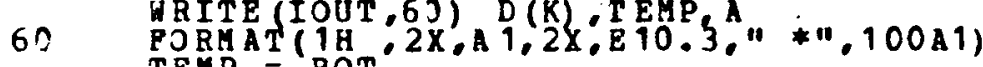

03850

03860

03870

ก 3880

03890

C 3900

त 3910

03920

C 3930

C 3940

03950

03960

03970

03983

03990

त $40 \mathrm{CO}$

$0401 n$

04020

त 4030

04040

04050

$r 4060$

04070

04080

04090

04100

04110

r. 4120

04130

ก 414 n

ก 4150

C.4160

C417n

त 4180

04190

r4200

१ 4210

C 4220

C 4230

04240

04250

$r 4260$

34270

त4280

04290

$\therefore 4300$

0.4310

r. 4320

04330

C434n

ก 4350

04360

24370

2438 ?

04390

04400

$\lcm{4490}$

TEMP $=$ BOT

DO $70=I=1 \frac{1}{h} 100$

70 COMTNUE

75 CONTINUE

80 FORMAT (18T, $\left.17 X_{1}, 10(" \$ * * * * \$ * * * n), " \$ n\right)$

90. PORMAT $(1 \mathrm{H}, 93 \mathrm{X}, 11(\mathrm{~F} 6.0 .4 \mathrm{X}))$

RET UR N

EN D

SUBROUTINE RDN (N, IEXIT)

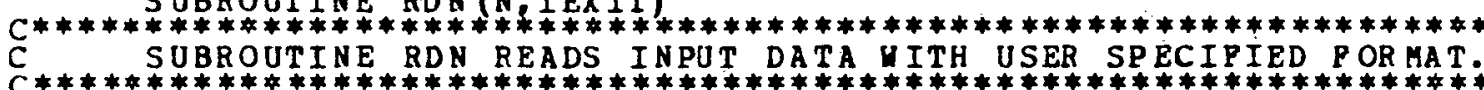

COMMON /DAT/DATA $(1000,4)$ IFRMT (8), ID, NO, IE, IA

COHMON /DAT2/ISEL,YMIK, YMAX,XMIN XMAX

COMMON/IO/IOUT, IPT, IPCH, ICOMP, ITAPE, TITLE(8) , MAXA

DIMENSION $2(3)$

$N=0$

I EXIT $=2$

10 READ (ITAPE, 10, TITLE

IP (EJP (ITAPE) NE. O) RETURN

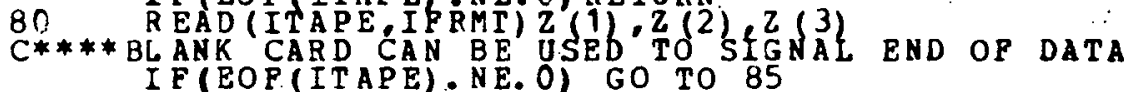

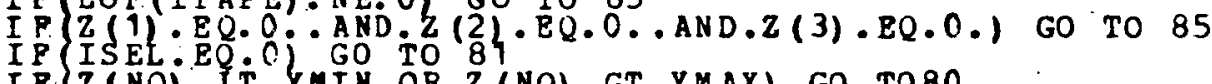

I $P$ Z NOj. LT. YMIN. OR.Z (NO) GT YMAX) GO TO 80

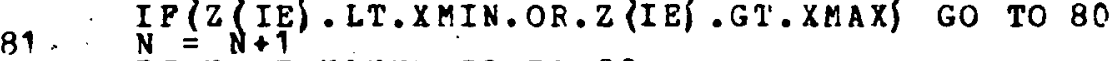

IF (N.GT.MAXN) GO TO 83

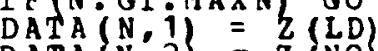

DATA $N: 2\}=2$.

DATA $\left.\left\{\begin{array}{l}\mathrm{N}: 3 \\ \mathbf{D} \\ \mathbf{N}\end{array}\right\}=2\right\}$ I

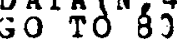

$85 \quad$ IEXIT $=1$

IFJN.GT. I) RETORN

210 FORMAT(" INPUT DATA ERROR", 3X, I5," DATA POINTS PRESENT")

IEXIT $=3$

RETURN

R.ND

SUBROUTINE RSCOR (N, IEX.IT)

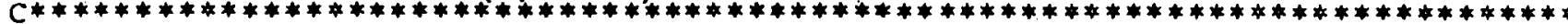

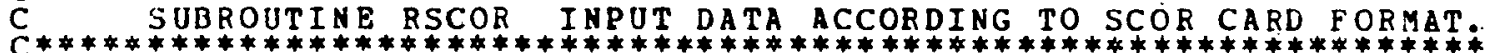

COMMJN /DAT/DATA $(1000$ 4) IFRMT (8) ID NO,IE. IA

COMMON. /DAT2/ISEI,YMIN,YGAX,X HIN, XHAX

COMMON / IO/IOUT. I ET, I PCH, ICÓMP, ITAPE, TITLE (8), MAXN

DIMENSION Z (5)

$N=0$

IEXIT $=2$

$1 n$

READ (ITAPE, 1J) TITLE

I E (EOP (ITAPE) . NE.D) RETURN 
04425

04440

0445 ?

04460

34470

ก.448?

04490

04509

84510

04520

04530

04540

04550

C 456 ?

04570

04580

ก 4590

C 4600

04610

04629

ก.4630

0464 ?

80: READTTAPE.20)Z F

I P SOP IT APE). NE. OJGO TO 85

C****BCANK CARD CAK BE USED TO SIGNAL END OP DATA

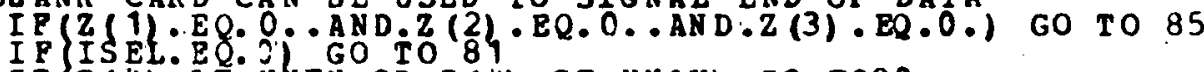

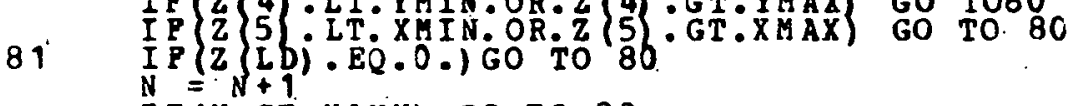

IP(N.GT.MAXN) GO TO 83

DATA $(N, i)=2(L D)$

DATA N, 2$\}=2(4)$

DATA,$: 3\}=\mathrm{Z}(5\}$

DATA $(N, 4)=3$.

85 I EXIT $=.1$

IP(N.GT.1) RETURN

$210 \quad \mathrm{THE}$ IOUT 210$)$ N

FORMAT (" INPIIT DATA ERROR",3X,I5," DATA POINTS PRESENT") I EXIT $=3$

RETURN

END 
APPENDIX B

VARIOGRAM DISPLAY PROGRAM "VARPLOT"

USER'S GUIDE 


\section{SECTION I: PROGRAM IDENTIFICATION}

\subsection{PROGRAM TITLE:}

1.2 PROGRAM CODE NAME:

1.3 PROGRAM WRITER:

PROGRAM DOCUMENTATION: Young C. Kim

VARPLOT

Young C. Kim
Calcomp Plotting Program of Experimental Variograms

Harvey P. Knudsen

Department of Mining and Ceological Engineering University of Arizona

Tucson, Arizona.

November 10,1976

One. Version: II

CDC 6400 Computer Systems - FORTRAN Fxtended Version IV.

\subsection{ABSTRACT:}

Program VARPLOT is a Calcomp plotter program for plotting the experimental variogram values. To use this program, the user must have an access to a Calcomp plotter as well as the standard Calcomp subroutines.

The program is currently dimensioned to plot a maximum of five different variograms on one graph. The program limits the total number of pluts during one run to fifteen (15). If desired, a spherical variogram model can be superimposed on the same graph or drawn as a new graph. 


\section{SECTION II: ENGINEERING DOCUMENTATION}

\subsection{NARRATIVE DESCRIPTION:}

Program VARPLOT is a Calcomp plotter program which plots the experimental variogram values. To use this program, the user must have an access to a Calcomp plotter as well as the standard Calcomp subroutines. Five such subroutines are;

1. AXIS Subroutine

2. SYMBOL Subroutine

3. NUMBER Subroutine

4. PLOT Subroutine

5. LINE Subroutine.

Prior to executing this program, a variogram computation program such as the Program GAMMA (see Appendix A of this report) should be executed to generate the above variogram values. These values, then, become the necessary input data to VARPIOT program.

Since this is a Calcomp plotter program, run control parameters specifically for the plotter must'be specified ahead of the main input data. Examples of such parameters are the size of a graph, size and color of the pen, and type of symbols to use. These parameters are read into the program only once during the program run.

The program is currently dimensioned to plot a maximum of five different variograms on the same graph using different symbols.. The program allows a total of fifteen different plots during one run. If desired, a spherical variogram model can be superimposed on the same graph or drawn on a new graph. If the model is to be drawn on a new graph, it must be the first plot for that rum. 


\subsection{ME:TIOD OF SOLUTION :}

The method of solution is straightforward, if one is familiar with the Calcomp subroutines.* Use of these subroutines is not described in this user's guide, however.

The computed experimental variogram values which have been obtained from another program such as GAMMA, are plotted on a graph whose dimensions are specified by the user. The recommended dimensions are 8 inches along $\mathrm{Y}$-axis and 10 inches along $\mathrm{X}$-axis.' The variogram values are plotted along $\mathrm{Y}$-direction whereas the distance values are plotted along X-direction.

In addition to the variogram values, other pertinent information regarding the variogram results is also given on the bottom of the graph as shown in Figure 1. This information consists of 1) title of the plot, 2) direction window, and class size used, and 3) mean, variance and sample size.

If more than one variogram is to be plotted on the same graph, the above information regarding the second and the subsequent plots are not given, however. Similarly, if a spherical variogram model is either superimposed on the same graph or drawn on a new graph, neither the title of the model nor the model parameters are given on the plot.

In the program, several indices are used to control the type of plotting operation being performed. For example, the index "NEW" is used to designate if the plot is 1) a new one, 2) to be plotted on the same graph, or 3) for a variogram model. The "NSY" index is used as a counter for multiple plots on one graph, whereas the "NPLOT" index is used as a counter for the total number of plots during the same run. The variable "ICK" is a switch used for drawing the axes of the graph for a new plot.

* $\quad$ Programing Calcomp Pen Plotters, California. Computer Products, Inc., 305 Muller Ave., Anaheim, California 92083, September 1969. 


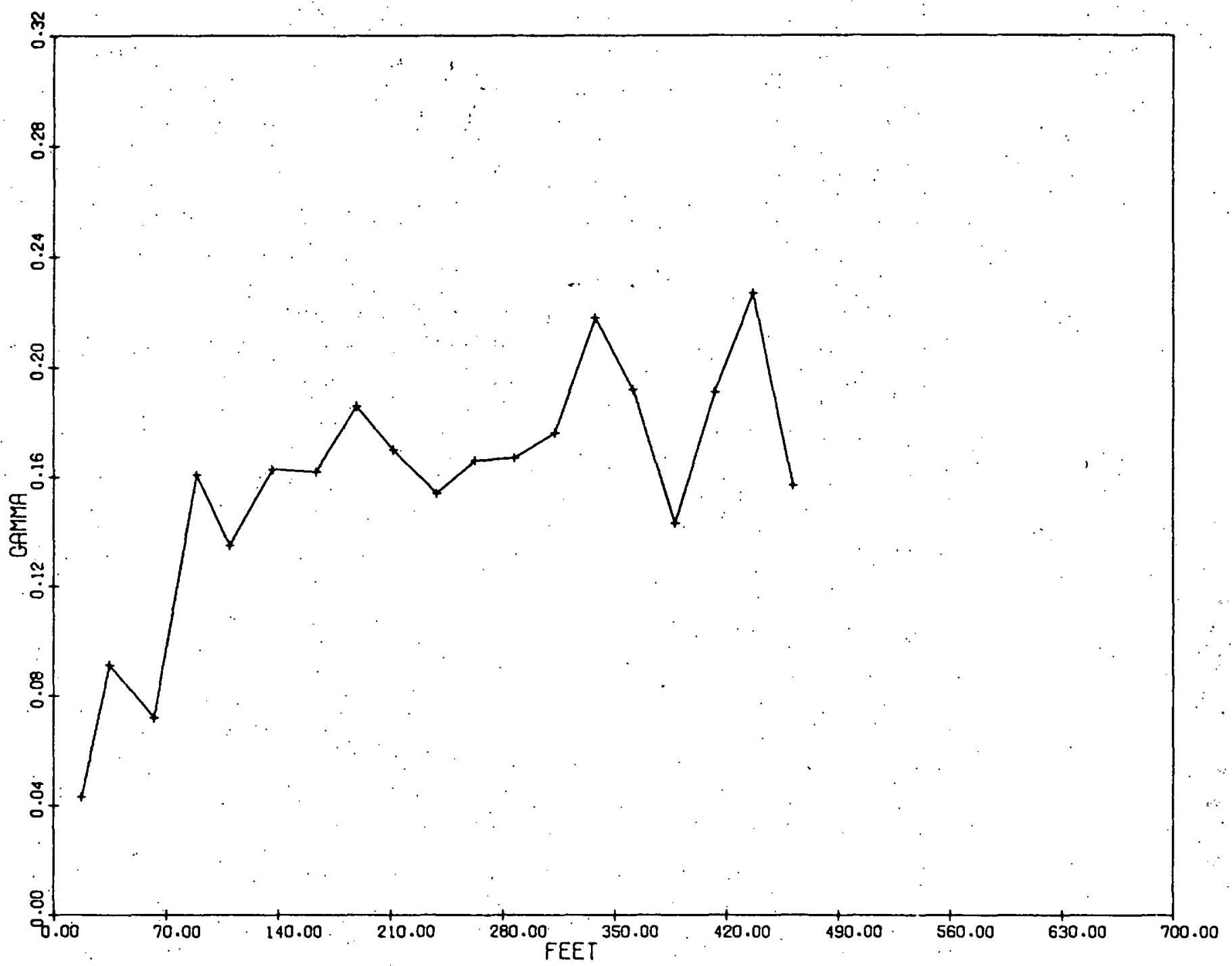

1590.0 - 1500.0 BENCHES. NW-SE DIRECTION, 30 OEG WINOOW.

OLRECTION $=.45 . \quad$ HINDOW $=30 . \quad$ MFAN $=0.582$

CLASS SIZE $=25.00$

VFRIANCE $=0.1810$

LOCAR I THMS -

NO. OF SAMPLES $=893$

Figure 1

A SAMPLE OUTPUT OF A VARIOGRAM PLOT 


\subsection{PROGRM CAPABILITTES:}

Program VARPLOT limits the total number of plots during one run to fifteen (15). This limit can be easily modified by the user by changing the "NPMAX" value given in the DATA statement. Similarly, the program is currently dimensioned to allow a total of five (5) multiple plots on the same graph. If more than five multiple plots are called for by the user, a message is printed and the current plot is ignored. The program proceeds to the next plot until a new plot is encountered.

As it is currently dimensioned, there can be a maximm nf twenty (20) data points for each variogram. If there are more than 20 data points, the remaining points are ignored.

The program performs other checks on the possible inconsistencies of the input data. If data points fall outside the limits of the graph, these points are reset to coincide with the graph boundaries. If the index 'NEW' is not specified in the, fijpst column of the title card, then the program assumes that the plot is a new p.lnt: If the spherical variogram model paranl" eters are improperly specified, plotting the model is omitted after printing a message.

\subsection{DATA INPUTS:}

1. CARD TYPE ONE. RUN PARAMETER CARD (NEEDED ONLY ONCE).

\begin{tabular}{|c|c|c|c|}
\hline COLUMN & FORMAT & $\begin{array}{l}\text { IARIABLE } \\
\text { NAME } \\
\end{array}$ & DESCRIYIION \\
\hline $1-5$ & F5. 0 & PEN & PLOT PEN DESIRED (NORMALLY $=0.3$ ). \\
\hline $6-10$ & I5 & INK & COLOR OF INK DESIRED ( $0=$ BLACK). \\
\hline $11-20$ & F10.0 & TOP & VARIOGRAM VALUE AT TOP OF GRAPH. \\
\hline $21-30$ & H10.0 & BOT & VARIOGRAM VALUE AT BOTTOM OF GRAPH. \\
\hline $31-40$ & F10.0 & EAST & DISTANCE VALUE AT EAST EDGE OF GRAPH. \\
\hline $41-50$ & F10.0 & WEST & DISTANCE VALUEE AT WEST EDGE OF GRAPH. \\
\hline $51-60$ & F10.0 & XLEN. & LENGTH OF X-AXIS IN INCIES (NORMALLY $=10$ ) \\
\hline $61-70$ & F10.0 & YLEN & LENGTH OF Y-AXIS IN INCHES (NORMALLY $=8$ ). \\
\hline
\end{tabular}


2. CARD TYPE TWO. PLOT CONTROL AND TITLE CARD (REQUIRED FOR EACH PLOT).

\begin{tabular}{|c|c|c|c|}
\hline COLUMN & FORMAT & $\begin{array}{l}\text { VARIABLE } \\
\text { NAME } \\
\end{array}$ & DESCRIPTION \\
\hline 1 & I1 & NEW & $\begin{array}{l}\text { CODE USED TO DISTINGUISH THE TYPE OF THE } \\
\text { CURRENT PLOT. } \\
\text { IF NEW }=1 \text {, NEW PLOT. THEREFORE, DRAW THE } \\
\text { AXES ALSO. } \\
\text { IF NEW }=2 \text {, PLOT ON SAME GRAPH. } \\
\text { IF NEW }=3 \text {, PLOT VARIOGRAM MODEL. }\end{array}$ \\
\hline $2-80$ & 7Al0,A9 & TITLE & $\begin{array}{l}\text { DESCRIPTION OF THE PLOT TO BE WRITTEN OUT ON } \\
\text { THE GRAPH. USED ONLY WHEN NEW }=1 .\end{array}$ \\
\hline
\end{tabular}

3. CARD TYPE THREE. VARIOGRAM INFORMATION CARD (NEEDED IF NEW $=1$ OR 2).

\begin{tabular}{|c|c|c|c|}
\hline COLIMN & FORMAT & $\begin{array}{l}\text { VARIABLEE } \\
\text { NAME } \\
\end{array}$ & DESCRIPTION \\
\hline & E10.3 & & DIRECTION IN WHICH THE VARIOGRAM WAS COMPUTED. \\
\hline & E10 & & THE SPREAD OR THF WINDOW ALLOWED IN COMPUTATI \\
\hline $21-30$ & E10.3 & SMEAN & SAMPLE MEAN OF ALL DATA POINTS. \\
\hline $31-4$ & $\mathrm{E} 10.3$ & VARI & SAMPLE VARIANCE OF ALL DATA POINTS. \\
\hline $41-$ & Eio.3 & CLASS & CLASS SIZE USED TO GROUP THE DATA POINTS. \\
\hline $51-$ & & DLOG & LOGARITHMIC TRANSFORMATION OF DATA. YES OR NO \\
\hline $61-70$ & F10.0 & $\mathrm{SN}$. & TOTAL NUMBER OF DATA POINTS. \\
\hline
\end{tabular}

4. CARD TYPE FOUR. DATA CARDS (ONE CARD FOR EACH DATA POINT). NEEDED IF $\mathrm{NEW}=1$ OR NEW $=2$.

\begin{tabular}{|c|c|c|c|}
\hline COLUMN & FORMAT & $\begin{array}{l}\text { VARIABLE } \\
\text { NAME } \\
\end{array}$ & DESCRIPTION \\
\hline & E10.3 & 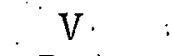 & LRRAY USED FOR VARIOGRAM VALUES. \\
\hline $41-5$ & E10.3 & DIS & D FOR THE CORRESPONDING \\
\hline
\end{tabular}

5. CARD TYPE FIVE. END OF DATA CARDS (NEEDED IF NEW $=1$ OR 2 ). A 7/8/9 CARD IS USEDD TO INDICATE END OF DATA.

NOTE: CARD TYPES 2, 3 AND 4 CAN BE AUTOMATICALLY GENERATED BY EXECUTING THE PROGRAM CAMMA, WHICH COMPUTES THE EXPERIMENTAL VARIOGRAM VALUES. THEY ARE NEEDED IF THE INDEX VALUE OF NEW IS EITHER 1 OR 2. IF THE VALUE OF NEW IS EQUAL TO 3, A SPHERICAL VARIOGRAM MODEL PARAMETERS. MUST BE SPECIFIED USING THE FORMAT GIVEN BELOW, RIGHT AFTER THE CARD TYPE TWO.

6. CARD TYPE SIX. MODEL PARAMETER CARD (NEEDED IF NEW = 3).

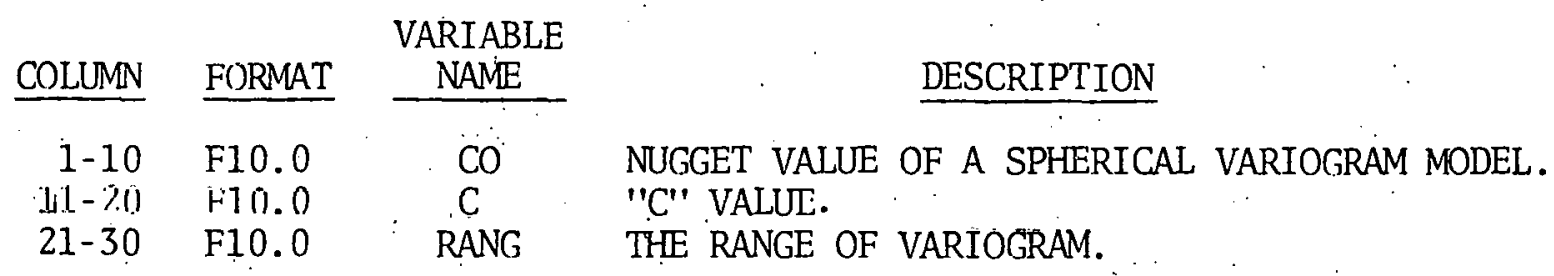

NN. END OF DATA CARD IS REQYJIRED AFTER TYPE SIX CARD. 
A 80-80 1isting of sample input data is shown in Figure 2.

2.5 PROGRAM OPTIONS:

None.

2.6 OUTPUT:

There are basically three types of output:

1. The plot of variogram computation results.

2. The plot of the user specified spherical variogram model, if desired.

3. Error or limitation messages, if encountered.

Figure 3 shows a sample output of multiple plots including the user specified variogram model which is superimposed. 


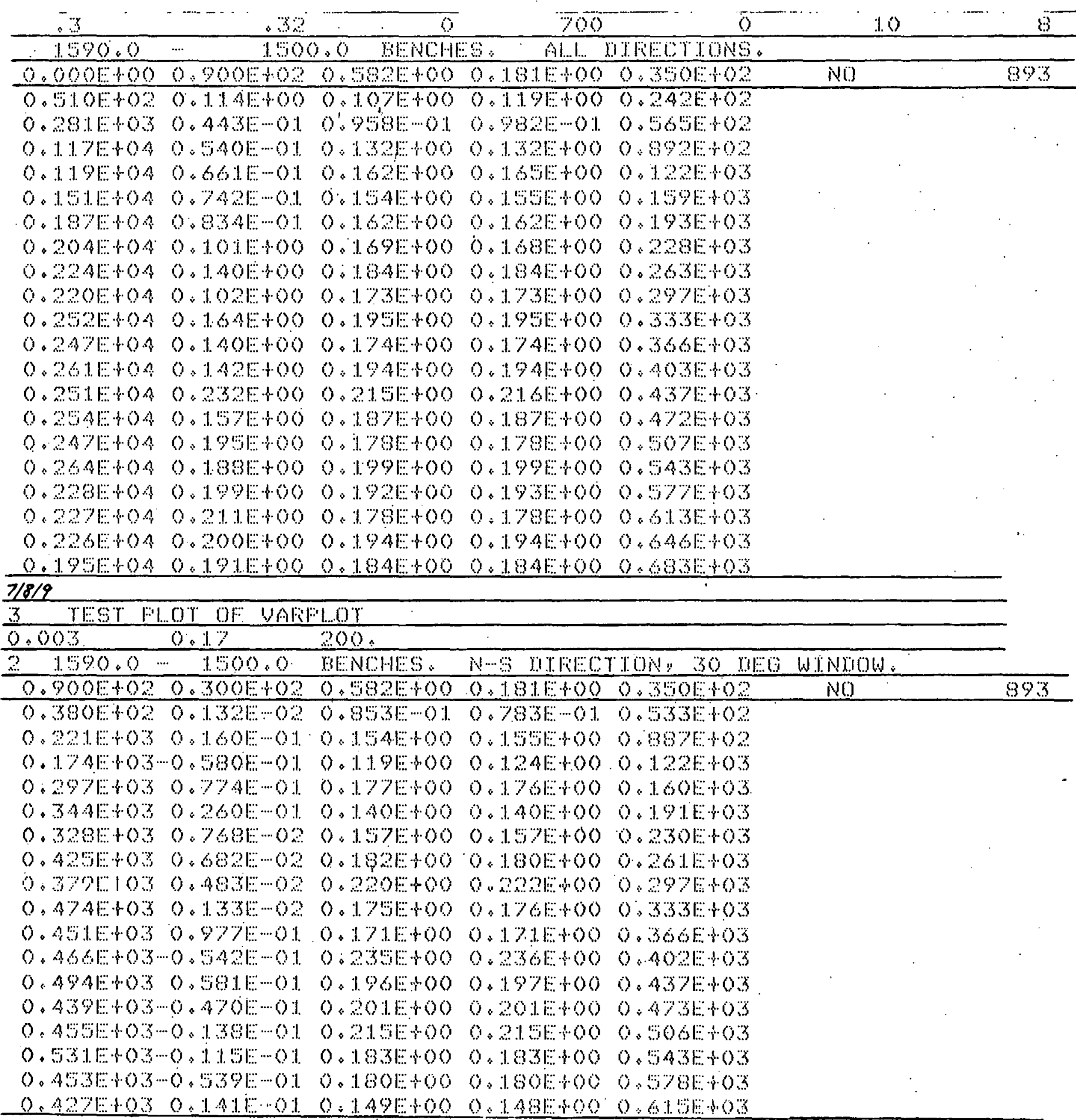

Figure 2

A 80-80 LISTING OF SAMPLE INPUT DATA

(See Figure 3 for P1ots) 


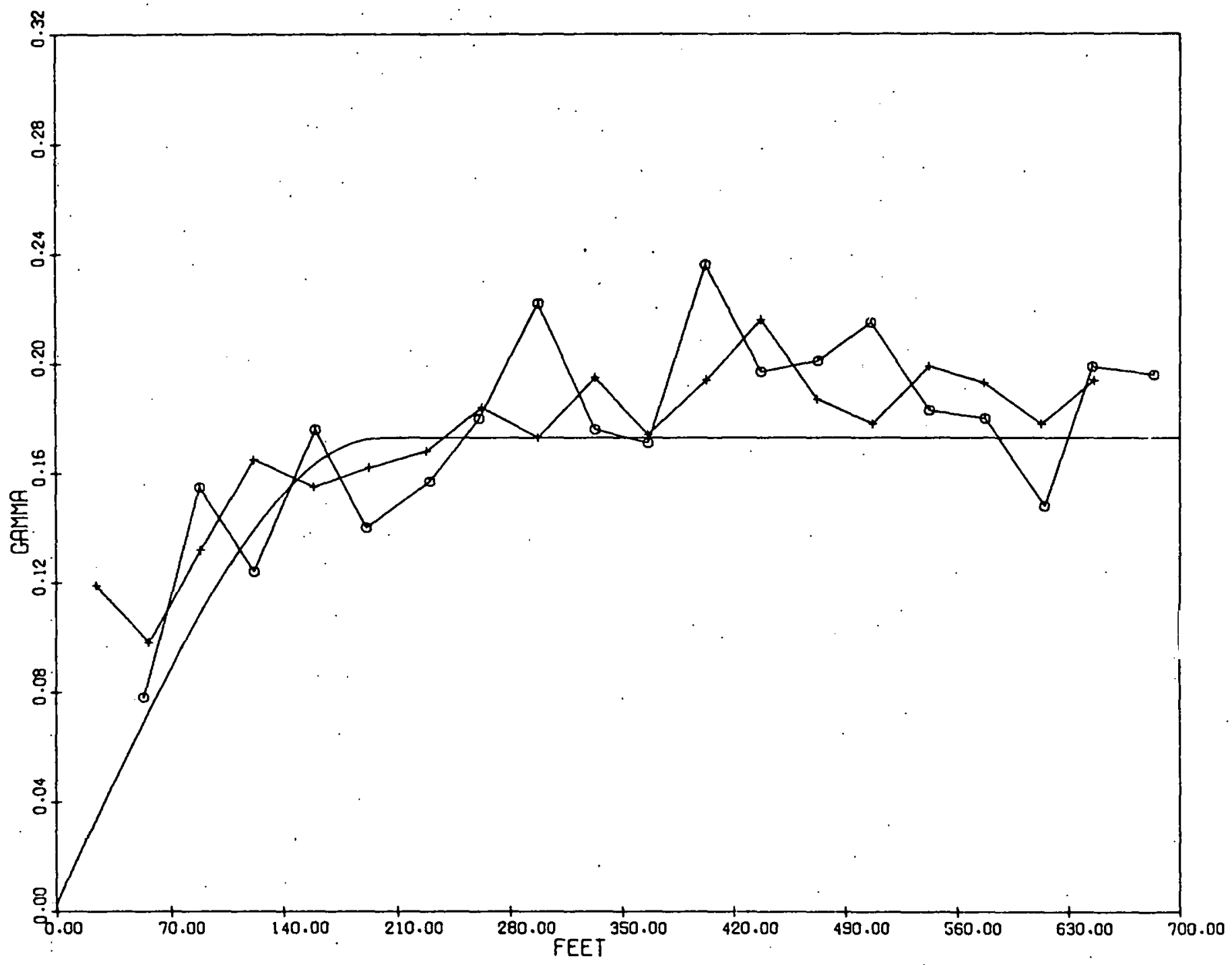

1590.0 - 1500.0 BENCHES. RLL OIRECTIONS.

OLRECTION $=0 . \quad$ WINOOW $=90 . \quad$ MEAN $=0.582$

CLASS SIZE $=35.00$

VARIANCE $=0.1810$

LOGARI THMS -

NO. OF SAMPLES $=893$

Figure 3

A SAMPLE OUTPUT OF MULTIPLE PLOTS 


\section{SECTION III: SYSTEM DOCUMENTATION}

\subsection{COMPUTER EQUIPMENT:}

The VARPLOT program was run on a CDC 6400 computer using 50K-core central memory.

\subsection{PERIPHERAL EQUIPMENT:}

The following peripheral equipment was used in the execution of the VARPLOT program:

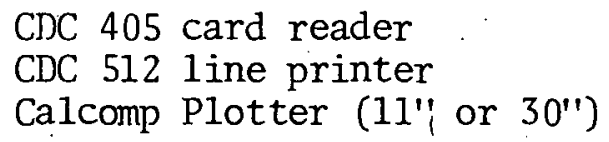

\subsection{SOURCE PROGRAM:}

A source program listing is given at the end of this Appendix.

\subsection{VARIABLES AND SUBROUTINES:}

A listing of all major variables is given in the program listing.

Program VARPLOT utilizes the following Calcomp subroutines:

1. AXIS: Draws the axes of the graph using the user specified scaling factor.

2. SYMBOL: Draws the user specified symbols.

3. NUMBER: Plots the number in FORTRAN F-type format.

4. PLOT: Generates the actual plotter command.

5. LINE: Produces a line plot of the pairs of data values in two arrays ( $X$ and $Y$ ).

6. INITIAL: See comments below.

In addition to the above five standard Calcomp subroutines, the program utilizes one (1) nonstandard University of Arizona subroutine called "INITIAL". This subroutine is called at the beginning only once for the purpose of 
initializing the plotter subroutines. As such, this INITIAL subroutine performs the task of Calcomp "PLOTS" subroutine.

3.5 DATA STRUCTURES:

No files are created or read by this program.

3.6 STORAGE REQUIREMENTS:

As presently structured, program VARPLOT requires approximately 50K storage on the CDC 6400 .

3.7 MAINTENANCE AND UPDATES:

This is the second version of the variogram plotting program. The first version was written by Harvey P. Knudsen in July 1976. 


\section{SECTION IV: OPERATING · DOCUMENTATION}

4.1 OPERATING INSTRUCTIONS:

Program VARPLOT is operated under the CDC 6400 , SCOPE 3.4 , operating system.

4.2 OPERATING MESSAGES:

Error messages produced by the program are self-explanatory. In addition, normal system messages are produced.

\subsection{CONTROL CARDS:}

The program may be executed with standard SCOPE 3.4 control cards. As run on the University of Arizona $\operatorname{CDC} 6400$, the makeup of the input deck is as : follows:

Job Card

FTN.

LGO.

$7 / 8 / 9$

$<$ SOURCE PROGRAM

$7 / 8 / 9$

\INPUT DATA>

$6 / 7 / 8 / 9$

4.4 ERROR RECOVERY:

If certain errors occur, the program will make assumptions and continue execution of the program. iA warning message will be printed. If a fatal error occurs in execution, the program must be restarted.

4.5 RUN TIME:

Run time depends on number of plots. Typical run time is about 1 second per plot. A typical plotter time is 3-5 minutes per plot on the 11 " plotter. 
VARPLOT PROGRAM LISTING

B-13 

$1=\mathrm{PLOT}$ DIMENSION DIS (22), (22), TITLE (8), NSYHB 5 )

DATA INPT, IPR. IUNIT, NPLÓT. NSY ICK $/ 1.3 .7 .0 .0 .01$

DATA NPMAX, NSMAX, NDMAX $/ 15,5,26 \%$

DATÁ YSN, PÁPER/0:0,0.0\%

DATA NS YMB $/ 3,2,1,0,5 \%$

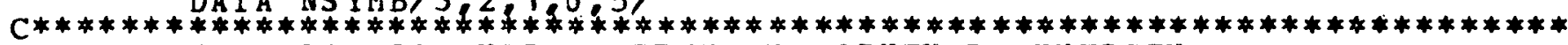
C THIS PROGRAM WAS HRITTEN BY HARVEY P. KNUDSEN.

C DEPARTHENT OP MINING E GEOLOGICAL ENGINEERING UNIVERSITY OF ARIZONA, TUCSON, ARIZONA. JOLY, 1976.

THE ORIGINAL' PQOGRAM WAS MODIFIED BY YOUNG C. KIM ON NOVEMBER 10, 1976 .

PROGRAM VARPLOT IS A CALCOMP PLOTTER PROGRAM FOR PLOTTING THE BXP ER IMENTAL VARIOGRAM VALUES IT IS CURRENTLY DIMENS IONED TO ACCBPT A TOTAL OF 20 DATA POINTS FOR A VAR IOGRAM. PRJ GRAM IS CAPABLE OP PLOTTING A MAXIMUM OF FIVE DIPPERENT VARIOGRAMS ON ONE GRAPH, AND OP PLOTTING A TOTAI OF FIFTEEN 115 DIFPERENT PLOTS DURING ONE RUN. IF DESIRED, A SPHERICAL VARIOGRAM MODEL CAN BE SUPERIMPOSED ON THE SAME GRAPH OR DRALY ON A NEH GRAPH, HONEVRR, NEITHEB THE TITLE NOB THE MODEL PABAAETE ARE SHOWN ON THE GRAPH.

\section{DEPINITION OP VARIABLES.}

$\begin{array}{ll}\text { PEN } & = \\ \text { INK } & =\text { SOLE OP INK PEN DESIRED (RECOMMEN DED SIZE }=0.3)\end{array}$

TOP

BบT

$=$ COLOR OF INK (RECOMMENDED CODE = O AT U. OF A.)

EAST

WEST

$X \mathrm{LEN}$

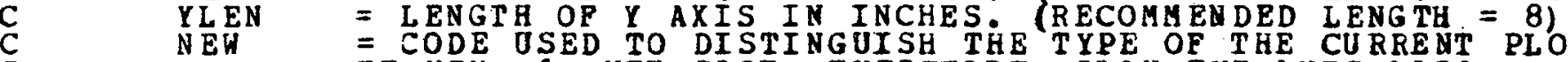

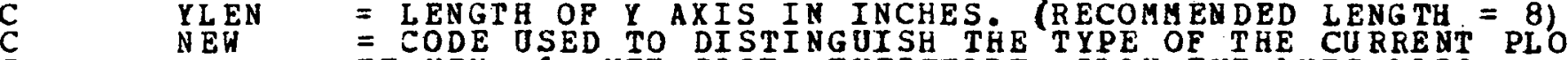

LO E

= VARIOGRAM VALUE AT BOTTOM OF GRAPH

= DISTANCE VALUE AT EAST EDGE OF GRAPH

$=$ DISTANCE VALUE AT WEST EDGE OF GRAPH

$=$ LENGIB OP X AXIS IN INCHES. (R ECOMMENDED LENGTH = 10

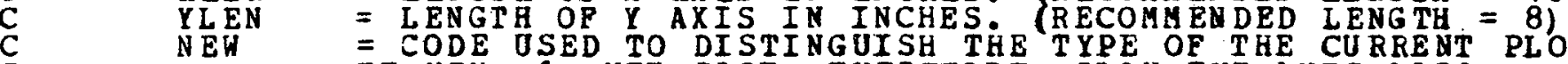

$\begin{array}{lll}C & \text { TITLE } \\ \text { C } & \text { ICK } & = \\ C & \text { NSY } & =\end{array}$

IF NEW $=1$, NEW PLOT THEREPORE, DRAH THE AXES ALSO.

IF NER $=2$; PLOT ON SAME GRAPH.

IP NEW $=3$, PLOT VARIOGRAH MODEL

TTE OF GRAPH

$=$ CODE USED TO CHECK IF THE AXES HAVE BEEN.DRAVN EARLI

$=$ INDEX USED TO SPECIPY THE TYPE OP SYHBOLS TO BE USED IT IS ALSO OSED TO CHECK THE TOTAL NUMBER. OP PLOTSO THE SAME GRAPH

NSYMB = ARRAY FOR STORING THE INDEX FOR SYMBOL CHARACTERS.

NPLOT = COUNTER POR THE TOTAL NUMBER OF GRAPHS BEING PLOTTBD

XMOVE = THE DISTANCE TO MOVE THEORIGIN ALONG X-AXIS POR NEU PLOT.

NPMAX = MAX. NUMBER OF TOTAL PLOTS ALLOHED DURING ONE RUN.

NSMAX = MAX. NOMBER OF PLOTS ALLOWED ITHIN ONE GRAPH.

NDMAX = MAX. NUHBER OP DATA POINTS CURRENTIY DIAENSIONED.

ANG

YIN D

SMEAN

$=$ DIRECTION IN HICH THE VARIOGRAH UAS COHPUTED.

VAR I

CLASS

DL 0 G

VN

DIS

= THE SPREAD OR THE HINDOH ALLOHED IN COHPUTATION

= SAMPLE HEAN OF ALI DATA POINTS

= SAMPLE VARIANCE OP ALL DATA POINTS.

= CLASS SIZE USED TO GROUP THE DATA POINTS.

= LOGARITHMIZ TRANSPORMATION OF DATA. YES OR NO.

= TOTAL NUMBER OF DATA POINTS.

= ARRAY USED POR VARIOGRAM VALUES.

$=$ ARRAY CONTAINING THE COKRESPONDING DISTANCES.

C* C***READ IN PLOTTER CONTROL CARD***

READ (INPT,5) PEN, INK,TOP,BOT, EAST, WEST, XLEN, YLEN 
70
$\vdots$
30
0170

01300

ก 1310

01320

C 1330

01340

01350

01360

01370

01380

0139 ก

01400

01410

01420

01430

01440

01450

07460

01470
01480

01490

01500

C1510

01520

01530

01540
$\cap 1550$

$012=0$

กิ:

01590

01600

01610

01620

01630

01640

ก 1659

01660

01670

01680

(1690

C 1700

61710

01720

ก 1730

01740

C 1750

(1760

C 1770

01780

C 1790

C 1800

C 1810

01820

01830

01840

C 1850
$\operatorname{DIS}(I+1)=$ WEST

IF $(N E$ EQRO 21 GO TO 34

CALL AXIS $(0,0.0,5$ HGAMMA, 5 YLEN, $90 \ldots V(I+1), V(I+2), 10.1)$

CALL AXIS $30,0,4$ HPEET, $-4, X L E N, 0:, 0 I S(I+1), D I S(I+2), 10)$

CALL PLOT (XLEN,0.0,3)

CALI PLOT XLEN,YLEN, 2)

CALL PLOT 0 , Y YEN, 21

C** DRAL LINES AND SYMBOLS OF VARIOGRAM VALUES.

34

IES EN EQ. 3$\}$ GO TO 40

CALL LINE(DIS, V.I, 1,1 , NSYMB (NSY))

NPLOT = NPLOT +1

IP (NPLOT.EQ.NPMAX) GO TO 210

C**\#RAD IN VARIOGRAM MODEL ASSUME a SPHERICAL VARIOGRAM MODEL.

C CO

$C=C$ VALOE

RANG = RANGE OF VAEIOGRAM

C** IP THERE IS AN ERROR IN INPUT DATA, SKIP PLOTTING THIS VABIOGBAM.

40 BEAD (IN PT, 45 ) $\triangle 0, C$, RANG

IF (EJP (INPT) ONE.0) GO TO 99

FORMAT $(3 \mathrm{~F} 15.0)$

SILL $=$ CO $+C$

IF (BANG. LT.J.J. OR. CO. IT.0.0) GO TO 230

IF SILL.GT.TOP.OR.RANG.GT.EAST) GO TO 230

$\mathrm{NINC}=15 * X \mathrm{~L} E \mathrm{~N}$

$\mathrm{X}=0.0$

$Y=(\dot{C} O-B O T) / D I P Y$

DALL 50 PLOT $(X, Y, Y, 3)$

$X=X+0.1$

$\mathrm{H}=X * \mathrm{D}$ IF $X$

IF (H.LT.RANG) GO TO 47

$\mathbf{G H}=\mathrm{C} 5+\mathrm{C}$

$47 \quad$ GHTO $=43+C *(1.5 * H / R A N G-.5 *(H / R A N G) * 3)$

$48 \quad \mathrm{Y}=(\mathrm{GH}-\mathrm{BOT}) / \mathrm{DIPY}$

CALL PLOT $(X, Y, 2)$

50 . CNTTNE

NPLOT $=$ NPLOT $\$ 1$

IP (NPLOT.EQ.NPMAX) GO TO 210

230 PORMAT $231 / 25 X 1)$, ERROR IN VARIOGRAM MODEL SPECIFICATION. IGNORE 1) TTING THE MODEL" $/ /$ ) GO TO 6

210 GORTE 211 TPR 2311 , TOTAL $N$, OF GRAPHS EXCEEDS THE MAXIMUM ALLONED 1 HENCE. PLOTTING I IS BEING TERMINATED. "I/)

220

990 WRITE TPR 202 200 OP PILE ENCOONTERED. ASSOME NORMAL END OF JOB. 212 END 
APPENDIX C

KRIGING PROGRAM "UKRIG" USER'S GUIDE 


\section{SI:C'IION I : PROGIRM IIDINTIFICA'IION}

1.1 PROGRM TITLE:

1.2 PROGRAM CODE NAME:

1.3 PROGRAM WRITER:

PROGRAM DOCUMENTATION: Young C. Kim

1.4 ORCANIZATION:

1.5 DATE:

1.6 UPDATES:

1.7 SOURCE LANGUAGE:

1.8 ABSTRACT:

UKRIG Version IV.
Kriging Program for Bedded Deposit

Harvey P. Knudsen

Department of Mining and Geological Engineering University of Arizona

Tucson, Arizona

November 3, 1976

None. Version: 1.

CDC 6400 Computer Systems - FORTRAN Extended -

This is a kriging program designed for bedded tabular deposits, such as roll-front type uranium deposits. Both the thickness and grade-thickness product are estimated by kriging, using user specified number of surrounding drill hole assay values. The variogram model used for kriging is assumed to be a spherical variogram.

Printed output from the program consists" of 1) parameter values used for the run, and 2) the kriged block values and associated kriging variances. The program also generates a data file containing the kriging results similar to those that are printed. 


\section{SECTION II: ENGINEERING DOCUMENTATION}

\subsection{NARRATIVE DESCRIPTION:}

Program UKRIG is a kriging program written in FORTRAN IV. It is designed especially for bedded tabular deposits such as roll-front type uranium deposits. For each user specified block, the thickness of ore and the grade thickness product are estimated by kriging using a specified number of drill holes near the block center.

The variogram model used for kriging is assumed to be a spherical variogram. It is also assumed that any anisotropy present is of the simple geometric type. Hence only the range (a), nugget effect $\left(C_{0}\right), C$ value (c), horizontal anisotropy factor (AFH), vertical anisotropy factor (AFV) and the anisotropy angle (ANG) are read into the program.

The horizontal anisotropy factor is defined as the maximum range of influence divided by the minimum range of influence in the horizontal plane. The anisotropy angle (ANG) is measured in degrees from E-W direction to the major axis (i.e., maximum range of influence). The angle is positive if it is measured in counterclock direction. It is negative, otherwise. The vertical anisotropy factor is the maximm range of influence in the horizontal plane divided by the vertical range of influence.

If three-dimensional instead of two-dimensional kriging is desired, it can be accomplished by specifying a nonzero value for the vertical anisotropy factor. If this factor is zero, then two-dimensional kriging is performed.

The program is modularized so that the basic mechanics of the kriging computations, are performed in subroutine KRIG, which is readily adaptable 
to any other driving (or main) program.

Printed output from the program consists of 1) parameter values used for the run, and 2) the kriged block values and associated kriging variances. The program also generates a data file containing the kriging results similar to those that are printed.

If debug option switch is on, additional information is printed during the program run. Similarly, the entire input data assays are printed if list option switch is on.

\subsection{PETHOD OF SOLUTION:}

The theoretical basis of kriging procedure is not discussed here. Instead the reader is referred to other suitable references or to Chapter 4 of this report.

Since kriging is an extension procedure which provides an unbiased estimate having the least extension error, the objective of kriging is to find the appropriate weights to use in extending the assays of the surrounding holes to the block. Mathematically, the extension error is defined as follows:

$$
\sigma_{E}^{2}=\sigma_{K}^{2}=\sigma_{v}^{2}-2 \sum_{i=1}^{N} \lambda_{i} \sigma_{v x_{i}}+\sum_{i=1}^{N} \sum_{j=1}^{N} \lambda_{i} \lambda_{j} \sigma_{x_{i}} x_{j}
$$

Equation (1) above is a quadratic equation having $N$ variahles, i.e., $\lambda_{1}, \lambda_{2} \ldots, \lambda_{n}$. Here, the value $N$ is equal to the number of data points to be used in kriging and $\lambda_{i}$ 's are the variables of interest, i.e., the kriging weights . 
The first term $\sigma_{\mathrm{E}}^{2}$ in Equation (1) is the block variance* within the deposit. Naturally, there is a unique block variance for a given size block in a given deposit. Consequently, one needs to compute the block variance only once during kriging operation.

The second term in Equation (I) is the covariance between the current block and the $\mathrm{i}$-th data point. This covariance must be computed for all $\mathrm{N}$ data points for the current block. The process must be repeated for all blocks to be computed.

Similarly, the third term in Equation (1) represents the covariance between two data points, i.e., $x_{i}$ and $x_{j}$, and must be computed for all $N$ data points and for a11 blocks.

In the program, a maximm number of data points to be used is specified by the user, and a search is made within a prespecified radius of search from the center of the current block. Consequently, the actual number, i.e., $\mathrm{N}$ can vary between block to block depending on whether or not enough data points have been found during this search. If less than two (2) data points are found for the current block, then the block is not kriged. Instead, the program proceeds to the next block.

In attempting to minimize the extension error given in Equation (1), there is however a constraint regarding the kriging weights, $\lambda_{i}$ 's. The constraint is that the sum of these weights adds up to 1, as given in Equation (2) below.

$$
\sum_{i=1}^{N} \lambda_{i}=1
$$

*Assume one divides the lentire deposit into blocks of a given size. Then the block variance is the variance of these block grades. 
Consequently, the kriging problem now becomes the constrained optimization problem of $\mathrm{N}$ variables. This constrained optimization problem is solved using the method of Lagrange multiplier, as discussed in Chapter 4.3 of this report.

Next, the actual mechanics of computational steps used in the program is described briefly. After reading in the necessary run parameters such as the area definition, variogram values, anisotropy factors, the program first computes the block variance $\left(\sigma_{\mathrm{v}}^{2}\right)$ for the specified block size. This computation is accomplished in SUBROUTINE BLOCK and it is performed only once during the run.

Afterwards, kriging of each block commences row by row, starting from the N-W corner of the area. To krig a block, the user specified number of holes located nearest to the current block is first determined, by searching within some maximum search radius.

The obtained holes are then used to krig the block by calling SUBROUTINE KRIG, which in turn calls other appropriate subroutines for computing the covariance between a hole and the block $\left(\sigma_{\mathrm{vx}}\right)$ as well as covariance between two samples $\left(\sigma_{x_{i} x_{j}}\right) \cdot$

SUBROUTINE COVAR determines the covariance between a hole and the block, whereas the covariance between two samples is directly obtained by the difference in the variogram values from SUBROIJINE SUBGAM.

Finally, a set of simultaneous linear equations are solved for the kriging weights to be used for the current block in SUBROUTINE FINDT. The method of solution used here is the Gaussian Elimination Technique.

In computing the block variance as well as the covariance between a point and the block, a total of. 16, equally spaced points within the block is 
used to approximate the total area of integration.

The method of solution is summarized in Figure 1.

\subsection{PROGRAM CAPABILITIES:}

Program UKRIG is currently dimensioned to handle up to 500 assay data points. If there are more data points, only the first 500 data points are used for kriging. A message is printed out and the remaining data points are ignored.

These assay data points are read under the user specified format. The following information for each assay data is assumed to be read into the program during execution, under the variable names given below. A data point is assumed to be given as one record or one data card.

a) Hole identification under HOLID(I).

b) $X, Y$, and $Z$ coordinates of data point location under $X E(I), Y N(I), Z L(I)$.

c) Three values, such as grade, thickness and $G-T$, under $\mathrm{GD}(\mathrm{I}, \mathrm{J}), \mathrm{J}=1,2,3$.

In kriging a block, a maximm of fifty (50) surrounding assay data points can be used. However, between 10 to 20 points are sufficient for all practical purposes.

The program assumes that the variogram model used for kriging is a spherical variogram. However, any other variogram model can be used by modifying one subroutine called SUBGAM. The same variable arrays used to store the coefficients of a spherical variogram model can be used to store other variogram model coefficients.

Since a block is kriged one at a time and the results are printed as well as stored on a data file, there is no limit as to the number of blocks that can be kriged at one run. The program krigs both thickness and grade-thickness. 


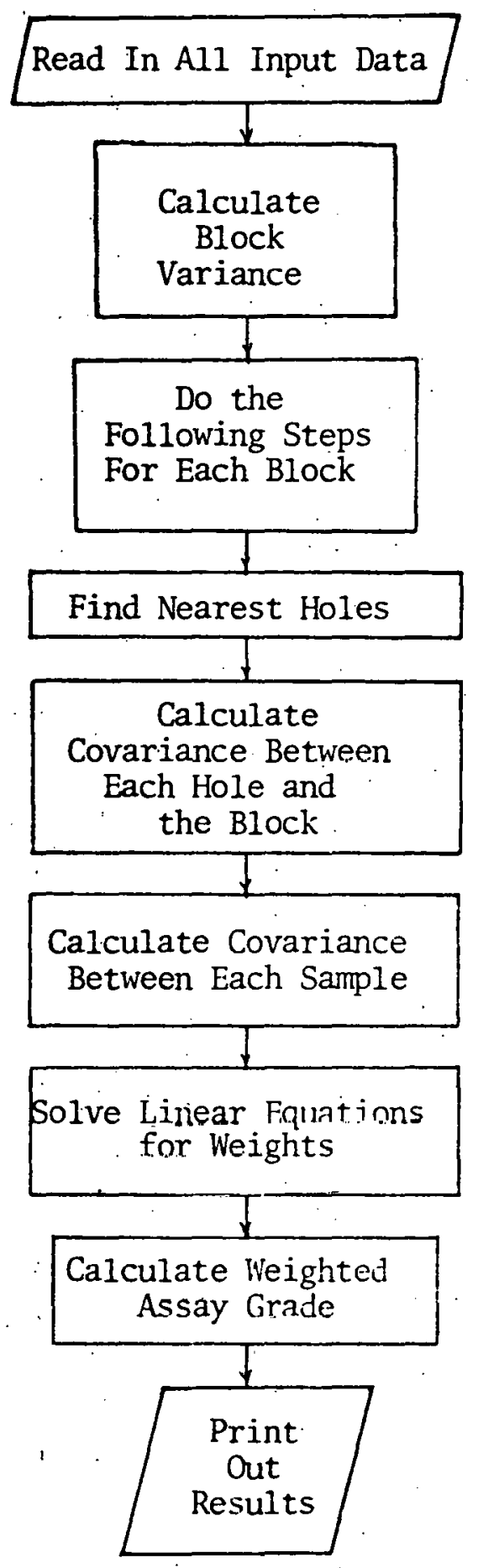

Figure 1

METHOD OF SOLUTION SUMMARY

C-7 
2.4 DATA INPUTS:

The following describes the data inputs:

INPUT CARDS

$\underline{\text { COLUMN }} \begin{aligned} & \text { VARIABLE } \\ & \text { NAME }\end{aligned}$

CARD ONE. DEFINITION OF AREA TO BE KRIGED

$\begin{array}{rll}1-5 & \text { NBC } & \text { STARTING COLUMN } \\ 6-10 & \text { NEC } & \text { ENDING COLUMN } \\ 11-15 & \text { NBR. } & \text { STARTING ROW } \\ 16-20 & \text { NER } & \text { ENDING ROW } \\ 21-30 & \text { YMAX } & \text { MAXIMUM NORTHING (ROW 1) } \\ 31-40 & \text { XMIN } & \text { MINIMUM EASTING (COL 1) } \\ 41-50 & \text { WIDY } & \text { BLOCK WIDTH IN NORTH DIRECTION } \\ 51-60 & \text { WIDX } & \text { BLOCK WIDTH IN EAST DIRECTION }\end{array}$

CARD TWO. HOLE ACCEPTANCE AND DEBUGGING PARAMETERS

$\begin{array}{ccl}1-5 & \text { RMAX } & \text { MAXIMUM DISTANCE FROM BLOCK FOR HOLE TO BE } \\ 6-10 & \text { NK } & \begin{array}{l}\text { INCLUDFD IN KRIGING } \\ \text { MAXIMUM NLMBER OF HOLES TO BE USED FOR EACH }\end{array} \\ 11 & \text { BLOCK. MUST BE LESS THAN OR EQUAL TO 50 } \\ 12 & \text { ILIST } & \begin{array}{l}\text { DEBUG (1=YES, O=NO) } \\ \text { LIST DRILL HOLES . (1=YES, } 0=\mathrm{NO})\end{array}\end{array}$

CARD THREE. VARIOGRAM PARAMETERS FOR GRADE X THICKNESS.

\begin{tabular}{|c|c|c|}
\hline $1-10$ & $\mathrm{CO}$ & NUGGET VALUE \\
\hline $11-20$ & $\mathrm{C}$ & C VALIJE OF VARIOGRAM \\
\hline $21-30$ & RANG & RANGE OP VARIOGRAM \\
\hline $31-40$ & ANG & $\begin{array}{l}\text { ANGLE OF ANISOTROPY IN DEGREES FROM X-AXIS } \\
\text { TO THE MAJOR. AXIS. THE ANGLE IS PLUS IF } \\
\text { COUNTERCLOCKWISE, MINUS IF. CLOCKWISE. }\end{array}$ \\
\hline $41-50$ & AFH & $\begin{array}{l}\text { HORIZONTAL ANISOTROPY FACTOR (MAJOR AXIS } \\
\text { OVER MINOR AXIS) }\end{array}$ \\
\hline $51-50$ & AFV & $\begin{array}{l}\text { VERTICAL ANISOTROPY FACTOR (SET EQUAL TO } 0 \\
\text { FOR BEDDED DEPOSITS, I.E. FOR 2-DIMENSIONAL } \\
\text { KRIGING) }\end{array}$ \\
\hline
\end{tabular}

CARD FOUR. VARIOGRAM PARAMETERS FOR THICKNESS. USE SAME FORMAT AS CARD THREE

DATA CARDS

CARD ONE. VARIABLE FORMAT CARD TO READ IN SUUBSEQUUENT ASSAY DATA CARD TWO \& ON:

$\begin{array}{cl}\text { HOLID } & \text { HOLE IDENTIFIC } \\ \text { XE } & \text { X-COORDION NAME . } \\ \text { YN } & \text { Y-COORDINATE OF THE DATA POINT. (N-S) } \\ \text { XL } & \text { Z-COORDINATE OR ELEVATION OF DATA POINT. } \\ \text { GD } & \text { ARRAY CONTAINING THREE } \Lambda \text { SS } \Lambda Y \text { VNLUES. }\end{array}$

THE ABOVE INFORMATION REGARDING A DATA POINT MUST BE GIVEN AS ONE RECORD OR ONE DATA CARD. 
A sample 80-80 1isting of input data is given in Figure 2.

\subsection{PROGRAM OPTIONS:}

There are three program options. Extreme care in the use of these options is strongly emphasized because of the voluminous printed output and potential mistake in 3-D kriging.

1. Debug Option - If the debug option switch (IDBUG) is on during the program execution, the following additional information is printed for the prespecified number of blocks (MAXPR).

a) augmented matrix value elements.

b) the holes used to krig each block.

2. List Option - If this switch (ILIST) is on, the entire drill hole assay data are listed prior to performing kriging computation.

3. Three (3) Dimensional Kriging - The program is capable of performing 3-D kriging, although most bedded deposits are more amenable to 2-D kriging. For kriging in 3-dimensions, the vertical anisotropy factor (AFV) must have some positive value. In addition, the value of B(3) array must be initialized to some datum plane (see line 1460 in the source program listing given at the end of this user's guide).

2.6 OUTPUT:

Figure 3 shows a typical printed output. This output is obtained after setting both the debug and list option switches to zero, i.e., off position.

Figure 4 shows an 80-80 listing of the created data file which contains the kriged results of each block. 


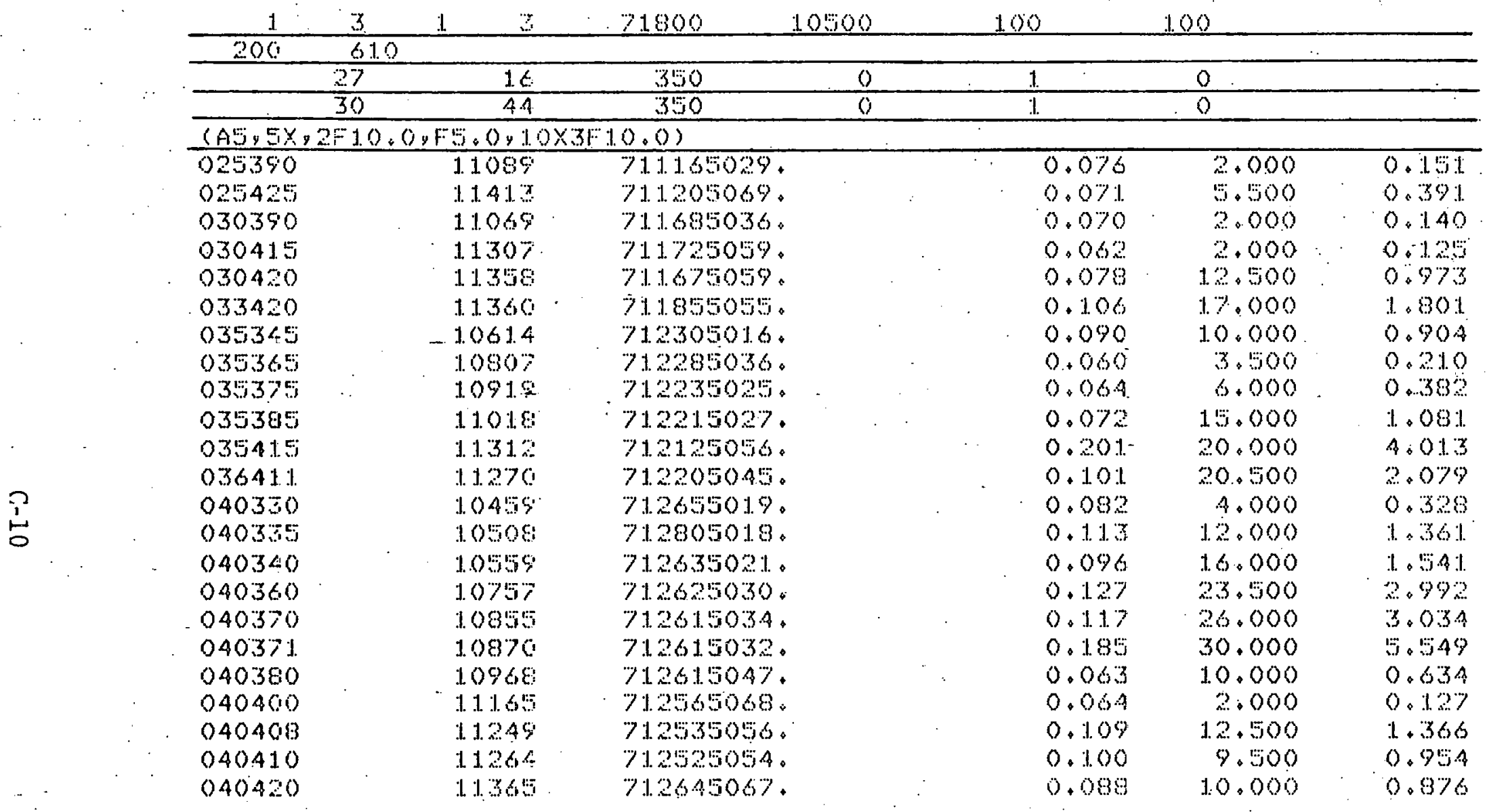

Figure 2

SAMPLE 80-80 LISTING OF INPUT DATA 


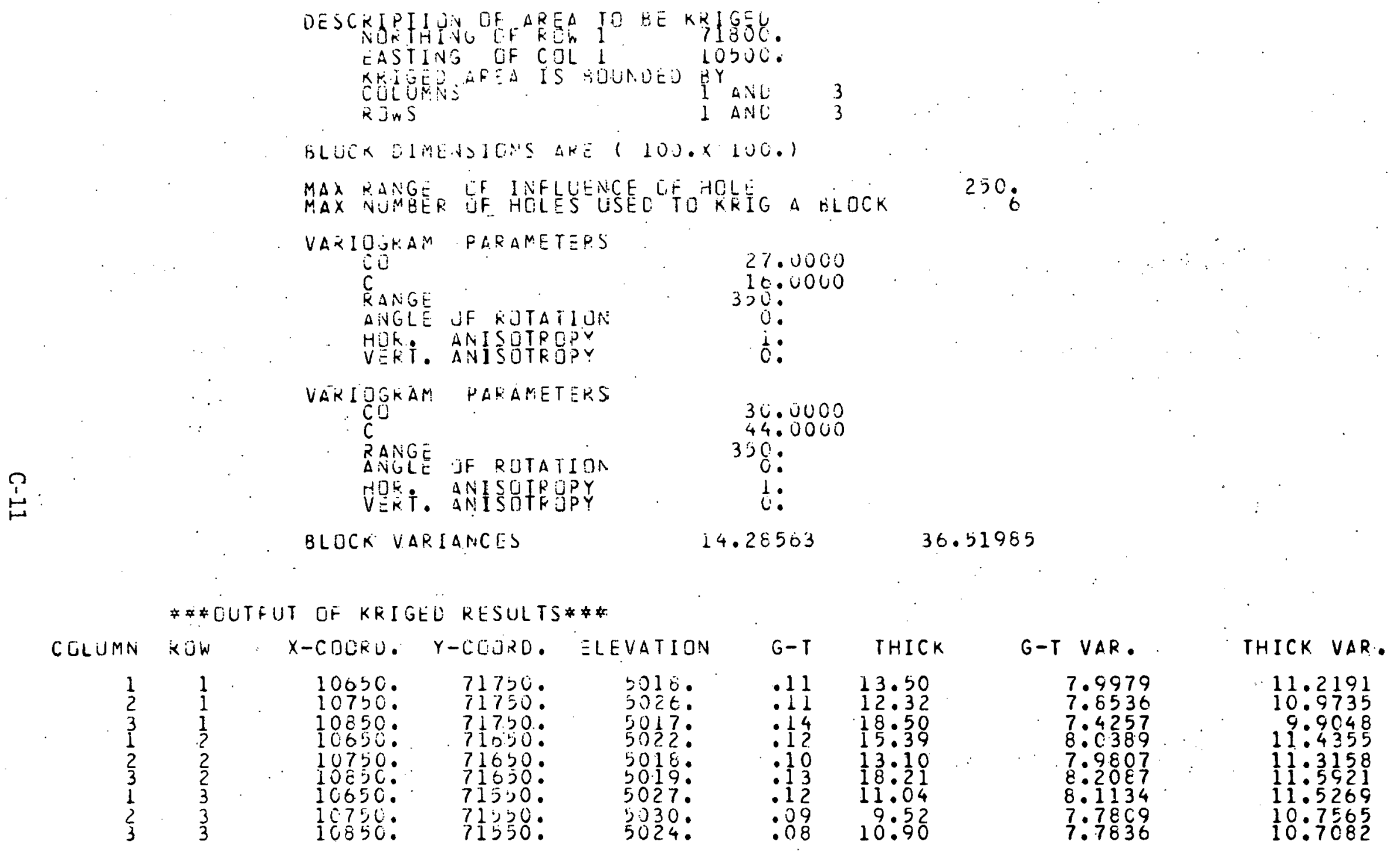

Figure 3 


\begin{tabular}{|c|c|c|c|c|c|c|}
\hline $\begin{array}{l}10.650 \\
10750 \\
10850 \\
10650 \\
10750 . \\
10850 \\
10650 \\
10750 \\
10850 .\end{array}$ & $\begin{array}{l}71750.518 . \\
71750.5026 . \\
71750.5017 . \\
71650.5022 . \\
71650.5018 . \\
71650.5019 . \\
71550.5027 . \\
71550.5030 . \\
71550.5024 .\end{array}$ & $\begin{array}{l}.1121 \mathrm{E}+00 \\
.1078 \mathrm{E}+00 \\
.1377 \mathrm{E}+00 \\
.1162 \mathrm{E}+00 \\
.1140 \mathrm{E}+00 \\
.13 \mathrm{C} 1 \mathrm{E}+00 \\
.1195 \mathrm{E}+00 \\
.9341 \mathrm{E}-01 \\
.8169 \mathrm{E}-01\end{array}$ & $\begin{array}{l}.1350 E+C 2 \\
.1232 E+02 \\
.1850 E+02 \\
.1539 E+02 \\
.1310 E+C 2 \\
.1821 E+02 \\
.1104 E+C 2 \\
.9523 E+C 1 \\
.1090 E+C 2\end{array}$ & $\begin{array}{l}.8298 E-02 \\
.8748 E-C 2 \\
.7445 E-02 \\
.7553 E-02 \\
.7941 E-02 \\
.7141 E-02 \\
.1082 E-01 \\
.9809 E-02 \\
.7496 E-02\end{array}$ & $\begin{array}{l}.7998 E+C 1 \\
.7854 E+C 1 \\
.7426 E+C 1 \\
.8039 E+01 \\
.7981 E+C 1 \\
.8209 E+C 1 \\
.8113 E+01 \\
.7781 E+01 \\
.7784 E+C 1\end{array}$ & $\begin{array}{l}.1122 E+02 \\
.1097 E+02 \\
9905 E+01 \\
11144 E+C 2 \\
.1132 E+02 \\
11159 E+02 \\
.1153 E+02 \\
.1076 E+02 \\
.1071 E+02\end{array}$ \\
\hline
\end{tabular}

Figure 4 


\section{SECTION III: SYSTEM DOCUMENTATION}

\subsection{COMPUTER ENUIPMENT:}

The UKRIG program was run on a CDC 6400 computer using 60K-core central memory.

\subsection{PERIPHERAL EQUIPMENT:}

The following peripheral equipment was used in the execution of the UKRIG program:

$$
\begin{aligned}
& \text { CDC } 405 \text { card reader } \\
& \text { CDC } 512 \text { line printer }
\end{aligned}
$$

\subsection{SOURCE PROGRAM:}

A source program listing is given at the end of this user's guide.

\subsection{VARIABLES AND SUBROUTINES:}

A listing of all major variables is given in Figure 5.

Program UKRIG consists of the following subroutines:

1. UKRIG: Main program which reads input data, controls the kriging operation, and outputs the results.

2. KRIG: Performs the basic mechanics of kriging computations by sequentially calling other supporting subroutines.

3. BLOCK: Computes the block variance for a given size block in the deposit.'

4. COVAR: Computes the covariance between a hole and a block.

5. SUBGAM: Computes the variogram value for a given distance.

6. FINIT: Solves a set of simultaneous linear equations using the Gaussian elimination technique.

7. DSORT: Sorts the selected drill hole assays into increasing order of distance. 


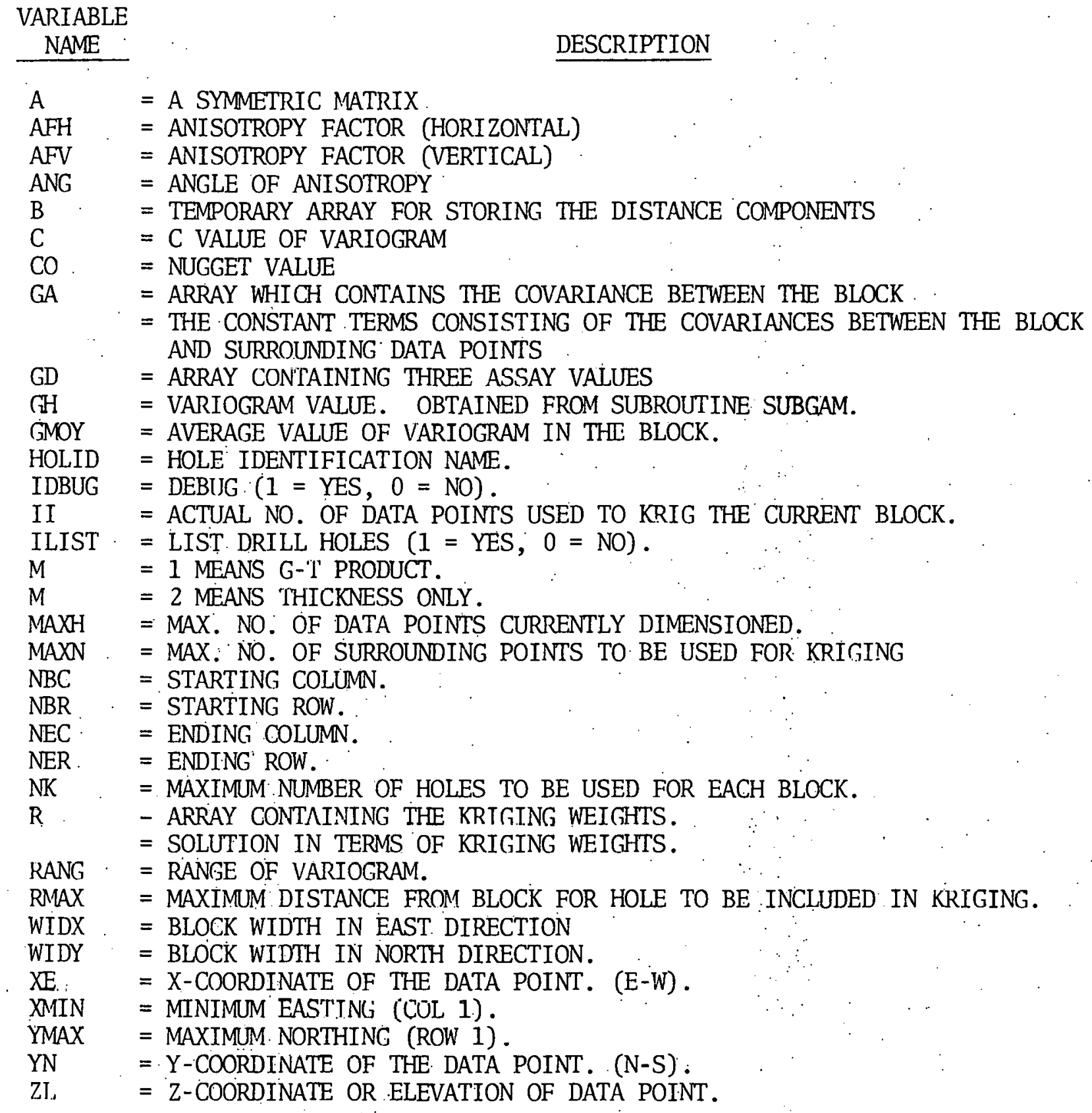

Figure 5

LISTING OF ALL MAJOR VARIABLES 
3.5 DATA STRUCTURES:

A data file containing the kriged results is generated on system logical unit device \#5. Structure of this data file is shown in Figure 4. Each record contains $X$ and $Y$ coordinates of the block, the elevation of the first data point, computed grade-thickness, thickness and grade of the block, and kriging variances.

3.6 STORAGE RERUIREMENTS:

As presently structured, program UKRIG requires approximately $60 \mathrm{~K}$ storage on the $\operatorname{CDC} 6400$.

3.7 MAINTENANCE AND UPDATES:

None to date. 


\section{SECTION IV: OPERATING DOCUMENTATION}

4.1 OPERATING INSTRUCTIONS:

Program UKRIG is operated under the CDC 6400, SCOPE 3.4, operating system.

4.2 OPERATING MESSACES:

Error messages produced by the program are self-explanatory. In addition, normal system messages are produced.

\subsection{CONTROL CARDS:}

The program may be executed with standard SCOPE 3.4 control cards. As mun on the University of Arizona $\operatorname{CDC} 6400$, the makeup of the input deck is as follows:

Job Card
FTN.
LGO
$7 / 8 / 9$
r.SOURCE PROGRAM>
7/8/9
<INPUT DATA>
$6 / 7 / 8 / 9$

1.4 ERROR RFCOVERY:

If certain errors occur, the program will make assumptions and continue execution of the program. A warning message will be printed. If a fatal error occurs in execution, the program must be restarted.

4.5 RUN TIME:

Run time depends on number of holes selected for kriging a block and the number of blocks to be kriged. Typical run time is about 20 to 50 seconds for kriging a medium size open-pit bench area.

$1 \cdot C-16$


UKRIG PROGRAM LISTING

1 
Y0.0 10

00030

Onoun

Cno 50

50060

00070

0008 ก

$\cos 90$

00100

oc 110

กत120

oc $13 n$

rc 140

กก1 150

Co 160

or 170

no18n

OC190

กó 2 ก́n

CO210

0,0220

cin 230

00240

C:0250

ic 260

Cत 270

ro2 80

กत290

तc 300

rर 320

nत 330

r. 340

$\therefore 0350$

r:c 360

C 370

0
-3
0

crouon

rnutn

$\therefore 420$

00430

(n4 4 .

r. 450

वियदि

r. 470

Cr.48

rre 49 n

rison

risin

ros $2 n$

Cत5 4n

$\because 050$

त 56 .

r $(57)$

- C580

0590

rre

in 630

PROGRAB OKRIG (INPOT, OUTPUT, PUNCA, TAPE1=INPUT, TAPE3=OUT PUT, 1 TAPE5

COMMON /SYS/IPT, IOOT, IPR, IDBUG, IDPR, MAXPR

COMMON /BLK/WX2, WY $2,4 \times 4,4 Y 4, W X 8, W Y 8$

COMMON /GAM/CO (2) C'(2) RANG (2) CST(2),SIT (2),APH (2),ARV (2)

COMMON /KRG/IHOL (51) GA (51) R (51)

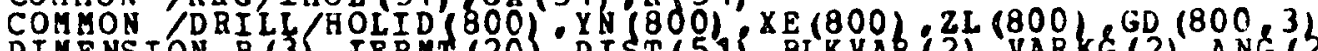

DIMENSION B (3), IFRMI (20):DIST (51), BLK VAR (2), VARK $(2)$, ANG (2)

DIMENSION GR (2)

DATA MAXH MAXK, MAXPR IDPR/800,50,5, C/

DATA IPT, IOUT, IPR $/ 1,5,3 /$

THIS PROGRAM. HAS WRITTEN BY HARVEY PP RNUDSEN.

UNI VERS ITY OF ARIZONA TUCSON, ARIZONA.

PROGRAM UKRIG IS' A RRIGING PROGRAM DESIGNED POR BEDDED

TABULAR DEPOSITS. BOTH THE THICKNESS AND GRADE-THICKNESS

PRODOCT ARE KRIGED.

THIS PROGRAM ASSUMES THAT THE VARIOGRAM MODEL POR KRIGING

IS A SPHERICAL VARIOGRAM.

PROGRAM OKRIG IS PRESENTLY DIMENSIONED TO ACCEPT UP TO

50 ASSAT VALUES.

DESCR IPTION OP INPUT CARDS

CARD ONE. DEFINITION OF AREA TO BF KRIGED. COL.

$6-19 \quad$ NEC ENDING COLUMN

11-15 NBR STARTING ROH

$16-25$ NER ENDING ROE

$21-30$ YMAX MAXIMUM NORTHING (ROH 1)

$31-45$ XMIN MINIMUM EASTING (COL 1)

$41-55$ HIDY BIOCK HIDTH IN NORTH DIRECTION

$51-60$ HIDX BLOCK HIDTH IN EAST.DIRECTION

CARD THO, HOLE ACCEPT ANCE AND DEBUGGING PAEAMETEKS RAX G

$6-10$ NK HOLETO BE INCLUDED IN KRIG ING

USED FOR EACH BLOCK. MUST BE LESS THAN OR EOUAL TO 50 .

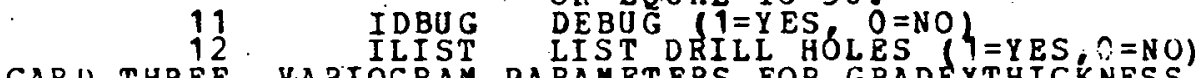

CARD THREE. VARIOGRAM PARAMETERS FOR GRADEXTHICKNESS

COL 1.15 CO NUGGET VALOE

$\begin{array}{lll}11-20 & C & C V A L U E \text { OP VARIOGRAM } \\ 21-30 & \text { RANG } & \text { RANGE OF VARIOGRAM }\end{array}$

ANGLE OP ANISOTROPY IN DEGREES FROM

$X$-AXIS TO THE MAJOR AXIS. THE ANGLE IS PLUS IF COUNTERCLOCKWISE; MINUS IF CLOCK

41-41 APH

- WISE.

$51-5 C \quad A F V$

HORIZONTAL ANISOTROPY FACTOR (MAJUK AXIS OVER MINOR. AXIS

VERTICAL AN ISOT ROPY PACTOR

(SET EQUAL TO O FOK BEDDED DEPOSITS,I.E.

CARD FOUR, VARIOGRAM PARAMETERS FOR THICKN ESS

USE SAME FORMAT AS CARD THREE

DATA CARDS

CARD ONE. VARIABLE PORMAT CARD TO READ IN SUBSEQUENT ASSAY DATA CARD TWO E ON : 


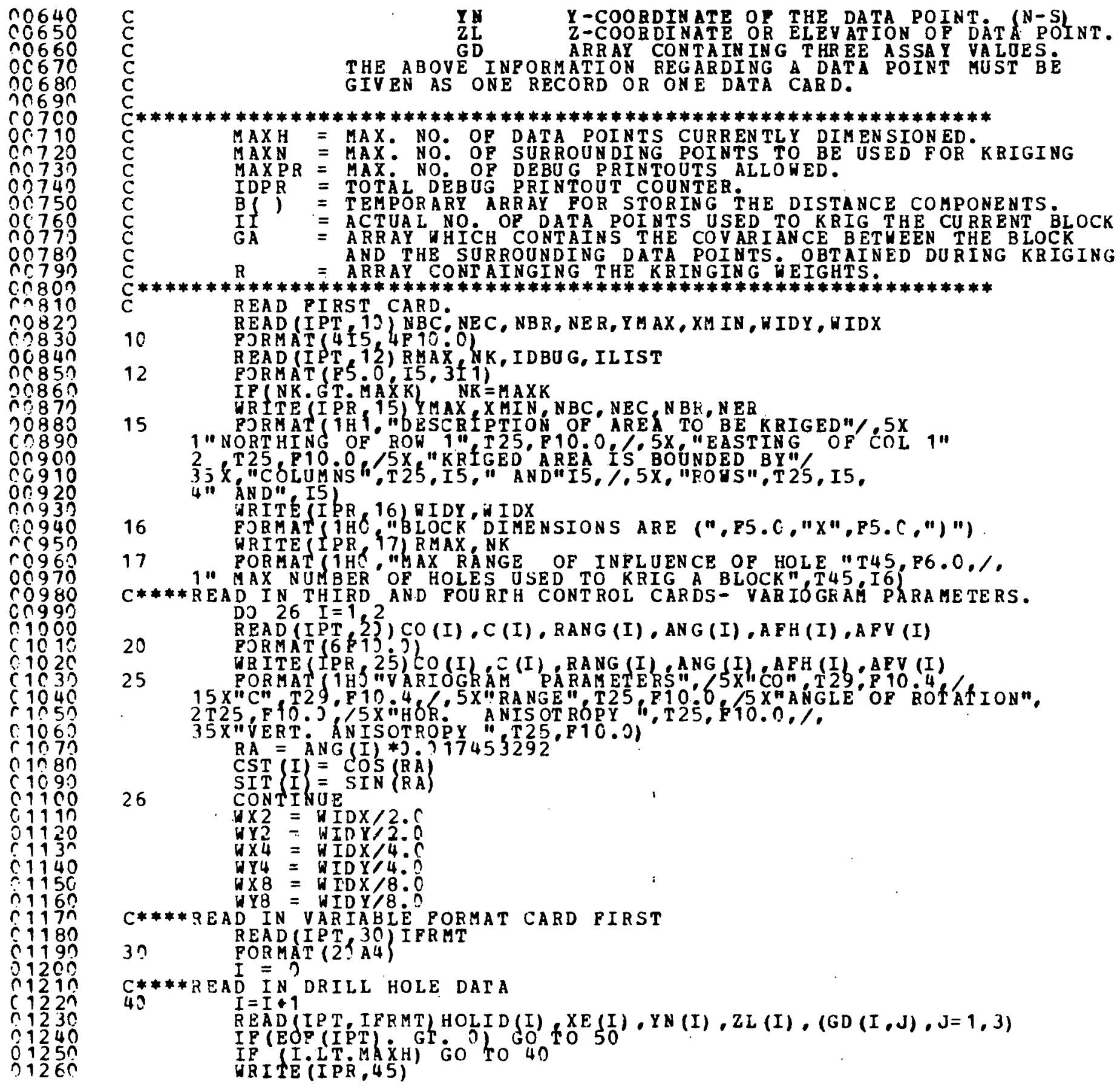




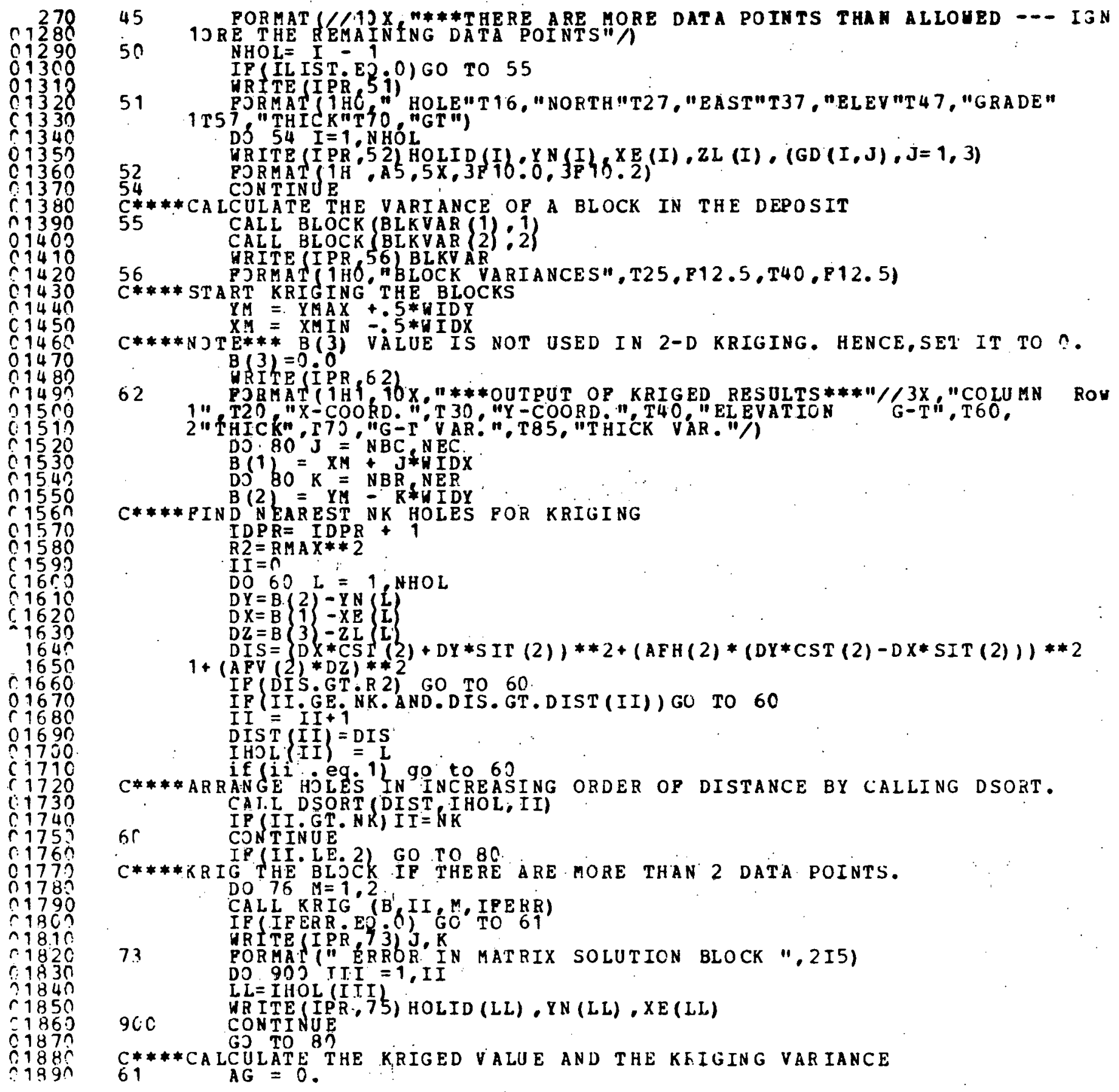


ก1900

ก1910

01920

C1930

01940

ก1950

ก1960

ก1970

त1980

C 1990

c 2000

C20 10

त2020

02030

02040

$\bigcirc 2050$

ก 20

त 2080

C 2090

ก2100

C2120

ก214n

ก. 2150

C2160

त217n

02180

ก2190

C 2200

C.2210

ก 22230

त2240

ก2 50

ก2260

○2270

广2 280

C.229

ก2300

ก 2310

○2 320

02339

C2340

C2350

j236n

r:2370

C 2380

c239n

C240n

02412

ก 2420

त243n

C. 2440

त2 450

ก2460

C 2470

ก 248 ?

(.2 2490

02530

ก251?

65

GR ( $)=3$ I

$1 \mathrm{~T} 52$ "UEIGHT

Dó $70 \mathrm{~L}=1, I I$

L. $\mathrm{L}=$ IHOL (L)

$A G=A G+G A(L) * R(L)$

$G R(M)=G R(H)+G D(L L, M) * R(L)$

IP IbBUG. GE. 1. AND. IbPG. LT. AXPB) URITE (IPB, 75) HOLID (LL), YN (LL).

75. 1XE(LL) FORLAT $\left\{\begin{array}{l}\mathrm{LL}) \\ 7 \mathrm{C}\end{array}\right.$

VARKG (H)=BLKVAR (H)-AG-R (II+1)

76.

CONTINUE

C****NOTE***FOR 2-D KRIGING, THE ELBVATION OF ORE IN THE NEAREST HOLE

IS ASSIGNBD TO THE BLOCK.

$K K=I H O L L\left(\begin{array}{c}1 \\ K K\end{array}\right.$

ELEV =ZL

81

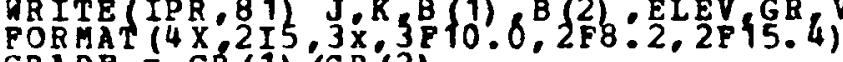

GRADE = GR (1L KR $(2)$

78
80

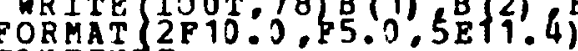

CONTINDE

STOP

EN D

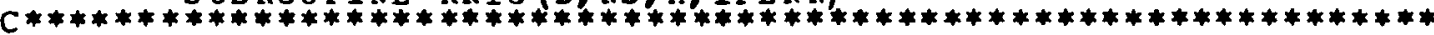

THIS SUBROUTINE PERFORMS TRE BASIC MECHANICS OF KRIGING

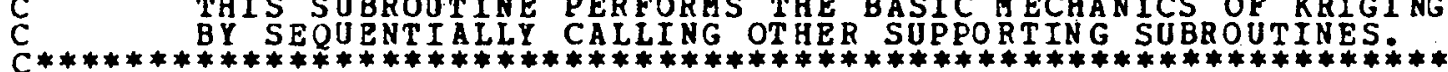

COMHON /S YS/IPT, IOUT, IPR IDBUG IDPR, MAXPR

COMMON /KRG/IHOE ( 51$)$ GA ( 5 T) R R 51$)$

COMMON /DRILL/HOLID $(800)$, Y Y (800), XE $(800), \mathrm{ZL}(800), \mathrm{GD}(800,3)$

CUMMON /GAM/CO (2) C 2) RANG (2),CST(2),SIT (2),ABH(2),APV (2)

C** CALCULATE COVARIANCES ( Nb. SET-UP MATRIX FOR SIHOLTANEOUS EQUATION:

C

$R \quad=$ SOLUTION IN TERMS OP KRIGING HEIGHTS.

GA. = THE CONSTANT TERMS CONSISTING OF THE COVARIANCES BETWEEN

THE BLOCK AND SURROUNDING DATA POINTS.

GH = VARIOGRAY VALUE. OBTAINED PROM SUROUTINE SUBGAM.

GMJY = AVERAGE VALUE OF VARIOGRAM IN THE BLOCK.

DO $15 K=1, N S$

$\mathrm{KK}=I$ HO L $(\mathrm{K})$

P1 11$)=$ XE (KK)

$\mathrm{P} 1\} 2\}=Y \mathrm{~N}\left\{\begin{array}{l}\mathrm{K} K \\ \mathrm{~K} K\end{array}\right.$

P1. $\{3\}=Z L\{K K\}$

$K 1=K+1$

C****COMPUTE COVARIANCE BETHEEN THE CURRENT HOLE AND OTHER HOLES. IF (K1.GT.NS) GO TO 11

DO $13 \mathrm{~L}=\mathrm{K} 1 \mathrm{NS}$

LL $=$ IHOL (L)

P2 $(1)=X E(L)$

P2 $\left\{\begin{array}{l}2 \\ \text { P }\end{array}\right\}=$ Y L L L L

CALL SU BGAM (P 1, P 2, GH, M)

$A(K, L)=C O(M)+C J M)-G H$

$10 \quad$ CONTTUE

C* * * CDMPUTE CJVARIANCE BETHEEN THE CURRENT HOLE AND THE BLOCK.

11

CALL $(K)=L_{A R}\left(B, b 1, G M C_{Y}, M\right)$ 


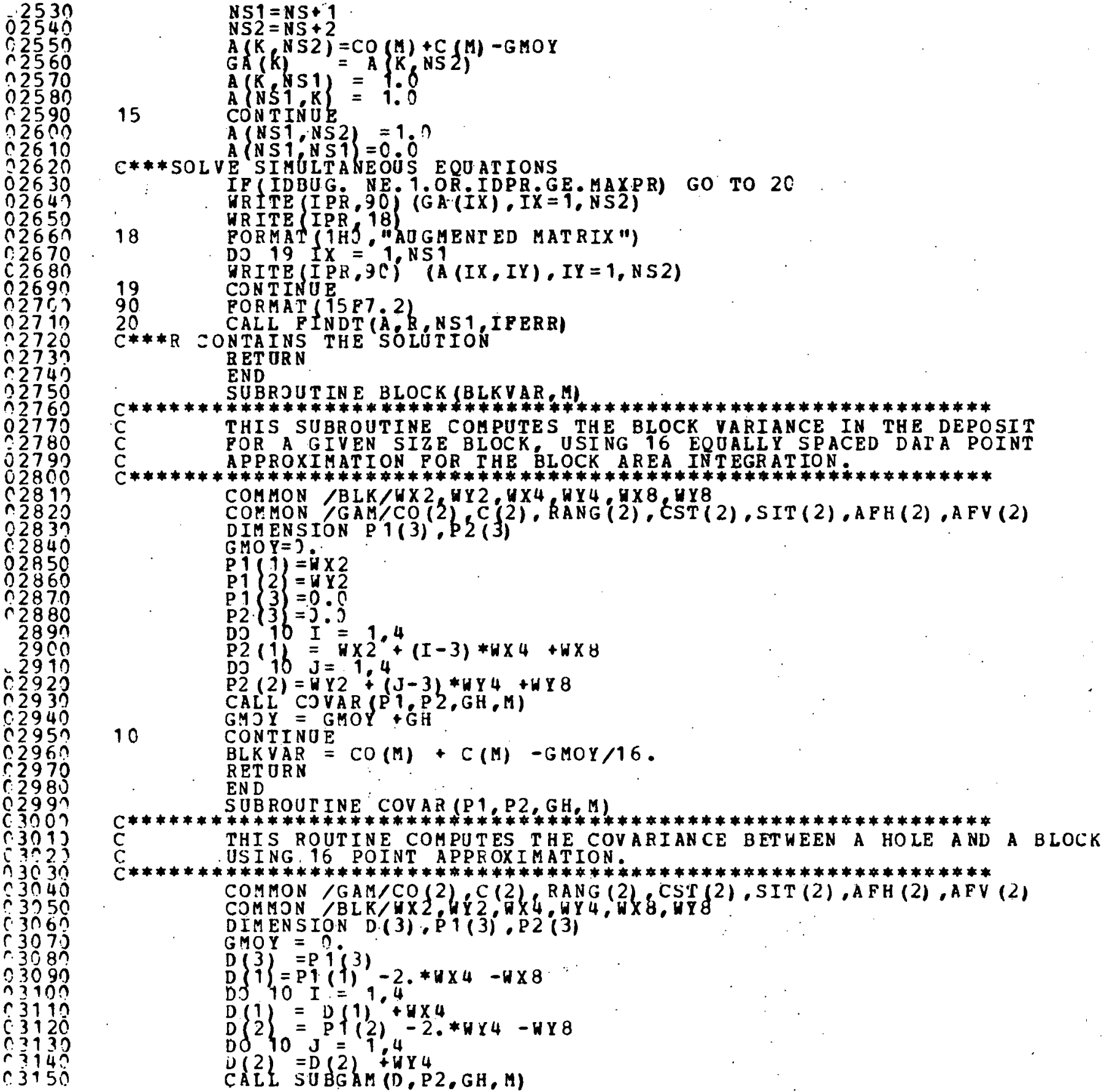




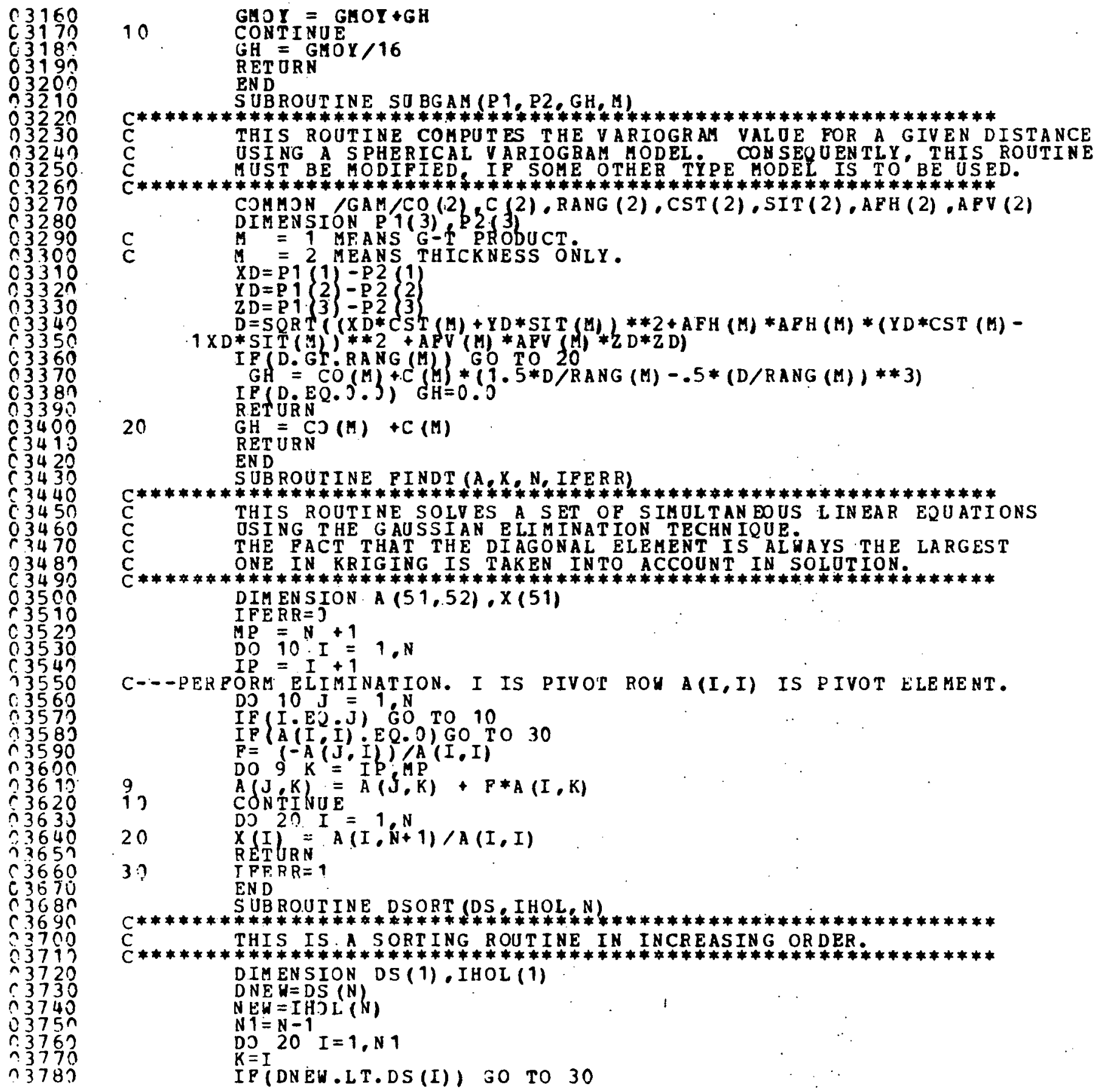


APPENDIX D

MAP CREATION PROGRAM "MAP"

USER'S GUIDE 


\section{SECTION I: PROGRAM IDENTIFICATION}

\subsection{PROGRAM TITLE: Program To Create A Map Of Block Values}

\subsection{PROGRAM CODE NAME: MAP}

\subsection{PROGRAM WRITER: Harvey P. Knudsen}

1.4 ORGANIZATION: - Department of Mining and Geological Engineering Universi.ty of Arizona

Tucson, Arizona

1.5 DATE: November 20, 1976

1.6 UPDATES: None.

1.7 SOURCE LANGUAGE: CDC 6400 Computer Systems - FORTRAN Extended Version IV.

\subsection{ABSTRACT:}

This program creates a plan map of block values on the line printer. The block values can be the estimated grades by kriging or by other extension methods. Or, they can be any other attributes such as thickness, $\mathrm{G}-\mathrm{T}$, etc.

The size of a block on the printed map is $1 / 2$ inch square, although the actual block need not be a square block. If the true size of the block is $100 \mathrm{ft}$. by $100 \mathrm{ft}$., the printed map will have a scale of 1 inch to $200 \mathrm{ft}$.

This program must be executed with a line printer capable of printing eight (8) lines per inch, in order to obtain $1 / 2$ inch square blocks. Up to three integer values, each value not exceeding four (4). characters, may be printed within each block. Consequently, the block values must be properly scaled by the user, using the user specified scaling parameters.

Program MAP is currently dimensioned to handle a maximum of 100 blocks along the $\mathrm{Y}$-direction (N-S) and an unlimited number of blocks along the $\mathrm{X}$ direction. 


\section{SECTION II: ENGINEERING DOCUMENTATION}

\subsection{NARRATIVE DESCRIPTION:}

Program MAP is a FORTRAN IV program written to create a plan map of block values on the line printer. This program is designed to display grades assigned to individual blocks by kriging or other interpolation methods. This program can also be used for any other attributes of the block such as thickness, grade-thickness, etc.

The size of a block on the printed map is $1 / 2$ inch square if the line printer prints eight (8) lines per inch. Up to three integer values, each value not exceeding four (4) characters, may be printed within each block. Appropriate scaling factors must be specified to convert the actual block values to the values printed on the map.

If the line printer prints six (6) lines per inch instead of eight (8) and if the user desires for the printed block size of $1 / 2$ inch square, the program requires a slight modification. In this instance, only two instead of three values can be printed within each block.

The blocks'may be'square' or rectangular but if the blocks are square the resulting printer map will have no distortion. For the square blocks, the scale of the map is 1 inch to two times the true block dimension. Thus if the blocks are 100 feet by 100 feet the map will have a scale of 1 inch to 200 feet.

The program is presently dimensioned to output a map up to 100 blocks in the $Y$ (North-South) dimension and an unlimited number of blocks in the $\mathrm{X}$-direction. The horizontal direction on the line printer is the X-direction. The map is printed in strips of 20 blocks in the $\mathrm{x}$-direction and up 
to 100 blocks in the $\mathrm{Y}$-direction. If the map is wider than 20 blocks the strips will have to be taped together to form the entire map.

The block values to be printed are read in one card per block, using the user specified format. The items to read in from each card are; 1) north coordinate, 2) east coordinate, and 3) up to three values of block attributes. Because of the manner in which the map is printed, the block values must be ordered in increasing east coordinates prior to being read into the computer.

\subsection{METHOD OF SOLUTION:}

The method of solution is simple. The area to be mapped is defined by the user. The coordinates of the Northwest corner of the first block in row one and column one, and the beginning and ending rows and columns bounding the area are specified by the user. Next, the block dimensions in both $\mathrm{X}$ and $\mathrm{Y}$-directions are specified, regardless whether the block is a square or a rectangular block. Finally, the scaling parameters for the maximum of three (3) values to be printed as well as the format for reading in these values and their coordinates are specified by the user.

Figure 1 shows a sample printer map of block values created by the program MAP. As it can be seen from Figure 1, each block is $1 / 2$ inch square if the printer prints eight lines per inch.

It should be noted in Figure 1 that the coordinates printed on the printer map are coordinates of the edges of the blocks, not the centers. The values printed within each block, however, are assumed to be either those at the center of the block or the average values for that block. In other words, the coordinates of the block associated with the input data 


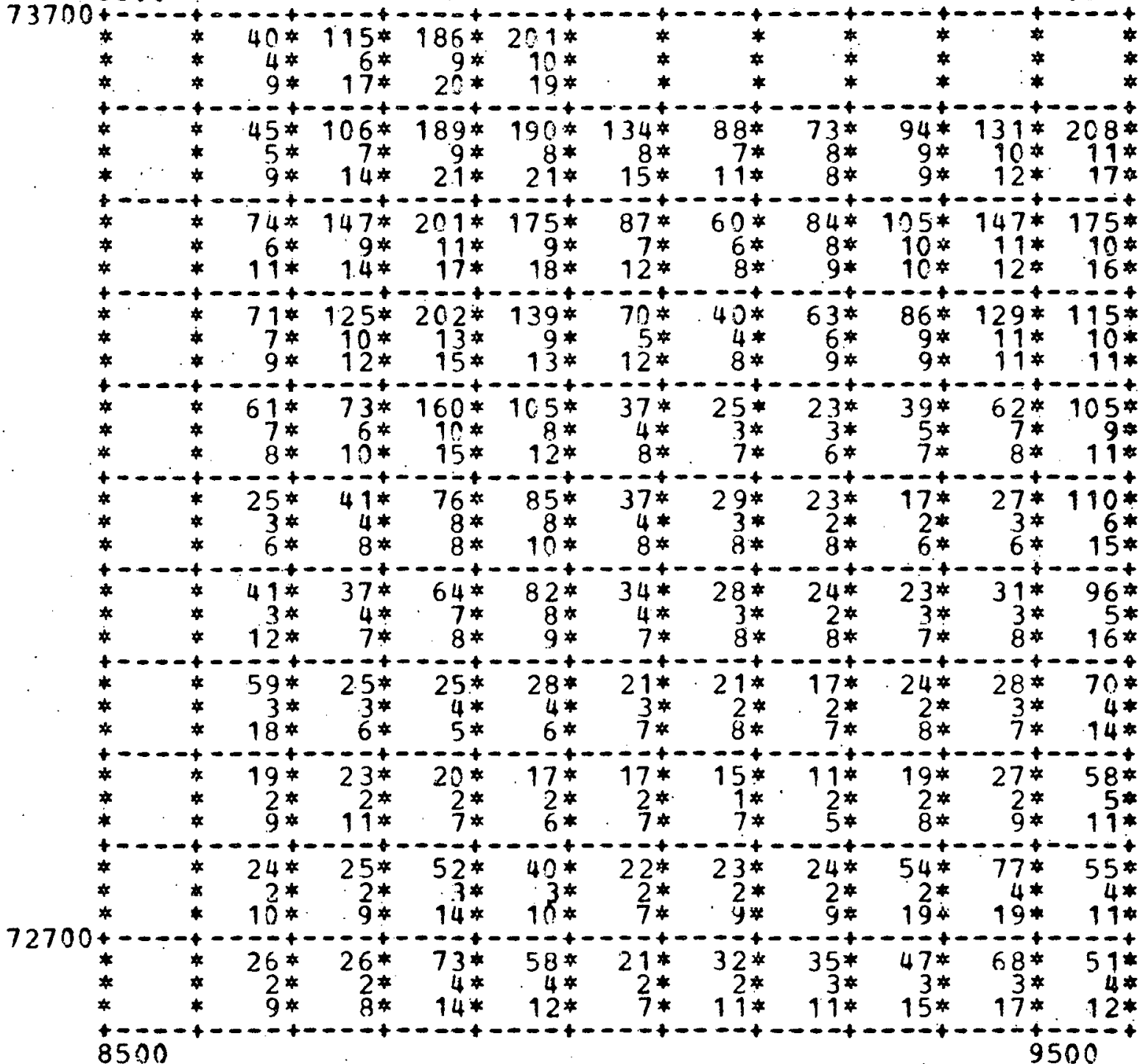

Figure 1 SAMPLE PRINTER MAP OF BLOCK VALUES 
should be as close to the midpoint of the block, if not exactly at the center of the block.

When reading in the block values, these values must be presorted by increasing eastings. This is necessary because the map is printed in strips of 20 blocks in the X-direction. Thus for a strip the blocks are read in until a block is encountered that lies on the next strip. The strip is printed and the program starts to read in blocks for the new strip. This is continued until the map is completed.

Up to three values may be printed in each block if the line printer prints eight (8) lines per inch. If the line printer only prints six (6) lines per inch the program will have to be modified and only two values could then be printed within the block. The scaling parameters for the block values should be chosen carefully so that the value can be printed within 4 spaces. For example, the value 13.45 could be scaled by multiplying by 100 . The printed value would then be 1345 .

Up to 100 blocks may be printed in the Y-direction. If this is insufficient the program can be modified by increasing the dimensions of the MAP and the variable MAXR to the required size.

\subsection{PROGRAM CAPABILITIES:}

Program MAP is presently dimensioned to print a map 100 blocks in the $\mathrm{Y}$-direction and an unlimited number of blocks in the X-direction. Up to three integer values, each not exceeding 4 characters can be printed within each block, using eight lines per inch line printer. The same number of values can be printed for each block using six lines per inch line printer. However, the block dimension will no longer be $1 / 2$ inch square. If a $1 / 2$ 
inch square block is desired using six lines per inch printer, only two values can be printed after the necessary program modification.

All scaling parameters are user specified. The block values are read in under user specified format. In addition to the northing and easting the program assumes that three additional values will be read in for each block.

2.4 DATA INPUTS:

A11 data is read in from cards. The following describes the data inputs:

CARD ONE.

\begin{tabular}{|c|c|c|c|}
\hline COLUMN & FORMAT & $\begin{array}{l}\text { VARIABLE } \\
\text { NAME }\end{array}$ & DESCRIPTION \\
\hline $1-10$ & F10.0 & YMAX & NORTH COORD. OF UPPER EDGE ROW ONE. \\
\hline $11-20$ & F10.0 & XMIN & EAST COORDINATE OF COL ONE. \\
\hline $21-25$ & F5.0 & WIDY & BLOCK SIZE IN Y DIMENSION. \\
\hline $26-30$ & F5.0 & WIDX & BLOCK SIZE IN X DIMENSION. \\
\hline $31-35$ & I5 & NBC & $\begin{array}{l}\text { BEGINNING COLUMN NUMBER OF AREA TO BE } \\
\text { MAPPED. }\end{array}$ \\
\hline $35-40$ & 15 & NEC & ENDING COLUMN. \\
\hline $41-45$ & I5 & NBR & BEGINNING ROW. \\
\hline $46-50$ & I5 & NER & ENDING ROW. \\
\hline
\end{tabular}

CARD TWO.

$\begin{array}{ccc}\text { COLUMN } & \text { FORMAT } & \begin{array}{c}\text { VARIABLE } \\ \text { NAME }\end{array} \\ 1-10 & \text { F10.0 } & \text { SCALE (1) } \\ & \vdots & \\ 11-20 & \text { F10.0 } & \text { SCALE(2) } \\ 21-30 & \text { F10.0 } & \text { SCALE (3) }\end{array}$

DESCRIPTION

SCALING PARAMETER FOR VARIABLE 1. THE SCALING PARAMETERS SHOULD BE CHOSEN TO MAKE THE VARIABLE AN INTERGER. SCALING PARAMETER FOR VARIABLE 2. SCALING PARAMETER FOR VARIABLE 3. 
CARD THREE.

\begin{tabular}{|c|c|c|c|}
\hline COLUMN & FORMAT & $\begin{array}{l}\text { VARIABLE } \\
\text { NAME }\end{array}$ & DESCRIPTION \\
\hline $1-80$ & $8 \mathrm{Al} 0$ & IFRMT & $\begin{array}{l}\text { VARIABLE FORMAT FOR INPUT DATA. } \\
\text { THE FOLLOWING INFORMATION MUST BE } \\
\text { READ IN FOR EACH BLOCK (ONE CARD PER } \\
\text { BLOCK) IN THE FOLLOWING ORDER: } \\
\text { NORTH COORDINATE } \\
\text { EAST COORDINATE } \\
\text { VARIABLE } 1 \text { (THIS WILL BE PLOTTED } \\
\text { ON LINE } 1 \text { OF THE PRINTED BLOCK.) } \\
\text { VARIABLE } 2 \\
\text { VARIABLE } 3\end{array}$ \\
\hline
\end{tabular}

A sample listing of input data is given in Figure 2 .

2.5 PROGRAM OPTIONS:

Other than the ability to specify the map size and various scaling parameters as described in Section 2.4 there are no options.

2.6 OUTPUT:

Figure 1 shows a typical printed map. There is no other output from this program. 


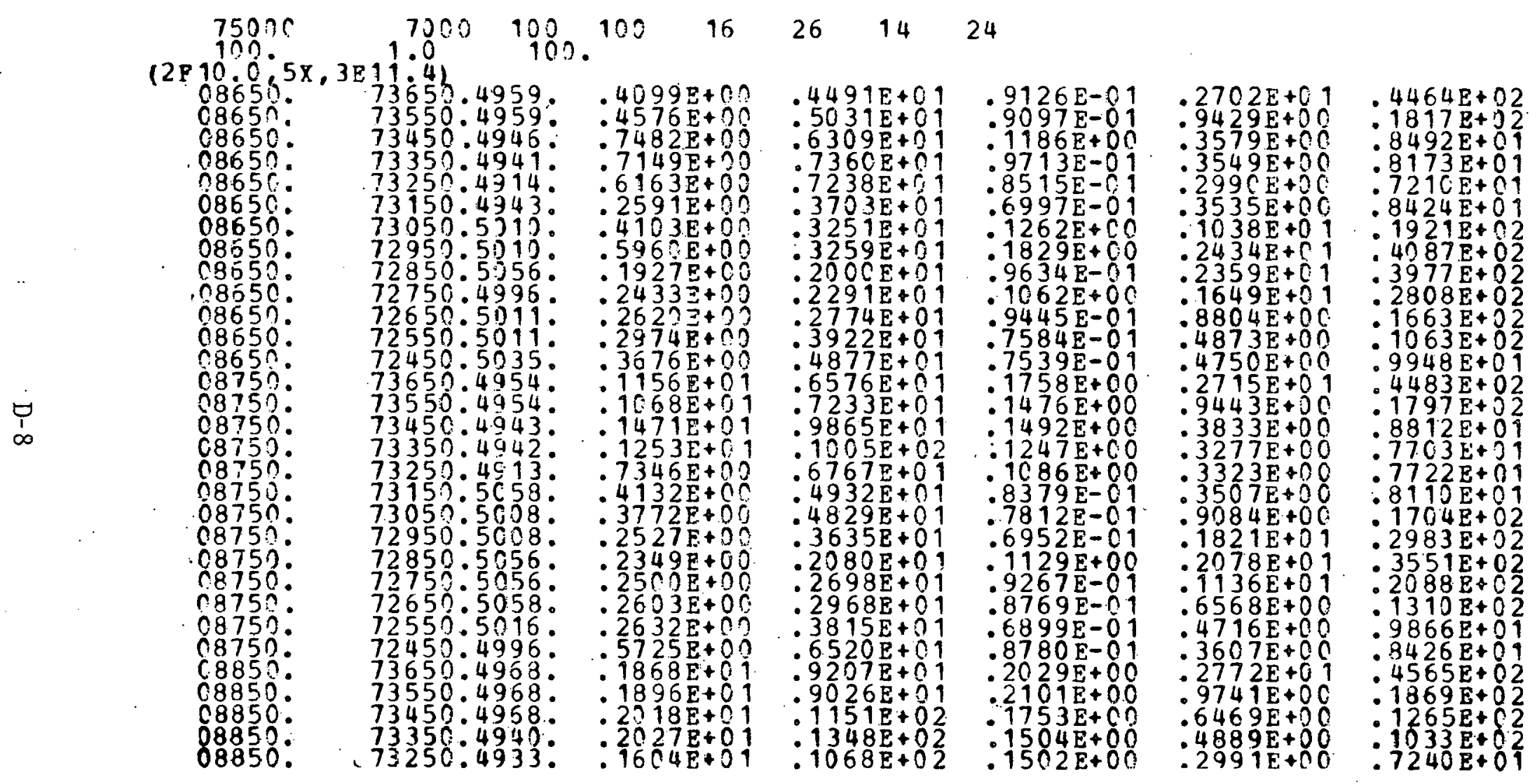

Figure 2 


\section{SECTION III: SYSTEM DOCUMENTATION}

3.1 COMPUTER EQUIPMENT:

Program MAP was run on a CDC 6400 computer.

3.2 SOURCE PROGRAM:

A source program listing is given at the end of this user's guide.

\subsection{VARIABLES:}

A listing of major variables is given in the program listing.

3.4 STORAGE REQUIREMENTS:

Program MAP requires 50K storage on the CDC 6400.

\subsection{MAINTENANCE AND UPDATES:}

None. 
SECTION IV: OPERATING DOCUMENTATION

4.1 OPERATING INSTRUCTIONS:

Program MAP is operated under the CDC SCOPE 3.4 operating system.

4.2 OPERATING MESSAGES:

No special operating messages are provided by the program.

4.3 CONTROL CARDS:

The program is executed with standard SCOPE 3.4 control cards.

4.4 ERROR RECOVERY:

There are no error checks in the program. If the map specified is too large the size is adjusted to the maximum allowable size with no error message being printed.

4.5 RUN TIME:

Run time depends on the number of blocks to be mapped. For instance, to block 100 blocks takes about 1 second. 
MAP PROGRAM LISTING

D-11 
PROGRAM MAPBLOC ( $T$ NPUT, OUT PUT, TAPE5=INPUT, TAP E6=OUTPUT)

DIMENSION TXCORD (3): IYCORD 103$)$ MAP $(20,3,100)$, I VAR (3)

DIMENSION YCRD (1CC): SCALE (3), VAR (3), I FRMT (8)

DATA IPT IOUT, BLN K, BLNK $2 / 5,6,5 \mathrm{H}-\cdots+-5 \mathrm{H}$

DATA YCRD/10ก $\$ 1 \cap H$

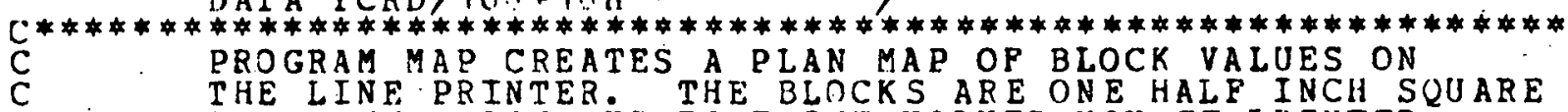
AS SHOWN BELOH. UP TO THREE VALUES MAY BE PRINTED CHARACTERS IN LENGTH. ALL SCALING PARAMETERS ARE USER SPECIFIED. NOTE.IP THE TRUE STZE OF THE BLOCK IS $100 \cdot \times 100^{\circ}$ THEN THE PRINTED MAP HIL HAVE A SCALE OP 1 INCH TO 200 FT. PROGRAM MAP IS CURRENTLY. DIMENSIONED TO OUTPUT A MAP UP TO 100 BLOCKS IN LENGTH IN THE Y DIMENSION AND ANY LENGTH IN THE X DIMENSION THE MAP IS PRINTED QITH 20 BLOCKS PER PAGE IN THE X DIMENSION. EXAMPLE OF OUTPUT IS GIVEN BELOW

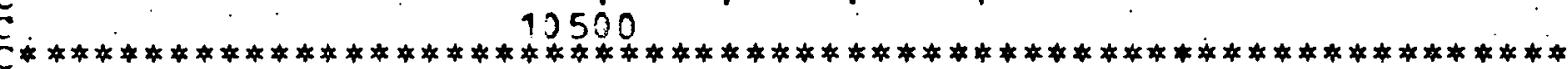

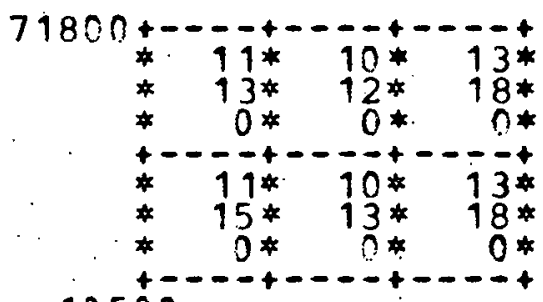

C CONTROL CARDS

$\begin{array}{ll}\mathrm{C} & \mathrm{CARD} O \mathrm{ONE} \\ \mathrm{C} & \mathrm{COL} 1-10\end{array}$

c

$11-20$ F10.0 YMAX

P10.0 XMIIN

$21-25$ F5. 0 . WIDY

$26-30$ F5 00 HIDX
$31-35 . I 5$

EAST COORDINATE OP COL ONE.

C

C

NBC

BIOCK SIZE IN X DIMENSION

$35-40$ I5 NEC

$41-45$ I5. NBE

BEGINNING COLUMN NUMBER OF

TO BE MAPPED.

ENDING ROW.

SCALING PARAMETER FOR VARIABLE 1. THE SCALING PARAMETERS SHOULD BE CHOSEN TO MAKE THE VARIABLE AN $11-20$ F 11) SCALE(2) SCALING

$21-3$ P $10: 0$ SCALE 3$\}$ CONTROL CARD THREE. COL $1-80$ 8A1O IPRMT

VARIABLE FORMAT FOR INPUT DATA. THE FOLLONING IN FORMATION MUST BE READ IN POR EACH BLOCK JONE CARD PER BLOCK) IN THE FOLLONING ORDER. NORTH COORDINATE

EAST COORDINATE

VARIABLE 1 THIS WILL BE PLOTTED

VARIABLE

VARIABLE 3

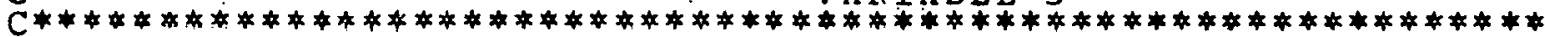
C****READ IN CONTROL CARD.ONE. 
n 0640 Ca650 00670 त 068 \% rn690 กn70n or 710 00720 nc 730 Ce 740 ט.c750 00770 rir $78^{\circ}$ cro 790 Cr 800 ro8 810 กC 820 oc 830 or 840 0
$0 r 8$ 850 00870 or 880 तC 890 cogon กत9 10 nrig 2 nr.g nc 940 Cr 950 rc9 90 c. nc 990 ก $\therefore 1010$ 01020 cin 30 $\mathrm{r} 10$ 4ก c 1050 ก 1n 60 01070 1080 ก 109 O

nj10n

ri110

ก 1120

C 1130

ก1140

ก115n

ก116n

C997

ก1180

Ci19n

C $12 \mathrm{co}$

01120

त.1230

01240 01260

READ (IPT: 2) YMAX, XMIN, WIDY, NIDX, NBC, NEC, NBR, NEE

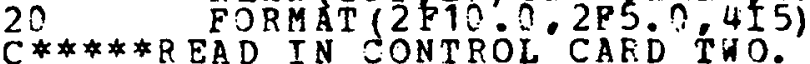

READ (IPT, 25) SCALE

25 FORMAT 3 F 15.0$)$

C*** READ IN CONTROL CARD THREE. READ (IPT:26) IPRMT

26 FORMAT (BA 10$)$

C* * $*$ SET UP MAP PAGING INDEXES

I T COL $=\mathrm{NEC}-\mathrm{N} \mathrm{BC}+1$

$J R O H=N E R-N B P+1$

IF (JROW.GT.10:) JROH=100

NPAGES $=($ ITCOL +19$) / 20$

$X N E W=X M I N+(N B C-1) * W I D X$

$X N E W=Y M A X-\{N B R-1\} * H I D Y$
$N=J R O W / 1 ?+1$

C* * * CALCULATE COORDINATES POR NORTHING TIC MARKS ON MAP. DO $35, T=1 . N$

I $\mathrm{I} \approx \overline{\mathrm{O} R \mathrm{D}}(\mathrm{II})=\mathrm{INEH}-\mathrm{I} * 10 * \mathrm{HIDY}$

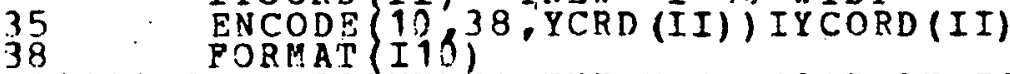

C*** * START PRINTTNG THE MAPE PAGE BY PAGE. DO $25 ? M P A G E=1$, NPAGES

$\mathrm{ICOL}=2 ?$

IF (ICOL *MPAGE. GT.ITCOL) ICOL $=I T C O L-(M P A G E-1) * 20$

$\bar{N} C=I C O L / 10+1$

$110 \quad$ WRTTE(IOUT, 110)

C* * * CALCULATE COSRDINATES FOR EASTING TIC MARKS ON MAP. DO 40 IIT $=1, N C$

42 IXCORD $(I I)=X N E W+(I I-1) * 10$ * IIDX

C***PRINT OUT UPPER BORDER OF MAP.

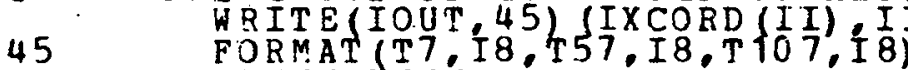

FORMAT $\{$ T T

ENCODE 10,38 IY) IYNEW

WRITE (IOUT, 5 R) IY, (BLNK, I=1, ICOL)

C* * READ IN BLOCK DATA- QUIT WHEN A BLOCK FROM THE NEXT PAGE IS FOUND

$55 *$ PEAD I TT IFRMT) XE, Y N,VAR

C**** CALCULATE POSTTION OP THIS BLOCK IN MAP JPOS $=(Y N E H-$ IDY $/ 2 .-Y N+0.0 D O 1) / H I D Y+1$

I POS $=(X E-\mathrm{XIDX} / 2.3-\mathrm{XNEW}+0.0001) / \mathrm{IDX}+1$

IF (IPOS.GT.20) GO TO 100

C*** FILL IN THE VALUES TO BE PRINTED IN THIS BLOCK

DO 62 I I $=1,3$

IVAR (II) $=V$ VR (II) *SCALE (II)

62 ENCODE $4,65, M A P(I P O S, I I, J P O S)$ ) IVAR (II)

$652 \quad$ FORMAT $(\mathrm{I} 4)$

C*** PRINT OUT PAGE

$990 \quad$ IEO $14=1$ ? $I=1 . \mathrm{JROW}$

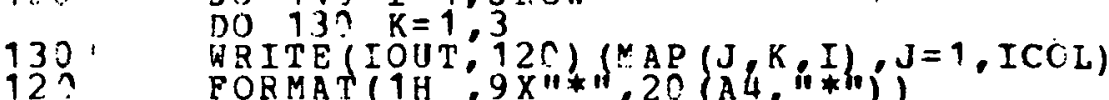

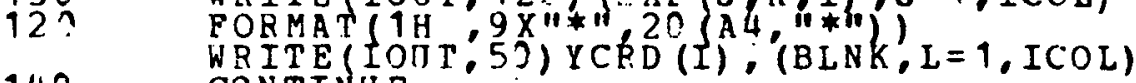

140 CONTINU.F.

C*** PAGE OUTPUT COMPLETE GO ON TO NEXT PAGE OF EXIT IF EOF HAS 


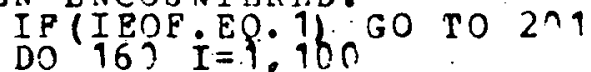

DO 16 ; $j=1,3$.

$\because 1320$

160 MAP. $(K, J) T=B L N K 2$

DO $160 \mathrm{~K}=120$

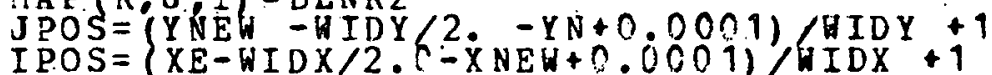

DO 162 II $=1,3$

I V.AR (II) =VAR (II) *SCALE (II)

ENCODE $(4,65$, AAP (IPOS, II, JPOS)) IVAR (II)

$X N E H=X N E W+20.4 I D X$

$20 ? \quad$ CONTINUE

205

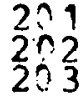

HRITE (IOUT 205)

FOBMAT "LÁST PAGE PRINTED. NORMAL END OF JOB.") GO TO 203 I I T T 202)

PORMAT(" END ÓE FILE ENCOUNTERED NORMAL END OP JOB") STOP 
APPENDIX E

ESTIMATION VARIANCE PROGRAM "ESTVAR"

USER'S GUIDE 


\section{SECTION I: PROGRAM IDENTIFICATION}

1.1 PROGRAM TITLE: Estimation Variance Calculation

1.2 PROGRAM CODE NAME: ESTVAR

1.3 PROGRAM WRITER: H. P. Knudsen

PROGRAM DOCUMENTATION: H. P. Knudsen

1.4 ORGANIZATION: Department of Mining and Geological Engineering University of Arizona Tucson, Arizona

1.5 DATE: November 20,1976

1.6 UPDATES: None. Version: 1.

1.7 SOURCE LANGUAGE: CDC 6400 Computer Systems - FORTRAN Extended Version. IV.

\subsection{ABSTRACT:}

Program ESTVAR calculates the estimation variance (estimation error) of assigning the average grade of a set of samples to a block. The block can be a rectangular 3-D block or an irregular 2-D block. Up to 15 nodes can be used to describe the irregular block and up to 500-data points may be included. The spherical variogram is assumed. 


\section{SECTION II: ENGINEERING DOCUMENTATION}

\subsection{NARRATIVE DOCUMENTATION:}

Program ESTVAR calculates the variance of the error (estimation variance) made by assigning the grade of a sample or samples to a block. This program can be used to solve many interesting problems concerning the estimation variance of various sampling grids. It can be used to calculate the estimation variance for a given set of samples. It can be used to test which of several sampling grids will give the smallest probable error. Or it can be used to calculate the reduction in the probable error made by adding one or more new samples, even before the samples are taken. If the unknown true grade of a block $V$ is $Z(V)$ and the known grade of a block $v$ is $Z(v)$ then the variance of the error of assigning the grade $Z(v)$ to $Z(V)$ is given by

$\operatorname{VAR}[Z(V)-Z(V)]=\sigma_{E}^{2}=\frac{2}{V V} \cdot \int_{V} d x \int_{V} \gamma(x-y) d y=\frac{1}{V^{2}} \int \frac{d x}{V} \int \gamma(x-y) d y-\frac{1}{V^{2}} \int_{V} d x \int_{V} \gamma(x-y) d y$

where $\gamma(x-y)$ is the value of the variogram for the distance between points $x$ and $y$. Thus, once the variogram is known, this equation can be used to calculate the magnitude of the estimation errors made during an ore reserve analysis.

In most cases instead of assigning to $Z(V)$ the grade $Z(v)$ of block $v$, the average grade of a set of samples is assigned to $Z(V)$. In this common case the estimation variance is given by

$\sigma_{E}^{2}=\frac{2}{N V} \sum_{i=1}^{N} \int_{V} \gamma\left(x_{i}-x\right) d x-\frac{1}{V^{2}} \int_{v} d x \int \gamma(x-y) d y-\frac{1}{N^{2}} \sum_{i=1}^{N} \sum_{j=1}^{N} \gamma\left(x_{i}-x_{j}\right)$

where $\mathrm{N}$ is the number of samples. 
The block $\mathrm{V}$ can be of two types, a regular block like a cube, or an irregular shaped block such as a polygon. The regular block is described by specifying its length, width and depth and its spatial position in the orebody, i.e., its northing, easting and elevation. The irregular block is described by specifying the coordinates of a set of nodes that outline the block. Up to 15 nodes may be used to define the block.

Up to 500 samples may be included in each run. The spatial location of each sample must be read in.

The spherical variogram model is assumed in the program. However subroutine SUBGAM may be modified if other models are desired. It is also assumed that any anisotropy in the variogram is of the simple geometric type.

\subsection{METHOD OF SOLUTION:}

For a given set of samples and a given block the estimation variance is calculated according to Equation 2. The only difficulty involved in the calculations is the evaluation of the integrats. This is atcomplishcd by using a discrete summation to approximate the integral. The volume over which the integration is performed is approximated by a set of regular grid points wi.thin the volume. For example, the square shown below could be approximated by the 16 points in the grid shown.

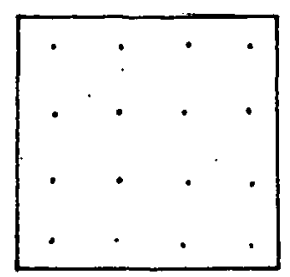

Number of points in X-Direction $=I X=4$

Number of points in $Y$-Direction $=I Y=4$

Total number of points $=(I X \cdot I Y)=16$

The quality of the approximation is dependent on the number of grid 


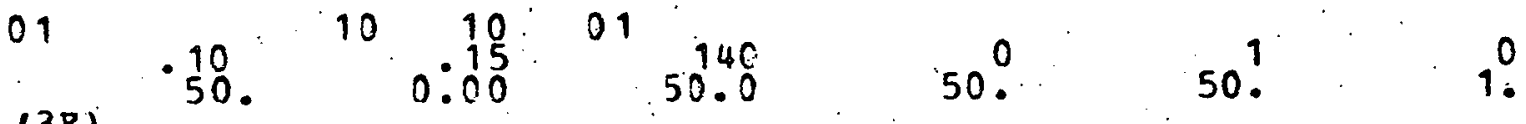

$$
\begin{aligned}
& \begin{array}{lll}
\text { (3P) } & 25 . & 25: 0 \\
12.5 & 12: 5 & 1.0 \\
12.5 & 37: 5 & 1.00 \\
37.5 & 12: 5 & 1: 0
\end{array} \\
& \begin{array}{lll}
37.5 & 37.5 & 1: 0
\end{array}
\end{aligned}
$$

Figure 1

EXAMPLE INPUT DATA

VABIOgRam parameters

CO

RANGE

ANGLE OF ROTATION

HOR. ANISOTROPY

VERT. ANISOTROPY
$1300 E+00$
$15008+00$

140 .

1:

DEPINITION OP BLOCK

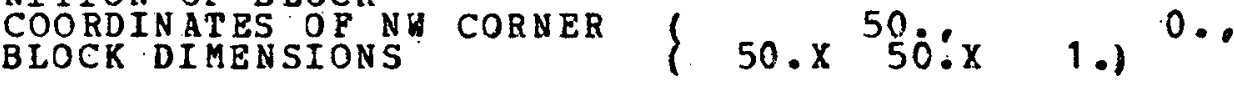

BSTIMATION VARIANCE $=3.20652 \mathrm{E}-01$

VARIANCE OF A POINT AITHIN THE BLOCK $=0.14087 E+00$

DRILL HOLE LOCATIONS

$\begin{array}{rrrrr}\text { NORTH } & \text { EAST } & \text { ELEV } & \text { NORTH } & \text { EAST } \\ 25.0 & 25.0 & 1.0 & 12.5 & 12.5 \\ 37.5 & 12.5 & 190 & 37.5 & 37.5 \\ 12.5 & 37.5 & 1.0 & & \end{array}$

37.5

ELE V
1.0
1.0

Figure 2

EXAMPLE OUTPUT 
points used. The total number of grid points is given by IX.IY $\cdot I Z$. The program is presently dimensioned to allow a maximum of 100 grid points. The number of grid points to use in a regular block is specified by the number of grid points in the $X, Y$ and $Z$ directions.

For irregular shaped blocks the grid is specified in the same manner as the regular block except that the vertical dimension is ignored, i.e., the block is considered to be two dimensional. This assumption is for simplicity in the program, because each of the grid points must be tested to see if it lies within the irregular shaped block.

This assumption is not overly restrictive because in many cases such as in open pit mines the sample length is the same as the block height, thus allowing the block to be considered two dimensional.

\subsection{PROGRAM CAPABILITIES:}

A maximu of 500 samples may be included in each data set. Either a regular block or irregular shaped block may be input. A maximum of 15 nodes may be used to describe the irregular block.

\subsection{DATA INPUT:}

Data is input from punched cards. The order of the control cards and data cards is given below.' The data cards are read in according to a user specified format. Figure 1 is a listing of sample input data.

1. CARD ONE. PROGRAM RUN PARAMETERS.

\begin{tabular}{|c|c|c|}
\hline COLUMN & $\begin{array}{c}\text { VARIABLE } \\
\text { NAME } \\
\end{array}$ & DESCRIPTION \\
\hline 1 & IBLK & TYPE OF BLOCK \\
\hline 2 & IPRT & $\begin{array}{l}0=\text { RECTANGULAR, } 1=\text { IRREGULAR. } \\
\text { PRINT OUT HOLES IF }=1\end{array}$ \\
\hline $11-15$ & IY & NUMBER OF POINTS IN Y DIRECTION. \\
\hline $16-20$ & IX & NUMBER OF POINTS IN $X$ DIRECTION. \\
\hline $21-25$ & $\mathrm{IZ}$ & NUMBER OF POINTS IN $Z$ DIRECTION \\
\hline
\end{tabular}


2. CARD TWO. VARIOGRAM PARAMETERS.

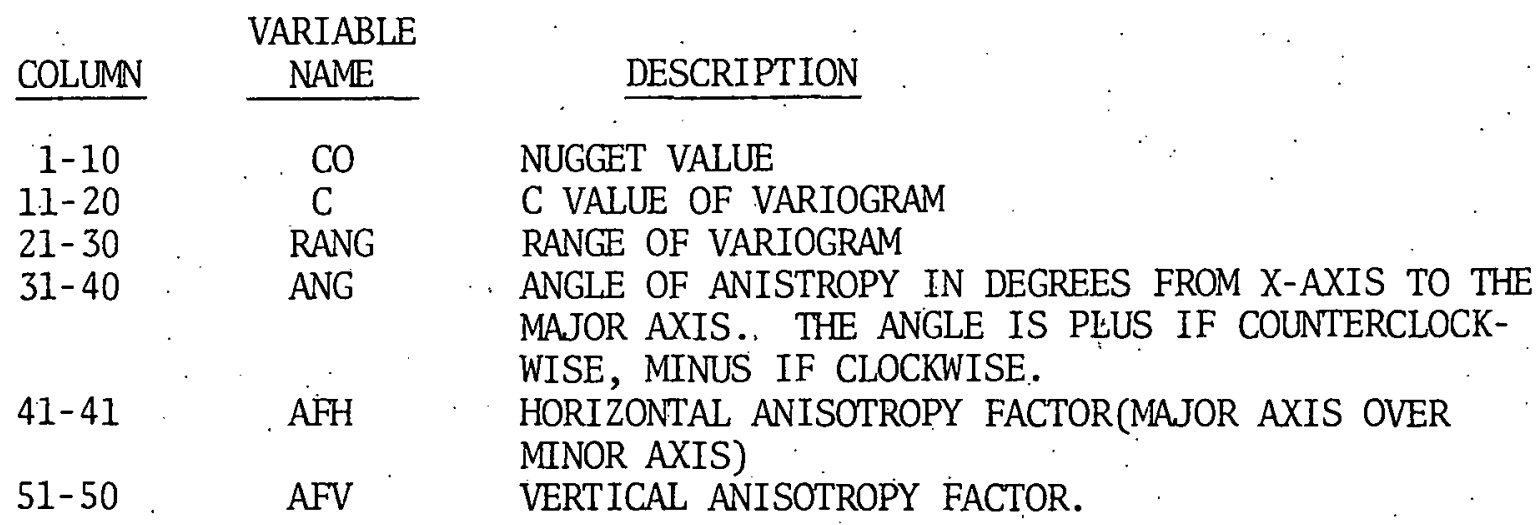

3. CARD THREE. FOR RECTANGULAR BLOCK.

\begin{tabular}{lll} 
COLIMN & $\begin{array}{l}\text { VARIABLE } \\
\text { NAME }\end{array}$ & \multicolumn{1}{l}{ DESCRIPTION } \\
$1-10$ & YMAX & NORTH COORDINATE OF UPPER LEFT CORNER. \\
$11-20$ & XMIN & EAST COORDINATE OF UPPER LEFT CORNER. \\
$21-30$ & ZMAX & ELEVATION OF UPPER EDGE OF BLOCK. \\
$31-40$ & WIDY & BLOCK WIDTH IN NORTH. DIRECTION. \\
$41-50$ & WIDX & BLOCK WIDTH IN EAST DIRECT ION. \\
$51-60$ & WIDZ & BLOCK DEPTH.
\end{tabular}

4. CARD THREE. FOR IRREGULAR BLOCK.

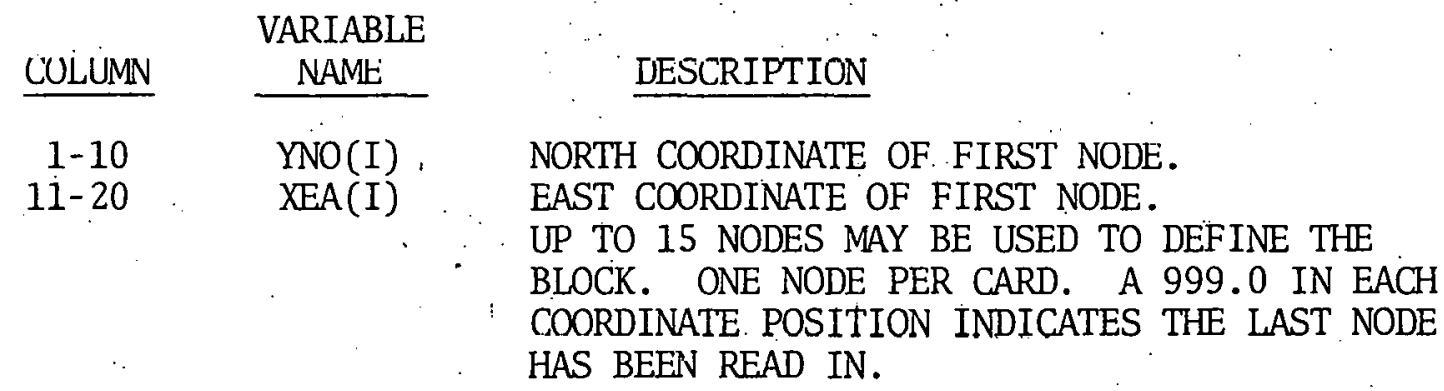

5. CARD FOUR. :VARIABLE FORMAT CARD FOR ASSAY DATA.

\begin{tabular}{|c|c|c|}
\hline COLUMN & $\begin{array}{l}\text { VARIABLE } \\
\text { NAME } \\
\end{array}$ & DESCRIPTION \\
\hline $1-80$ & IFRMT & $\begin{array}{l}\text { VARIABLE FORMAT. } \\
\text { ONLY THE NORTHING, EASTING, AND ELEVATIOI } \\
\text { ARE READ IN FOR EACH DRILL HOLE. }\end{array}$ \\
\hline DRILL HOLE & DATÁ CARDS. & $\begin{array}{l}\text { THE DATA CARDS FOLLOW CARD THREE AND ARE } \\
\text { FOLLOWED BY A } 7 / 8 / 9 \text { CARD. }\end{array}$ \\
\hline
\end{tabular}




\subsection{OUTPUT:}

Output from program ESIVAR consists of a listing of the input parameters, the calculated estimated variance and a listing of the sample points. Figure 2 is an example of the output. 
SECTION III: SYSTEM DOCUMENTATION

3.1 COMPUTER EQUIPMENT:

Program ESTVAR was run on a CDC- 6400 computer.

3.2 SOURCE PROGRAM:

A listing of the sourçe listing is given at the end of this Appendix.

3.3 VARIABLES AND SUBROUTINES:

A listing of major variables is given in the program listing.

Subroutines included in program ESTVAR are:

SUBGAM - calculates the value of the variogram between two points.

PTLOC - determines whether a point is within a closed boundary.

Subroutine. PTLOC was written by John K. Hall of the geological survey of Israel. Documentation and explanation of this subroutine were published in Mathematical Geology, Volume 7, November 1, 1975.

3.4 STORAGE REQUIREMENTS:

Program ESTVAR requires $46 \mathrm{~K}$ storage on the CDC 6400.

3.5 MAINTENANCE AND UPDATES:

None 


\section{SECTION IV: OPERATING DOCUMENTATION}

4.1 OPERATING INSTRUCTIONS:

Program ESTVAR is operated under the CDC 6400 SCOPE 4.3 operating system:

4.2 OPERATING MESSAGES:

No operating messages are generated by program ESTVAR.

4.3 CONTROL CARDS:

The program is executed with standard SCOPE 3.4 control cards.

4.4 ERROR RECOVERY:

The program will terminate if certain errors are encountered. Self explanatory error messages will be printed.

4.5 RUN TIME:

The run time is dependent on the number of grid points used and the number of sample points. The example run shown in Figure 2 required 1 second on the CDC- 6400 . 
ESTVAR PROGRAM LISTING

$E=10$ 
$0 \subset 500$

00700

$0 C 800$

00900

C1000

01100

C 1200

01300

01500

C 1600

C 1700

o 1800

01900

$020 \mathrm{co}$

$021 \mathrm{CO}$

220C

02400

02500

02600

02800

त2900

03000

C 3100

0320
03300

PROGRAM ESTVAR (INPUT, OUT PUT, TAPE5=INPUT, TAP E6=OUTPUT)

COMMON /GAM/CO C, RANG CST, SIT AFH, AFV

DIMENSION YN $(500), X E(500), Z L(500)$, I PRMT (8),P $(3,100), P 1(3)$

DIMENSION P 2 (3) YNO ( 65 . XEA $(16)$

DATA IPT, IOUT,MAXH, MAXN,MAXPT/5,6,500,15,1000/

$C * * * * * * * * * * * * * * * * * * * * * * * * * * * * * * * * * * * * * * * * * * * * k * * * * * * * * * * * * * * * * * *$
PROGRAM ESTVAR CALCULATES THE ESTIMATION VARIANCE OF

$\begin{array}{ll}C & \text { PROGRAM ESTVAR CALCULATES THE } \\ C & \text { A BLOCK FROM A SET OF SAMPLES. }\end{array}$

CONTROL CARDS

CARD ONE.PROGRAM RUN PARAMETERS. COL 1 IBLK TYPE OF BLOCK

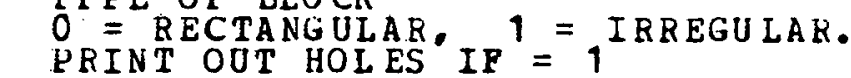

$11-15$ IY NUMBER OF GRID POINTS IN Y DIRECTION.

$\begin{array}{lll}16-25 & \text { IX } \\ 21-25 & \text { IZ } & \text { NUMBER OF GRID POINTS IN Y DIRECTION }\end{array}$

CARD TWO; VARIOGRAM PARAMETERS

COL $1-10$ CO NUGGET VALUE

11-20 C C VALUE OF VARIOGRAM

$21-30$ RANG RANGE OF VARIOGRAM

$31-45$ ANG ANGLE OF ANISTROPY IN DEGREES FROM

$X$-AXIS TO THE MAJOR AXIS. THE

ANGLE IS PLUS IF COUNTERCLOCKNISE, MINUS IF CLOCKWISE.

41-41 AFH HORIZONTAL ANISOTRDPY FACTOR MAJOR

$51-50$ AXIS OVER MINOR AXIS

CARD THREE. FOR APECTANGULARICAL ANISOTROPY EACTOR.

$1-10$ YMA

$11-20$ MMAX NORTH COOKDINATE OF UPPER LEFT CORNER.

XMIN EAST COORDINATE OF UPPER LEFT CORNER

ZMAX ELEVATION OF UPPER EDGE OF BLOCK

1-45 WIDY BLOCK HIDTH IN NORTH DIRECTION

$41-53$ HIDX BLOCK IDTH IN EAST DIRECTION

$51-60$ WIDZ BLOCK DEPTH.

CARD THREE. FOR IRREGULAR BLOCK.

$1-10$ YNO (I) NORTH COORDINATE OF ITH NODE.

11-25 XEA(I) EAST COORDINATE OF ITH NODE.

UP TO 15 NODES MAY BE USED TO

DEPINE THE BLOCK. THE NODES MUST

$B E$ IN CLOCK TSE OR DER . ONE NODE PER

CARD. A 999 . O IN EACH COORDINATE

POSITION IN DICATES THE LAST NODE

HAS BF.F.N FF.AD TN.

CARD FOUR. VARIABLE FORMAT CARD FOR ASSAY DATA. $1-80$ IFRMT VARIABLE FORMAT.

ONLY THE NORTHING, EASTING, AND

ELEVATION ARE REAB IN POK EACH DR ILL HOL E.

DRILL HOLE DATA CARDS. THE DATA CARDS FOLLOW CARD THREE

\section{AND ARE FOLLOHED BY A $7 / 8 / 9$ CARD}

MAJOR VARIABLES USED IN PROGRAM ESTVAR.

YN ARKAY CONTAINING NORTH COODINATE OF SAMPLE POINTS

$\mathrm{X} \mathrm{E}$

ZL

P1

ARRAY CONTAINING

EAST COORD. OF SAMPLE POINT.

ARRAY CONTAINING ELEVATION OF SAMPLE POINT.

ARRAY CONTAINING COORDINATES OF GRID POINTS.

COORDINATES OF SAMPLE POINT.

COORDINATES OF SAMPLE POINT.

VALUE OF VARIGRAM FOR A GIVEN DISTANCE. 
VARIANCE OR A POINT IN THE BLOCK.

AVERAGE COVARIANCE BETWEEN SAMPLE POINTS AVERAGE COVARIANCE BETHEEN SAMPLES AND BLOCK. ESTIMATION VARIANCE

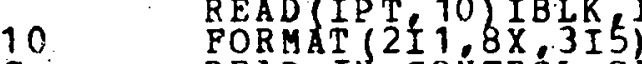

C READ IN CONTROL CABD THO

READ (IPT, 2) ) CO, C BANG, ANG, AFH, APV

20 PJRMAT 6 P 10.0,3I5)

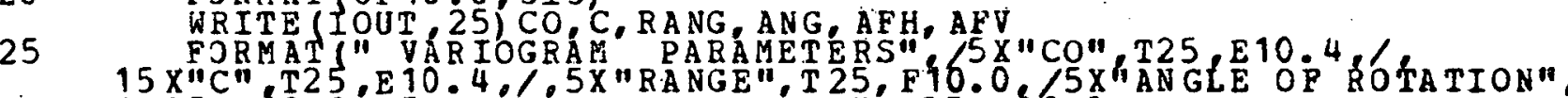

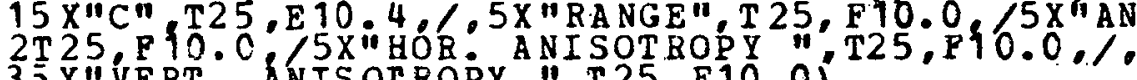

35 X"VERT. ANISOTEOPY ", T25, E10.0)

IF (IBLK.EO. 1) GO TO 32

C******READ IN CONTROI CARD THREE.

READ IPT, 2 J M MXXXMIN, MAX, IDY WIDX, GIDZ

30 FORMAT 1 HO: "DEFINITION ÓE BLOCK", $/ 5 X$ "COOORDINATES OF NG CORNER",

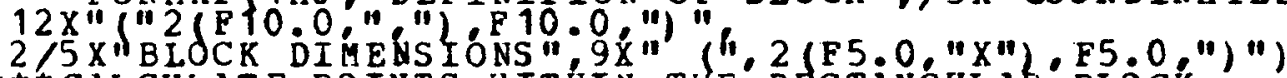

C* * * CALCULATE POINTS WITHIN THE' RECTANGULAk BĹCK

$D X=W I D X / I X$
$D Y=W I D Y / I Y$
$D Z=W I D Z / I Z$

$M=0$

DO $60 \quad I=1, I X$

DO $60 \mathrm{~J}=1$, IY

DO $60 \quad K=1:$ IZ

$M=M+1$

IF $(Y, M)=M A X P T) G O T O 220$

$\mathrm{P}\{2: M\}=\mathrm{YMAX}-\mathrm{DY} / 2=\left\{\begin{array}{l}\mathrm{J}-1 \\ \mathrm{~J}-1\end{array}\right) \begin{aligned} & * \mathrm{DX} \\ & \mathrm{K}-1\end{aligned}$

$60 \quad$ GONTTINE

C***** * READ IN CONTROL CARD THREE. IRREGULAR BLOCK .

$32 \quad I=1$

YIN $=99999999$.

YM A X $=0.000$

XMIN $=99999999$.

$X A X=0.0$

READ (IP' 2 ) Y YNO (I), XEA(I)

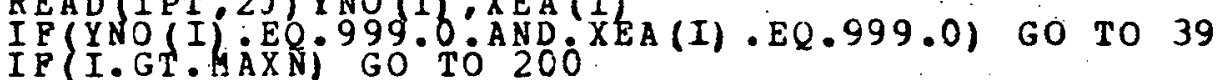

IF $\{$ Y NO (I),$G T \cdot Y M A X) Y M A X=Y N O(I)$

IF (YNO I I : IT. YIN Y Y IN=YNO (I)

IF XEA I I : GT: XAX XAX $=X E A(I)$

$I F(X E A(I): L T . X M I N) X M I N=X E A(I)$

$I=I+1$

$39 \quad$ NODES 33 T $=1$

WR ITE (IOUT, 36)

36 HRITE IOUT:38 (YNO (I),XEA (I), I=1,NODES)

38 FORMAT 1H:"s", F10.0,", F10.0,")")

WIDY = YMAX - YIN

UIDX $=X A X-X M I N$

C*****CALCULATE POINTS WITHIN THE IRREGULAR. BLOCK

$\mathrm{DX}=W I D X / I X$ 
DO $41, J=1, I X$

$X=X M I N+D X / 2+(I-1) * D X$

$Y=Y M A X-D Y / 2-(J-1) * D Y$

CALL PTLOC (NODES, XEA YNO, X, Y, LOC) $I F=M+1$

IF M.GT.10?) GO TO 37

P $\{f \cdot \dot{M})=\dot{x}$

41
37
35

CON TINUE

READ (IPT, 35) IFRMT

FORMAT (8A 10)

$A N G R=A N G * J .01745329252$

$\mathrm{CST}=\operatorname{CJS}(\mathrm{ANGR})$

C****** REAT IN SAMPLE DATA

40

$I=1$

READ (IPT TFRMI) YN (I) $X E$ (I), ZL (I)

IF $\{$ I.GT (IPT).NE.O) GO TO 50

$I=I+1$

$50 \quad$ GO TO 40

C******CALCULATE THE VARIANCE OF A BLOCK

$M 1=M-1$

GMOY $=0$.

DO $70 \quad I=1, M 1$

$\mathrm{II}=\mathrm{I}+1$

DO $70 \mathrm{~J}=\mathrm{II}, \mathrm{M}$

CALL SUBGAM $(P(1, I), P(1, J), G H)$

$70 \quad$ CONTINUE

CONTINUE $2 * G M O Y(M * M)+C O / M$

C******CALCULATE COVARIÁNCES

COS AM $=0$.

COBLK $=0$.

DJ $100 \quad I=1, N$ HOL

$\mathrm{II}=\mathrm{I}+1$

P $1\left(\begin{array}{l}1 \\ \text { P } 1 \\ ?\end{array}\right\}=\mathrm{X} E \mathrm{E}(\mathrm{I})$

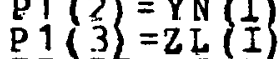

IF (II, GT. NHOL) GO TO 91

DJ $90^{\circ} \mathrm{J}=I I$, NHOL

$\mathrm{P} 2(1)=\mathrm{XE}(\mathrm{J})$

P $2\{2\}=Y$ N 2$\}$

CALL SUBGAK (P 1,P2,GH)

90 CONTINUE

91 DO $95 \mathrm{~K}=1, \mathrm{M}$

$95 \quad$ COBLK $=$ COBLK $+\mathcal{C} B(1, K), G H)$

$100 \quad$ CONTINUE

COS AM $=\cos A M /(.5 * N H O L * N H O L)+C O / N H O L$

COBLK $=$ COBLK (NHOL $*$ M)

C******ESTIMATION VARIANCE IS

EST $=2 *$ COBLK - BLKVAR - COSAM

110

WRITE (IOUT, 110 ) EST, BLKVAR

2 FORMAT (1HO "ESTIMATION VARIANCE =",E12.5.\%" VARIANCE OF WRITE (IOUT, 120) 
120 WRTTE(IOUT,125L (YN (I) XE (I) RL (I) I = I, NHOL)

12513 X, 3 (7X"NORTH"6X"EAST"5X"ELEV.", 3X.))

1.25 FORMAT $\{3(5 \mathrm{X}, 3$ F 10.1$))$

200 WRITE (IOUT, 140)

140 FORMAT "TÓO MANY NODES - JOB TERM IN ATED")

220

GJ TO $\$ 30$

FORM AT "TÓO GO TO 130

205 HRITE IOUT, 150)

150 PORMAT ("TÓO MANY SAMPLE POINTS")

END

SUBROUTINE SUBGAM (P1,P2,GH)

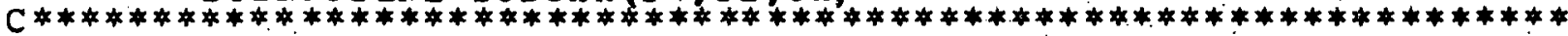

C SUBROUTINE SUBGAM CALCULATES THE VALUE OP THE VARIOGRAM

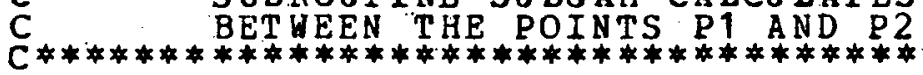

COMMON $/ G A M / C O, C, B A N G, C S T, S I T, A P H, A P V$

DIMENSION P1 (3), P 2 (3)

$\mathrm{XD}=\mathrm{P} 1$ (1) $-\mathrm{P} 2$ (1)

$\mathrm{Y} D=\mathrm{P} 1\} 2,-\mathrm{P} 2(2)$

$\mathrm{ZD}=\mathrm{P} 1\{3-\mathrm{P} 2\} 3$

$D=S Q R T(X D * C S T+Y D * S I T) * 2+A P H * A F H *(Y D * C S T-$

$1 X D * S I T) * 2+A F V * A F V * Z D * Z D$ )

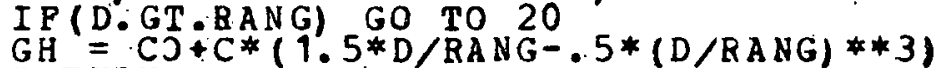

$2 c$

RET URN

1800

20

$21 \mathrm{Lu}$

2200

2300

2400

2600

2800

2900

3000

3700

3200

3300

$34 \mathrm{CO}$

3500

3600

3700

3800

3900

4000

4100

4200

4300

4400

4500

4600

4700

4800

4900

5000

5100

$\mathrm{GH}=\mathrm{CO}+\mathrm{C}$

RET URN

END

SUBROUTINE PTLOC (NP X, Y X P, Y P, LOC)

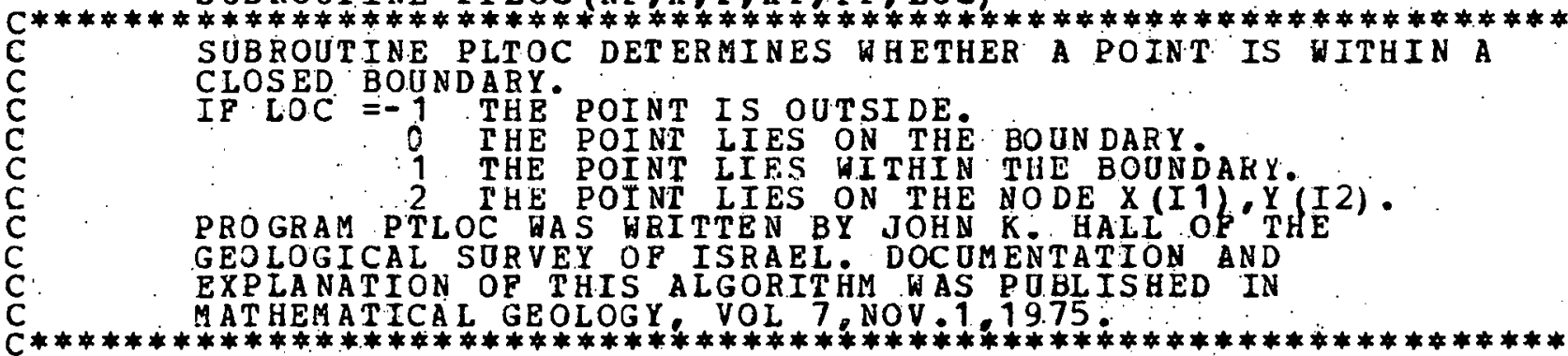

DIMENSION $X(1),(1)$

DATA C.180.10.9999999998/

$11=?$
$I 2=0$

ISR $\doteq J$

IEC $=0$

TSC $=0.0$

$\mathrm{SCC}_{\mathrm{TC}}=0.0 \mathrm{j}$

$C C=1.0$

$I P=N P$

$X 1=X(N P)-X P$

$Y 1=Y(N P)-Y P$

$R T=S O R T(X 1 * X 1+X 1 * Y 1)$

IF (R1.EQ.0.0) GO TO 65

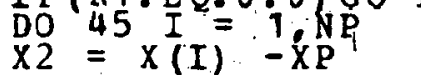


